\title{
Preventing falls and mobility impairments in elderly people living in the community
}

Citation for published version (APA):

van Haastregt, J. C. M. (2002). Preventing falls and mobility impairments in elderly people living in the community. [Doctoral Thesis, Maastricht University]. Universiteit Maastricht. https://doi.org/10.26481/dis.20020517jh

Document status and date:

Published: 01/01/2002

DOI:

10.26481/dis.20020517jh

Document Version:

Publisher's PDF, also known as Version of record

\section{Please check the document version of this publication:}

- A submitted manuscript is the version of the article upon submission and before peer-review. There can be important differences between the submitted version and the official published version of record.

People interested in the research are advised to contact the author for the final version of the publication, or visit the DOI to the publisher's website.

- The final author version and the galley proof are versions of the publication after peer review.

- The final published version features the final layout of the paper including the volume, issue and page numbers.

Link to publication

\footnotetext{
General rights rights.

- You may freely distribute the URL identifying the publication in the public portal. please follow below link for the End User Agreement:

www.umlib.nl/taverne-license

Take down policy

If you believe that this document breaches copyright please contact us at:

repository@maastrichtuniversity.nl

providing details and we will investigate your claim.
}

Copyright and moral rights for the publications made accessible in the public portal are retained by the authors and/or other copyright owners and it is a condition of accessing publications that users recognise and abide by the legal requirements associated with these

- Users may download and print one copy of any publication from the public portal for the purpose of private study or research.

- You may not further distribute the material or use it for any profit-making activity or commercial gain

If the publication is distributed under the terms of Article $25 \mathrm{fa}$ of the Dutch Copyright Act, indicated by the "Taverne" license above, 
Preventing falls and mobility impairments in elderly people living in the community

Jolanda van Haastregt 



\title{
Preventing falls and mobility impairments in elderly people living in the community
}

\author{
Proefschrift \\ ter verkrijging van de graad van doctor aan \\ de Universiteit Maastricht, \\ op gezag van de Rector Magnificus \\ Prof.dr. A.C. Nieuwenhuijzen Kruseman \\ volgens het besluit van het College van Decanen \\ in het openbaar te verdedigen \\ op vrijdag 17 mei 2002 om 14.00 uur \\ door \\ Johanna Cornelia Maria van Haastregt
}




\section{Promotor}

Prof.dr. H.F.J.M. Crebolder

\section{Co-promotores}

Dr. J.P.M. Diederiks

Dr. E. van Rossum

\section{Beoordelingscommissie}

Prof.dr. P.G. Knipschild (voorzitter)

Prof.dr. G.A.M. van den Bos (Universiteit van Amsterdam)

Prof.dr. G.J Dinant

Prof.dr. H. Huijer-Abu Saad

Dr. P.T.A.M. Lips (Vrije Universiteit Amsterdam)

The study presented in this thesis was supported by grants from "Zorg Onderzoek Nederland (31-29)" and "Stichting Onderzoek en Ontwikkeling Maatschappelijke Gezondheidszorg". 


\section{Voor Marise}




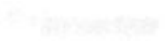

(n)

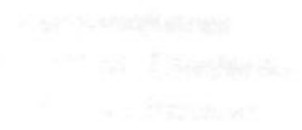

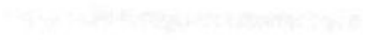

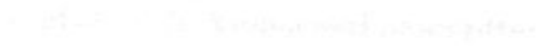

(n)

(n)

$\sqrt{2}$

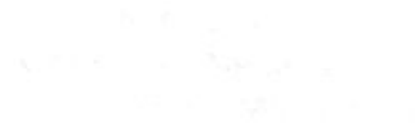




\section{Contents}

1 General introduction 9

2 Effects of preventive home visits to elderly people living 21 in the community: systematic review

3 Intervention and design

4 Effects of a mulitifactorial home visit programme on falls and mobility impairments in elderly people at risk: randomised controlled trial

5 Cost-effectiveness analysis of a mulitifactorial home visit programme among elderly persons at risk:

randomised controlled trial

6 Process evaluation of a multifactorial home visit programme among elderly people at risk

7 Lack of information on the intervention process in randomised controlled trials

8 General discussion

Summary

Samenvatting

Dankwoord 


\section{General introduction}




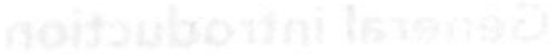




\section{Introduction}

This thesis describes the results of a randomised controlled trial into the effects of preventive home visits on falls and mobility impairments among elderly people at risk. Falls and mobility impairments are common problems among the aged population. There exists a considerable overlap between determinants and consequences of falls and mobility impairments. Falls and mobility impairments are associated with increased morbidity, mortality, health care utilisation, and decreased levels of independent functioning ${ }^{1.6}$. The prevention of falls and mobility decline is therefore an important issue. We developed a multifactorial intervention programme that combined the prevention of falls with the reduction of mobility impairments. This intervention consists of five preventive home visits performed by a community nurse over a period of one year. During these visits the elderly participants are screened for medical, functional, psychosocial, and environmental factors causing falls and mobility impairments, followed by specific recommendations, referrals, and other actions aimed at dealing with the hazards observed. The main subject of the present thesis is the evaluation of this multifactorial home visit programme.

In this chapter we describe the epidemiology and consequences of falls and mobility impairments among community-living elderly people, in order to demonstrate the magnitude and impact of these problems. We present a model integrating predictors and consequences of falls and mobility impairments. In addition, we give a brief overview of intervention programmes that have been used in the past decades to prevent falls and/or mobility impairment and we discuss our choice for a preventive home visit programme. Finally we present the research questions we aim to answer in this thesis and present the outline of the thesis.

\section{Falls}

We define a fall as an event that results in a person coming to rest inadvertently on the ground or other lower level. This definition is derived from the definition of "The Kellog International Work Group" 3

\section{Incidence and circumstances of falls}

Approximately $30 \%$ of the persons aged 65 years or over who live in the community fall at least once a year, and about $15 \%$ fall two or more times a year $^{7 \cdot 12}$. The incidence of falls and recurrent falls increases with age . $^{7 \cdot 9}$.

Elderly persons aged 70 or over seem to fall slightly more often inside the home or other indoor places (approximately 55\%) than outside (approximately $45 \%)^{8,13}$. The location of the fall seems to be related to age and sex. The very old elderly fall more often inside the home than younger elderly, and men tend to fall more often outside than women ${ }^{7,8,12,13}$. Falls inside the home occur in the most frequently used rooms: kitchen (19\%), bedroom (21\%), and lounge and dining area $(27 \%)^{13}$. Most falls occur during periods of maximum activity in the morning and afternoon ${ }^{13}$. Walking is the most common activity at the time of a 
fall, followed by going up or down stairs or steps, and transferring, stooping, or bending $8,12,14$. Only $2-5 \%$ of falls occur during hazardous activities such as running, standing on a chair, or climbing a ladder ${ }^{12,14}$. The most common causes reported by elderly persons for their falls are tripping or slipping $7,8,12,13$. In most situations the trip is minor and related to objects not regarded as potential hazards ${ }^{13}$. Other causes elderly people often report for falls are intrinsic factors such as dizziness, blackouts, and acute illness ${ }^{7,8,12,13}$. Among the oldest age group the percentage of intrinsic causes reported for falls tend to be higher than among the younger group ${ }^{8}$.

\section{Predictors of falls}

The majority of falls among elderly people appear to be multifactorial in aetiology, resulting from various combinations of intrinsic and extrinsic factors ${ }^{15}$. Recurrent falls are more likely to be associated with intrinsic factors that affect the control of balance and posture, than single accidental falls'. In the past two decades a considerable number of studies have assessed the predictors of falls. Roughly five categories of predictors can be distinguished: 1) mobility-related impairment; 2) cognitive impairment; 3) psychosocial

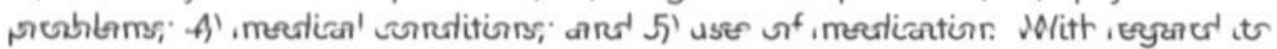
mobility-related impairment the following factors are frequently reported to be related to falls: muscle weakness, balance disorders, and gait disorders $9,10,12,13,15,16-21$. Cognitive impairments caused by dementia or other neurological disorders ${ }^{10,12,15,18-20,22,23}$, and psychosocial factors like depression and low levels of social support are reported to predict falls $\mathbf{s}^{10,11,15,19}$. Frequently reported medical conditions related to falls are postural hypotension, cardiovascular disease, the consequences of stroke, urinary incontinence, visual impairment, and dizziness $7,9-11,13,17,19,20,22,24$. With regard to medication two recent systematic reviews revealed that there is a small but consistent association between the use of most classes of psychotropic medication and fall $\mathbf{s}^{25}$. In addition, persons using digoxin, antiarrhythmic, or diuretic drugs and persons taking more than three or four medications are at increased risk of falls ${ }^{26}$.

In the aetiology of falls intrinsic factors seem to be more important than extrinsic factors. Environmental factors are not reported to be directly related to falls. The results of a study of Sattin et $\mathrm{a}^{27}$ among community-living people aged 65 and over, suggest that overall, after adjusting for important confounding factors, most postulated home environmental hazards are not associated with an increased risk of injurious falls. Stalenhoef et al also concluded that environmental hazards in the home have no predictive value for indoor falls ${ }^{28}$. It seems likely that these environmental factors are not to be considered primarily as causal factors, but as factors that trigger a fall ${ }^{28}$. 


\section{Consequences of falls}

Falls can have a substantial impact on physical and psychosocial functioning of elderly people. Nearly half of falls result in injury, which in the majority of cases are minor injuries such as bruises or abrasions ${ }^{9-14}$. About $5-10 \%$ of falls result in major injury such as hip fractures (1-2\%), other fractures (3-5\%), soft tissue injuries and head trauma $(5 \%)^{11,12,14,17}$. About $50 \%$ of fall injury events that occur at home and require hospital admission result in discharge to a nursing home ${ }^{2}$. Mortality associated with falls in older people is high. In 1997, about two thirds of accidental deaths in females aged over 65 were due to falls ${ }^{29}$. Fractured femur is associated with a $33 \%$ mortality within one year ${ }^{30}$. The costs of injurious falls are substantial $\left.\right|^{33,34}$. Health care costs increase with fall frequency and severity. Incurring one or more injurious falls was associated with increased annual hospital costs of $\$ 11,042$, nursing home costs of $\$ 5,325$ and total health care costs of $\$ 19,440$ in the United States ${ }^{35}$. In the Netherlands a study into the additional costs of medical care caused by incident hip and vertebral fractures, revealed that the additional costs in the first year after the hip fracture were almost $\$ 10,000$. In the second year these additional costs were still about $\$ 1,000^{36}$.

Falls may initiate a downward spiral of fear leading to decreased mobility, finally resulting in loss of independence in activities of self-care ${ }^{21}$. Tinetti et al reported that $43 \%$ of community-living elderly people older than 70 years were afraid to fall. Twenty-four percent of fallers acknowledged restricting activities because of fear of falling, as did $15 \%$ of non-fallers ${ }^{31}$. Elderly persons who express fear of falling exhibit significantly poorer postural performance ${ }^{32}$. Nevitt et al reported that a total of $42 \%$ of subjects who fell, limited their activities at least temporarily as a result of the fall(s) ${ }^{14}$.

\section{Mobility impairments}

Based on the definition of the "International Classification of Functioning, Disability and Health (ICF)", we define mobility as moving by changing body position or location or by transferring from one place to another, by carrying. moving or manipulating objects, by walking, running or climbing, and by using various forms of transportation?.

In the literature there is a considerable heterogeneity in defining mobility impairments. We define mobility impairments as problems in control over whole body movements and difficulties in executing mobility activities. Because in this definition we refer both to problems in function as to difficulties in executing activities, according to the ICF terminology it would have been more correct to use the term "mobility impairments and limitations" in stead of "mobility impairments". However for practical reasons we use the term 'mobility impairment' both for problems in body function and difficulties in executing activities. Examples of mobility impairment as we define it are problems with standing, kneeling, transferring oneself, lifting, walking, moving around in different locations, and moving around using equipment or transportation. 


\section{Prevalence of mobility impairments}

With increasing age changes in balance, posture, and locomotion occur. Advanced age is associated with a slumped, flexed posture and tenuous balance ${ }^{38}$. Many elderly people have a gait characterised by short and slow steps $^{38}$.

A large study performed in the Netherlands among people aged 55 years or over $(n=5,033)$ revealed that $22 \%$ of community-living men and $36 \%$ of communityliving women experienced mobility impairments ${ }^{39}$. In homes for the elderly these percentages were $84 \%$ and $97 \%$ respectively. Mobility impairments were assessed using 6 items of the Health Assessment Questionnaire measuring rising from a chair, getting in and out of bed, bending, getting in and out of a car, walking, and climbing stairs. Participant were considered to have locomotor impairments when they had difficulties with performing at least 3 of the 6 activities $^{39}$.

A Swedish study ${ }^{40}$ among 1,148 elderly people revealed that at age $70,15 \%$ of women and $9 \%$ of men reported some degree of mobility impairment. Among women, prevalence increased to $22 \%$ at age 75 and $32 \%$ at age 79 . It was consistently lower in men, increasing to $16 \%$ at age 75 and $29 \%$ at age 79 . A person was regarded to have a mobility impairment when he or she had at least one of the following characteristics: use of walking aids (a cane, crutch, walker or wheelchair); difficulty or inability to rise from a chair; or difficulty or inability to rise from bed. Among both sexes walking was the most common area of disability ${ }^{40}$.

\section{Predictors of mobility impairments}

Similar to falls, mobility impairments are often caused by a combination of factors. Several studies examined factors that are likely to play a role in the aetiology of mobility impairments in elderly people ${ }^{38,41 \cdot 45}$. The following categories of factors were related to mobility impairments according to these studies: neurological disorders such as dementia, stroke, Parkinson's disease, and peripheral neuropathy; psychological problems such as depressive states, poor motivation and fear of falling; social changes such as decline in occupational and leisure activities; orthopaedic disorders such as osteoarthrosis, foot problems, and unsuspected fractures; endocrinological disorders such as hypothyroidism; general muscle weakness; disuse atrophy; sensory impairments; medication; malnutrition; and chronic diseases such as rheumatoid arthritis.

\section{Consequences of mobility impairments}

Mobility impairments and mobility related disorders such as balance and gait disorders, are strong predictors of falls $\mathbf{s}^{9}, 10,12,13,15,16-21$. It has been estimated that between 10 to $25 \%$ of all falls are associated with poor balance and gait abnormalities $^{21}$. Impaired stance balance and mobility highly increase the probability for functional dependency among older adults ${ }^{21}$. Mobility impair- 
ment is directly related to decrease in physical activity. There are indications that decreased physical activity is related to decreased levels of well-being, life satisfaction and social functioning. Also the depression scores seem to be higher among elderly people with a decreased physical activity ${ }^{46-51}$. In general, impaired mobility is associated with poor functional status, ill being, increased use of health service, and mortality ${ }^{52.55}$.

\section{Integrating predictors and consequences of falls and mobility impairments}

There exists a considerable overlap between predictors and consequences of falls and mobility impairments. Based on the available evidence we developed a model in which we integrate the predictors and consequences of both falls and mobility impairments (see figure 1.1). In this model environmental triggers are not regarded as causal factors, but as factors which (in part of fall incidents) may trigger the fall.

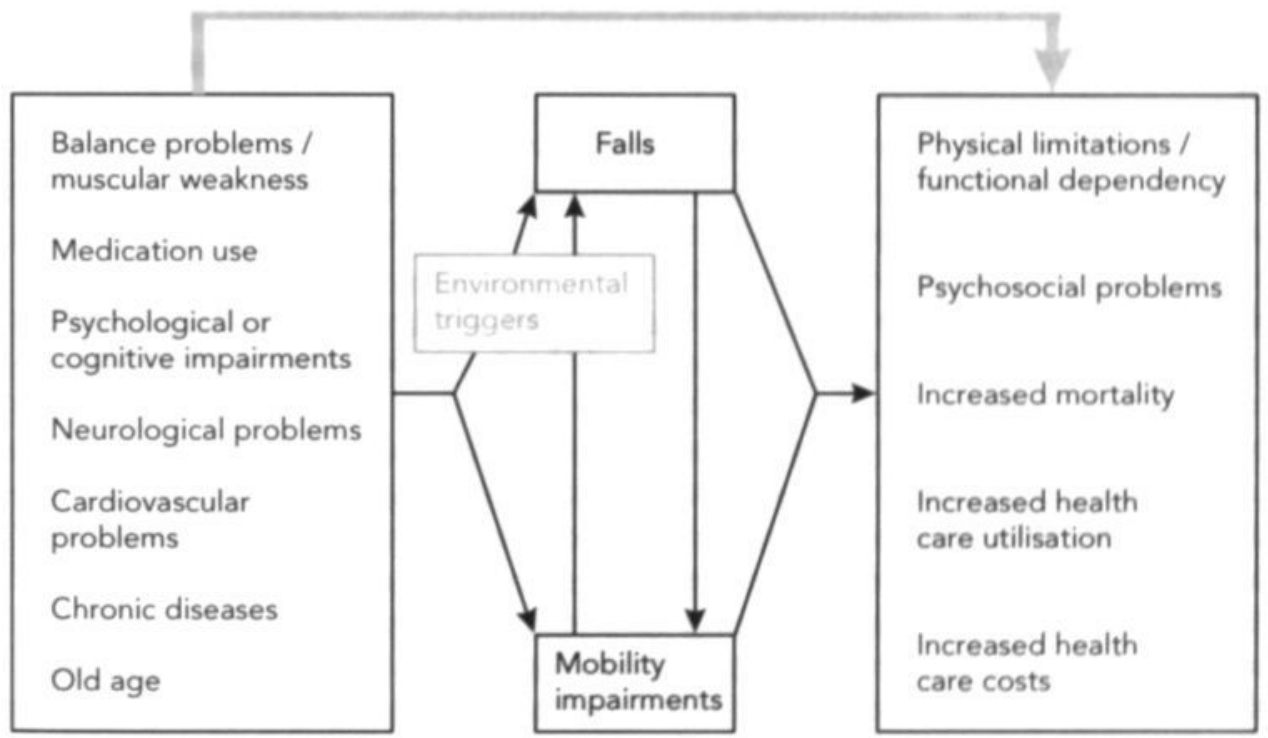

Figure 1.1 Predictors and consequences of falls and mobility impairments.

\section{Preventing falls and mobility decline in elderly people living in the community}

In the past decades several intervention programmes have been developed to prevent falls and/or mobility impairment. We searched the literature for evidence regarding the effectiveness of these intervention programmes. A systematic review of Gillespie et $\mathrm{al}^{56}$ into the effects of interventions aimed at the prevention of falls, revealed that unidimensional exercise interventions did not protect against falling. In addition, there was no evidence to support 
exercise in conjunction with health education classes, or of health education classes alone for the prevention of falls. Significant protection against falling was observed for interventions that targeted multiple, identified, risk factors in individual patients, and from interventions that focused on behavioural interventions targeting risk factors including environmental hazards ${ }^{56}$.

With regard to interventions which are primarily aimed at improving mobility and mobility related factors, a review of Buchner ${ }^{42}$ revealed that the evidence regarding the effectiveness of strength and endurance training on gait speed is ambiguous. Some trials found modest effects on gait speed, others did not. The effects among community-living people seem smaller than among people in nursing homes. It seems that if strength and endurance are already adequate, further increases in capacity would not be expected to change relative basic tasks like walking speed. The extent to which strength training improves mobility by improving balance is unclear ${ }^{42}$. Overall, exercise programmes seem to have modest positive effects on mobility related outcome measures. Due to the large diversity of programmes and outcome measures and the often small study groups in the trials it is difficult to distinguish which exercise activities are most effective and little information is available about the long term effects of these programmes ${ }^{42}$.

Underlying causes of mobility impairment and intermediary factors, such as chronic conditions, psychological impairments, and medication with regard to mobility activities have received little attention in mobility interventions.

Because of the considerable overlap between the underlying causes of falls and mobility impairments, and because of the promising effects of multifactorial interventions in the field of fall prevention, we decided to develop a multifactorial home visit intervention, simultaneously aimed at preventing falls and reducing mobility impairments among elderly people living in the community. This intervention (which is discussed in more detail in chapter 3) consists of five home visits performed by a community nurse during a period of one year. Visits consist of screening for medical, functional, psychosocial, and environmental factors causing (or triggering) falls and mobility impairments, followed by specific recommendations, referrals, and other actions aimed at dealing with the observed hazards. Community nurses were selected as interveners because they have sufficient expertise and skills with regard to the performance of the intervention, and because an intervention performed by community nurses is less costly and more easy to implement in regular care than an intervention performed by a general practitioner, geriatrician or other medical specialist.

At the time of the start of the study there were indications that preventive home visit programmes were more effective among elderly people at risk than among the general population of elderly people. Van Rossum et $\mathrm{al}^{57}$ concluded that their home visit programme aimed at the general population of elderly 
people was only effective among one subgroup of elderly people: those with a relatively poor health status at the start of the study. In addition, a multifactorial intervention programme specifically aimed at a group of elderly people at risk for falls showed promising results ${ }^{58}$. Based on these two trials it was decided to aim our multifactorial home visit programme at a subgroup of elderly people who are at risk for falls or (moderately) mobility impaired.

\section{Aims of the study and outline of the thesis}

Falls and mobility problems can have considerable negative consequences for elderly people. It seems therefore very important to develop efficient ways to prevent falls and improve mobility in the elderly. The primary aim of the present study is to evaluate the effectiveness and feasibility of a multifactorial home visit programme aimed at preventing falls and reducing mobility impairment in community-living elderly people at risk.

The main research questions are:

1. What are the effects of a multifactorial home visit programme on falls and mobility impairments among community-living elderly people at risk?

2. What are the effects of this programme on health care utilisation and associated costs?

3. To which extent is the programme feasible according to the persons performing and receiving the intervention?

We hypothesised that multifactorial home visits lead to decreased numbers of falls and less mobility impairment. In addition we expected the costs of health care utilisation to be comparable in the home visit and usual care group. The intervention is expected to be feasible for both nurses and the elderly participants.

In chapter 2 of this thesis we discuss the results of a systematic review of trials into the effectiveness of preventive home visit programmes among the elderly. This review covers randomised controlled trials performed in the period 1966 to March 1999 and aims at gaining insight into the overall effectiveness of preventive home visit programmes performed in the last decades. In chapter 3 the contents of our multifactorial home visit programme and the design of the evaluation study are described. Chapter 4 reports on the effects of the home visit programme on falls, mobility impairments and eight secondary outcome measures. Chapter 5 presents the results of the economical evaluation of our home visit programme, and chapter 6 presents the results of the process evaluation through which we try to gain more insight into the feasibility of the intervention programme and into process factors that may have influenced the effectiveness of the intervention. Chapter 7 reports on the results of a systematic review into the availability and quality of information provided on the intervention process in randomised controlled trials in the field of preventive home visits. Recommendations are made about the possibilities of improving the reporting of process data. The thesis is concluded in chapter 8 with a general discussion of the results and methodology of the study, the 
main conclusions of the study and its implications for health care practice and further research.

The chapters in this thesis have been published or submitted for publication in different international journals. The disadvantage of this is that there is some overlap between the chapters regarding the background and design of the study. The advantage is however that each chapter can be read independent from the other chapters.

\section{References}

1. Sattin RW. Falls among older persons: a public health perspective. Annu Rev Publ Health 1992;13:489-508.

2. Sattin RW, Lambert Huber DA, DeVito CA, Rodriquez JG, Ros A, Bacchelli S, et al. The incidence of fall injury events among the elderly in a defined population. Am J Epidemiol 1990;131:1028-1037.

3. Kellogg International Work Group on the prevention of falls in the elderly. The prevention of falls in later life. Dan Med Bull 1987;34(suppl)4:1-24.

4. Wolinsky FD, Johnson RJ. The use of health services by old adults. J Gerontol Soc Sci 1991;46:345-57.

5. Mulrow CD, Gerety MB, Cornell JE, Lawrence VA, Kanten DN. The relation between disease and function and perceived health in very frail elders. J Am Geriatr Soc 1994:42(4):374-80.

6. Reuben DB, Rubenstein LV, irsch SH. Value of functional status as a predictor of mortality: results of a prospective study. Am J Med 1992;93:663-69.

7. Blake AJ, Morgan K, Bendall MJ, Dallosso H, Ebrahim SBJ, Arie THD, et al. Falls by elderly people at home: prevalence and associated factors. Age Ageing 1988;17:365-72.

8. Luukinen H, Koski K, Hiltunen L, Kivela SL. Incidence rates of falls in an aged population in northern Finland. J Clin Epidemiol 1994;8:843-50.

9. O'Loughlin JL, Robitaille Y, Boivin J, Suissa S. Incidence of risk factors for falls and injurious falls among the community-dwelling elderly. Am J Epidemiol 1993;137:342-54.

10. Stalenhoef PA, Crebolder HFJM, Knottnerus JA, van der Horst FGEM. Incidence, risk factors and consequences of falls among elderly subjects living in the community: a criteria-based analysis. Eur J Publ Health 1997;7:328-34.

11. Tromp AM, Smit JH, Deeg DJH, Bouter LM, Lips P. Predictors for falls and fractures in the longitudinal Aging Study Amsterdam. J Bone Min Res 1998;13:1932-9.

12. Tinetti ME, Speechley M, Ginter SF. Risk factors for falls among elderly persons living in the community. N Engl J Med 1988;319:1701-7.

13. Campbell AJ, Borrie MJ, Spears GF, Jackson SL, Brown J, Fitzgerald JL. Circumstances and consequences of falls experienced by a community population 70 years and over during a prospective study. Age Ageing 1990;19:136-141.

14. Nevitt MC, Cummings SR, Hudes ES. Risk factors for injurious falls: a prospective study. J Gerontol 1991;46:M164-70.

15. American Geriatrics Society, British Geriatrics Society, and American Academy of Orthopaedic Surgeons Panel on Falls Prevention. Guideline for the prevention of falls in older persons. J Am Geriatr Soc 2001;49:664-72.

16. Campbell AJ, Borrie MJ, Spears GF. Risk factors for falls in a community based prospective study of people 70 years and older. J Geront: Med Sci 1989:44:112-7.

17. Nevitt MC, Cummings SR, Kidd S, Black D. Risk factors for recurrent nonsyncopal falls. A prospective study. JAMA 1989;261:2663-8.

18. Clark RD, Lord SR, Webster IW. Clinical parameters associated with falls in an elderly population. Gerontology 1993;39:117-23.

19. Graafmans WC, Ooms ME, Hofstee HMA, Bezemer PD, Bouter LM, Lips P. Falls in the elderly: a prospective study of risk factors and risk profiles. Am J Epidemiol 1996;143:1129-36. 
20. Tinetti ME, SK Inouye, Gill TM, Doucette JT. Shared risk factors for falls, incontinence, and functional dependence: unifying the approach to geriatric syndromes. JAMA 1995;273:1348. 53.

21. Shumway-Cook A, Baldwin M, Polissar NL, Gruber W. Predicting the probability for falls in community-dwelling older adults. Phys Ther 1997;77:812-9.

22. Prudham D, Grimley Evans J. Factors associated with falls in the elderly: a community study. Age Ageing 1981;10:141-6.

23. Campbell AJ, Reinken J, Allan BC, Martinez GS. Falls in old age: a study of frequency and related clinical factors. Age Ageing 1981;10:264-70.

24. Ivers RQ, Cumming RG, Mitchell P, Attebo. Visual impairment and falls in older adults: the Blue Mountains Eye Study. J Am Geriatr Soc 1998;46:58-64.

25. Leipzig RM, Cumming RG, Tinetti ME. Drugs and falls in older people: a systematic review and meta-analysis: I. Psychotropic drugs. J Am Geriatr Soc 1999:47:30-9.

26. Leipzig RM, Cumming RG, Tinetti ME. Drugs and falls in older people: a systematic review and meta-analysis: II. Cardiac and analgesic drugs. J Am Geriatr Soc 1999;47:40-50.

27. Sattin RW, Rodriguez JG, DeVito CA, Wingo PA, and the Study to Assess Falls among the Elderly (SAFE) Group. Home environmental hazards and the risk of fall injury events among community-dwelling older persons. J Am Geriatr Soc 1998;46:669-76.

28. Stalenhoef P, Diederiks J, Knottnerus A, de Witte L, Crebolder H. How predictive is a homesafety checklist of indoor fall risk for the elderly living in the community? Eur J Gen Pract 1998:4:114-20.

29. Swift CG. Falls in late life and their consequences-implementing effective services. Br Med J 2001;322:855-7.

30. Keene GS, Parker MJ, Pryor GA. Mortality and morbidity after hip fractures. Br Med J 1993;307:1248-50.

31. Tinetti ME, Mendes de Leon CF, Doucette JT, Baker DI. Fear of falling and fall-related efficacy in relationship to functioning among community-living elders. J Gerontol: Med Sc 1994;49:M140-7.

32. Maki BE, Holliday PJ, Topper AK. Fear of falling and postural performance in the elderly. J Gerontol: Med Sc 1991;46:M123-31.

33. van Weel C, Vermeulen $\mathrm{H}$, van den Bosch W. Falls, a community care perspective. Lancet $1995 ; 345: 1549-51$.

34. Alexander BH, Rivara FP, Wolf ME. The cost and frequency of hospitalisation for fall-related injuries in older adults. Am J Public Health 1992;82:1020-3.

35. Rizzo JA, Baker DI, McAvay G., Tinetti ME. The cost-effectiveness of a multifcatorial targeted prevention program for falls among community elderly persons. Med Care 1996;34:954-69.

36. de Laet CEDH, van Hout BA, Burger H, Weel AEAM, Hofman A, Pols HAP. Incremental cost of medical care after hip fracture and first vertebral fracture: the Rotterdam Study. Osteoporos Int 1999;10:66-72.

37. The International Classification of Functioning, Disability and Health-ICF. World Health Organization, Geneva, Switzerland; 2001.

38. Spirduso WW. Physical dimensions of aging, part III. Human Kinetics, Champaign; 1995.

39. Odding E, Valkenburg HA, Grobbee DE, Hofman A, Pols HAP. Locomotore beperkingen bij ouderen; het ERGO-onderzoek. Ned Tijdschr Geneeskd 1995;139:2096-2100.

40. Lundgren-Lindquist B, Jette AM. Mobility disability among elderly men and women in Sweden. Int Disabil Studies 1990;12:1-5.

41. Cunha UV. Diffential diagnosis of gait disorders in the elderly. Geriatrics 1988;43:33-42.

42. Buchner DM. Preserving mobility in older adults. West J Med 1997;167:258-64.

43. Fiaterone MA, O'Neill EF, Doyle N, Clements KM, Roberts SB, Kehayias JJ, et al. The Boston FICSIT study: the effects of resistance training and nutritional supplementation on physical frailty in the oldest old. J Am Geriatr Soc 1993;41:333-7.

44. Hart D, Bowling A, Ellis M, Silman A. Locomotor disability in very elderly people: value of a programme for screening and provision of aids for daily living. Br Med J 1990;301:216-20.

45. Tinetti ME. Performance-Oriented assessment of mobility problems in elderly patients. J Am Geriatr Soc 1986;34:119-26. 
46. Huijsman R, Wielink G, de Klerk MMY. Lichaamsbeweging bij ouderen: een literatuuroverzicht van effecten. Beweging \& Hulpverlening 1996;13:159-182.

47. Camacho TC, Roberts RE, Lazarus NB, Kaplan GA, Cohen RD. Physical activity and depression:evidence from the Alameda study. Am J Epidemiol 1991;134:220-31.

48. Farmer ME, Locke BZ, Moscicki EK, Dannenberg L, Larson DB, Radloff LS. Physical activity and depressive symptoms, the NHANES I epidemiologic follow-up study. Am J Epidemiol 1988; $128: 1340-51$.

49. Hill RD, Storaudt $M$, Malley $M$. The impact of long term exercise training on psychological functions in older adults. J Gerontol 1993:48:12-7.

50. Ross CE, Hayes D. Exercise and psychologic well-being in the community. Am J Epidemiol 1988;127:762-71.

51. McAuley E, Blissmer B, Marquez DX, Kramer JGJ, Katula AF. Social relations, physical activity, and well-being in older adults. Prev Med 2000;31:608-17.

52. Mulrow CD, Gerety MB, Cornell JE, Lawrence VA, Kanten DN. The relation between disease and function and perceived health in frail elders. J Am Geriatr Soc 1994;42:374-80.

53. Reuben DB, Rubenstein LV, Hirsch SH. Value of functional status as a predictor of mortality: results of a prospective study. Am J Med 1992;93:663-69.

54. Roos Nh, Havens B. Predictors of successful aging: a twelve year study of Manitoba elderly. Am J Public Health 1991;81:63-8.

55. Wolinsky FD, Johnson RJ. The use of health services by old adults. J Gerontol Soc Sci 1991;46:345-57.

56. Gillespie LD, Gillespie WJ, Cumming R, Lamb SE, Rowe BH. Interventions to reduce the incidence of falling in the elderly. Cochrane Library 1997;4:1-29.

57. van Rossum E, Frederiks CMA, Philipsen H, Portengen K, Wiskerke J, Knipschild P. Effects of preventive home visits to elderly people. Br Med J 1993;307:27-32.

58. Tinetti ME, Baker DI, McAvay G, Claus EB, Garrett P, Gottschalk m, et al. A multifactorial intervention to reduce the risk of falling among elderly people living in the community. N Engl J Med 1994;331:821-7. 


\section{Effects of preventive home visits to elderly people living in the community: systematic review}

This chapter is published as:

van Haastregt JCM, Diederiks JPM, van Rossum E, de Witte LP, Crebolder HFJM. Effects of preventive home visits to elderly people living in the community: systematic review. Br Med J 2000;320:754-8. 


\section{Summary}

Objective: To assess the effects of preventive home visits to elderly people living in the community.

Design: Systematic review of randomised controlled trials.

Methods: Fifteen trials were retrieved from Medline, Embase and the Cochrane Controlled Trial Register.

Main outcome measures: Physical function, psychosocial function, falls, admissions to institutions, and mortality.

Results: Considerable differences in the methodological quality of the fifteen trials were found, but in general the quality was considered adequate.

Favourable effects of the home visits were observed in 5 out of 12 trials measuring physical functioning, 1 out of 8 studies measuring psychosocial function, 2 out of 6 measuring falls, 2 out of 7 measuring admissions to institutions, and 3 of 13 measuring mortality. None of the trials reported negative effects.

Conclusions: No clear evidence was found in favour of the effectiveness of preventive home visits to elderly people living in the community. It seems essential that the effectiveness of such visits is improved, but if this cannot be achieved consideration should be given to discontinuing these visits. 


\section{Introduction}

The development of effective preventive interventions aimed at the maintenance of health and autonomy of elderly people living in the community has received much attention in the past two decades. In both North America and north west Europe a substantial number of randomised controlled trials have examined the effects of preventive interventions on elderly people living in the community. We focus on one specific category of these interventions: preventive home visits.

On the basis of the definition of comprehensive geriatric assessment by Stuck et al', we defined preventive home visits as visits to independently living elderly people, which are aimed at multidimensional medical, functional, psychosocial, and environmental evaluation of their problems and resources. This evaluation results in specific recommendations, aimed at reducing or treating the observed problems and preventing new ones.

In 1993 Stuck et al' performed a meta-analysis of randomised controlled trials examining the effects of five types of comprehensive geriatric assessment, one of which concerned elderly people living at home. This kind of geriatric assessment at home is fairly comparable to preventive home visits. The authors concluded that assessment of elderly people at home seems to have some positive effects on mortality, residential status (a higher percentage living at home) and number of hospital admissions. Owing to conflicting results and the small number of trials included in the analyses, however, many aspects of the potential effectiveness of such interventions remained unclear. In the past seven years a substantial number of new randomised controlled trials have been performed to gain more insight into the effects of preventive home visits to elderly people living in the community. Our systematic review provides an updated and elaborated qualitative analysis of available such trials. Given the considerable heterogeneity of the interventions we decided not to pool the data of the trials. Pooling the data in case of heterogeneity might lead to oversimplified conclusions ${ }^{2,3}$. We aimed to summarise the effects of preventive home visits on physical function, psychosocial function, falls, admissions to institutions, and mortality in elderly people living in the community and to assess the methodological quality of the trials included.

\section{Methods}

\section{Search Strategy}

We identified randomised controlled trials by searching Medline (1966 to May 1999), Embase (1989 to March 1999), and the Cochrane Controlled Trial Register and by screening references given in relevant systematic reviews and identified trials. No language restrictions were imposed. For the selection of randomised controlled trials the first stage of the search strategy recommended by the Cochrane Collaboration ${ }^{4}$ was used in conjunction with a specific search for the intervention and population at issue. We used the key words "geriatric assessment", "home visit", "health visit", and "health 
screening" combined with the exploded MeSH term "aged" and any of the words "prevent", "screen", "health education", or "health promotion". We used wild card characters to ensure that all forms of words were included.

\section{Selection of articles}

We included articles in two stages. At the first stage all articles were included that described randomised controlled trials studying the effects of interventions consisting of home visits to elderly people living in the community aged 65 and over. Inclusion criteria were applied independently by two reviewers (JvH and JD) to the abstracts, titles and keywords of the references retrieved by the literature search. Subsequently, the full text of the included articles was retrieved, and author, institution, and journal name were removed from the copies. At the second stage the two reviewers applied the following additional inclusion criteria to the "blinded" articles to make a final selection of articles for review: a) the home visits were aimed at prevention or reduction of problems and risks related to ageing; b) during the home visits a (multidimensional) evaluation of problems and resources in at least two of the following categories was performed: medical, functional, psychosocial, or environmental. This evaluation resulted in specific recommendations, aimed at reducing or treating the observed problems, and preventing new ones; c) the home visits were not exclusively aimed at patients who had been discharged from hospital; d) the home visits were not exclusively aimed at helping patients to cope with a specific illness; and e) data on at least one of the following outcome measures were presented: physical function, psychosocial function, falls, admissions to institutions, and mortality. Disagreement between the reviewers was resolved by consensus.

\section{Criteria based analysis}

To assess the methodological quality of the included trials we used an adapted version of the criteria list by van Tulder et al (figure 2.1) .

The quality assessments were performed independently by the two reviewers, with "blinded" copies of the articles. The maximum quality score for each study was 19 ("yes", 1 point; "partly", 0.5 points; and "no" or "unclear", 0 points). Disagreement between the reviewers was resolved by consensus.

\section{Data extraction}

The reviewers independently extracted the following data from the articles on a structured form: country, number of subjects in each study group, characteristics of subjects, duration of follow-up, characteristics of the intervention, and results regarding physical function, psychosocial function, falls, admissions to institutions, and mortality. 
Criteria list for assessment of methodological quality of trials

\section{Patient selection}

- Were the eligibility criteria clearly specified?

- Was a method of randomisation performed?

- Were the groups similar at baseline regarding the most (potential) prognostic indicators? Interventions

- Were the index and control interventions explicitly described?

- Were providers of regular care blinded to the intervention?

- Were there no co interventions?

- Was there good compliance in all groups?

- Were the respondents blinded to the intervention?

Outcome measurement

- Was outcome assessment blinded to the intervention?

- Were most outcome measures relevant?

- Were there no adverse effects of the intervention on the participants?

- Was the withdrawal or drop out rate acceptable?

- Was the withdrawal or drop out random?

- Were short term follow-up measurements performed?

- Was the timing of outcome assessment in both groups comparable?

Statistics

- Was the sample size for each group described?

- Did the analysis include an intention to treat analysis?

- Were point estimates and measures of variability presented for the primary care outcome measures?

Figure 2.1 Criteria list for assessment of methodological quality of trials.

\section{Results}

\section{Search strategy}

Overall, 244 abstracts were screened resulting in the first stage inclusion of 29 of potentially relevant articles ${ }^{6-33}$. After applying the second stage inclusion criteria to the full text of these articles, 16 studies remained. One study ${ }^{14}$ was an elaboration of a previously published study, so we decided only to review the previous one. We finally included 15 studies $^{9,11,13,15,17 \cdot 19,23,25,26,29.31-33}$.

\section{Methodological quality of the included studies}

Table 2.1 shows the methodological quality of the 15 studies. The quality scores ranged from $29 \%$ to $71 \%$, with a mean score of $54 \%$. The main shortcomings of the studies were in the areas of blinding the regular providers of care to the intervention, reporting on the presence or absence of cointerventions, reporting on compliance to the intervention, blinding of the subjects to the intervention, blinding of outcome assessors, handling of drop outs, and intention to treat analysis. In less than $50 \%$ of the studies, all these criteria were partly or completely fulfilled. 
Table 2.1 Methodological quality of trials examining effects of preventive home visits to elderly people living in the community.

\begin{tabular}{|c|c|c|c|c|c|c|}
\hline \multirow{2}{*}{$\begin{array}{l}\text { Study } \\
\text { Carpenter et al }\end{array}$} & \multirow{2}{*}{$\begin{array}{c}\text { Patient } \\
\text { selection } \\
\text { (max. 3) }\end{array}$} & \multirow{2}{*}{$\begin{array}{c}\begin{array}{c}\text { Interven- } \\
\text { tions } \\
\text { (max. 5) }\end{array} \\
0.5\end{array}$} & \multirow{2}{*}{$\begin{array}{c}\text { Measure- } \\
\text { ment } \\
\text { (max. 8) }\end{array}$} & \multirow{2}{*}{$\begin{array}{c}\text { Statistics } \\
\text { (max. 3) } \\
2.5\end{array}$} & \multicolumn{2}{|c|}{$\begin{array}{l}\text { Total }(\%) \\
\text { score } \\
\text { (max. 19) }\end{array}$} \\
\hline & & & & & 10.5 & (55) \\
\hline Fabacher et al" & 3.0 & 1.5 & 3.5 & 2.0 & 10.0 & (53) \\
\hline Hall et $\mathbf{a l}^{13}$ & 3.0 & 1.0 & 6.5 & 1.0 & 11.5 & (61) \\
\hline Hendriksen et al ${ }^{15}$ & 2.5 & 3.0 & 6.5 & 0.5 & 12.5 & (66) \\
\hline Luker" ${ }^{17}$ & 1.5 & 1.0 & 3.0 & 0.0 & 5.5 & (29) \\
\hline McEwan et al'o & 2.0 & 2.0 & 5.5 & 1.5 & 11.0 & (58) \\
\hline Pathy et al ${ }^{19}$ & 1.5 & 1.5 & 5.5 & 3.0 & 11.5 & (61) \\
\hline van Rossum et al $^{23}$ & 3.0 & 1.0 & 5.5 & 2.5 & 12.0 & (63) \\
\hline Sorensen et $\mathrm{al}^{25}$ & 1.0 & 1.0 & 3.5 & 1.5 & 7.0 & (37) \\
\hline Stuck et al $^{26}$ & 3.0 & 1.5 & 5.5 & 3.0 & 13.0 & (68) \\
\hline Tinetti et $a^{29}$ & 3.0 & 3.0 & 5.5 & 2.0 & 13.5 & (71) \\
\hline Vetter et al, Gwent ${ }^{31}$ & 2.5 & 0.5 & 4.0 & 1.5 & 8.5 & (45) \\
\hline Vetter et al, Powys" & 2.5 & 0.5 & 4.0 & 1.5 & 8.5 & (45) \\
\hline Vetter et $\mathrm{al}^{32}$ & 2.5 & 0.5 & 4.5 & 2.5 & 10.0 & (53) \\
\hline Wagner et $\mathrm{al}^{33}$ & 2.0 & 2.0 & 4.5 & 1.0 & 9.5 & (50) \\
\hline $\begin{array}{l}\text { total for category } \\
(\%)\end{array}$ & $\begin{array}{l}35.5 \\
(79)\end{array}$ & $\begin{array}{r}20.5 \\
(27)\end{array}$ & $\begin{array}{r}72.5 \\
(60)\end{array}$ & $\begin{array}{r}26.0 \\
(58)\end{array}$ & 154.5 & (54) \\
\hline
\end{tabular}

\section{Characteristics of the interventions}

The main characteristics and objectives of the included trials can be found in appendix I. Substantial differences are seen between the interventions of the 15 trials. In most of the trials the intervention was aimed at the general population of elderly people aged 65 or over, without a specific selection. Six trials focused on subjects aged 75 or over $91,18,23,25,26$. In only one trial was the intervention aimed at subjects with specific risk factors ${ }^{29}$. In nine trials the interventions lasted more than two years $9,13,15,19,23,26,31,32$, and in seven trials the intervention consisted of at least two visits a year, 11,15,17,23,26,29. In general, preventive home visits were tailored to the needs of the individual subjects. In nine trials, however, special attention was given to tailoring the intervention to the needs of the subjects by making the number of visits variable and dependent on the specific needs of the subjects $9,13,15,19,23,29,31,32$.

\section{Outcomes of the studies}

The main results of the included studies are shown in table 2.2. Overall, 94 outcome measures were investigated, all of which could be classed in one of the following five categories: physical function, psychosocial function, falls, admission to institutions, and mortality. Eight trials reported at least one (significant) favourable effect of the intervention, $11,15,17 \cdot 19,26,29$, five trials reported no effects ${ }^{13,23,25,32,33}$, and in the two combined trials of Vetter et al a favourable effect was reported in Gwent but no effects were reported in Powys $^{31}$. None of the trials reported negative effects. 
In five of the 12 trials, 11,17-19,23,25,26,29,31,33 investigating the effects of the intervention on physical functioning, the intervention group showed a significant improvement in at least one measure of physical functioning: basic or instrumental activities of daily living ${ }^{11.26}$, self rated health or health problem status $^{17,19}$, and balance, gait, and toilet transfer skills ${ }^{29}$.

Eight studies investigated psychosocial function (including satisfaction with life) ${ }^{13,17-19,23,25,31}$. In only one trial were favourable effects observed (attitude to own ageing, loneliness, isolation and emotional reaction) in the intervention group ${ }^{18}$.

Six trials investigated the number of falls $\mathrm{s}^{9,11,23,29,32,33}$. In two of these a significant reduction in the number of falls was observed in the intervention group 9.29 ,

Seven trials investigated admissions to institutions $11,15,19,23,25,26,29$. In two of these a significant reduction was observed in admissions to hospital ${ }^{15}$ and permanent nursing homes ${ }^{26}$.

Three of the 13 trials $911,15,18,19,23,25,26,29,31 \cdot 33$ that investigated mortality showed a significant lower mortality rate in the intervention than control group (in Gwent in the case of Vetter et $\left.\mathrm{al}^{31}\right)^{15,19}$.

\section{Discussion}

No clear evidence exists for the effectiveness of preventive home visits to elderly people living in the community. The observed effects of the interventions are considered to be fairly modest and inconsistent, especially as preventive home visits are costly and time consuming. This indicates a need for further improvement in the effectiveness of preventive home visits to make these interventions more beneficial in the long term. If substantial improvements in effectiveness cannot be achieved, consideration should be given to discontinuing such visits.

Although we found considerable differences in the methodological quality of the 15 trials -scores ranged from low $(29 \%)$ to good $(71 \%)$ - generally, the quality was considered adequate. Considerable methodological improvements are, however, still possible in the blinding of outcome assessors, handling of drop outs, checking for co interventions, assessing and reporting compliance to the intervention, and performing intention to treat analyses.

\section{Methodological issues}

Our results might be criticised for several reasons. Firstly, although several different search strategies were used to detect relevant trials it is possible that we failed to detect unpublished outcome data, owing to publication bias. Such bias arises when non-significant or negative outcome data are selectively omitted from publication. The potential effect of publication bias on the outcomes of our review might therefore be a further weakening of the already rather modest evidence for the effectiveness of preventive home visits. 
Table 2.2 Effects of preventive home visits to elderly people living in the community.

\begin{tabular}{|c|c|c|c|c|c|c|c|}
\hline Study (country) & $\begin{array}{l}\text { Follow-up } \\
\text { period }\end{array}$ & Number & Physical function & $\begin{array}{l}\text { Psychosocial } \\
\text { Function }\end{array}$ & $\begin{array}{l}\text { Effect on } \\
\text { falls }\end{array}$ & $\begin{array}{l}\text { Admissions to } \\
\text { institutions during } \\
\text { follow-up }\end{array}$ & $\begin{array}{l}\text { Mortality in } \\
\text { follow-up } \\
\text { period }\end{array}$ \\
\hline $\begin{array}{l}\text { Carpenter et al } \\
\text { (UK) }\end{array}$ & 3 years & $272(267)$ & $\begin{array}{l}\text { No significant effects } \\
\text { on disability score }\end{array}$ & Not assessed & $\begin{array}{l}\text { Significant } \\
\text { favourable } \\
\text { effects: } 12 \\
(36)^{2}\end{array}$ & Not assessed & Not significant \\
\hline $\begin{array}{l}\text { Fabacher et al" } \\
\text { (USA) }\end{array}$ & 1 year & $131(123)$ & $\begin{array}{l}\text { Significant favourable } \\
\text { effects on } \\
\text { instrumental activities } \\
\text { of daily living; no } \\
\text { significant effects on } \\
\text { activities of daily } \\
\text { living }\end{array}$ & Not assessed & $\begin{array}{l}\text { Not } \\
\text { significant }\end{array}$ & $\begin{array}{l}\text { No significant effects on } \\
\text { admissions to hospital and } \\
\text { nursing homes }\end{array}$ & Not significant \\
\hline $\begin{array}{l}\text { Hall et al }{ }^{13} \\
\text { (Canada) }\end{array}$ & 3 years & $81(86 / 81)$ & Not assessed & $\begin{array}{l}\text { No significant effects } \\
\text { on Memorial } \\
\text { University Happiness } \\
\text { Scale, Health Locus } \\
\text { of Control, } \\
\text { MacMillan Health } \\
\text { Opinion Index, UCLA } \\
\text { Loneliness Scale, } \\
\text { Social Readjustment } \\
\text { Rating Scale }\end{array}$ & Not assessed & Not assessed & Not assessed \\
\hline
\end{tabular}




\begin{tabular}{|c|c|c|c|c|c|c|c|}
\hline Study (country) & $\begin{array}{l}\text { Follow-up } \\
\text { period }\end{array}$ & Number & Physical function & $\begin{array}{l}\text { Psychosocial } \\
\text { function }\end{array}$ & $\begin{array}{l}\text { Effect on } \\
\text { falls }\end{array}$ & $\begin{array}{l}\text { Admissions to } \\
\text { institutions during } \\
\text { follow-up }\end{array}$ & $\begin{array}{l}\text { Mortality in } \\
\text { follow-up } \\
\text { period }\end{array}$ \\
\hline $\begin{array}{l}\text { Hendriksen et } \text { al }^{15} \\
\text { (Denmark) }\end{array}$ & 3 years & $285(287)$ & Not assessed & Not assessed & $\begin{array}{l}\text { Not } \\
\text { assessed }\end{array}$ & $\begin{array}{l}\text { Significant favourable } \\
\text { effects for admissions to } \\
\text { hospital: } 219(271) ; \text { no } \\
\text { significant effects on } \\
\text { admissions to nursing } \\
\text { homes }\end{array}$ & $\begin{array}{l}\text { Significant } \\
\text { favourable } \\
\text { effects: } 56 \text { (75) }\end{array}$ \\
\hline $\begin{array}{l}\text { Luker" } \\
\text { (UK) }\end{array}$ & 5 months & $60(60)$ & $\begin{array}{l}\text { Significant favourable } \\
\text { effects on health } \\
\text { problem status }\end{array}$ & $\begin{array}{l}\text { No significant effects } \\
\text { on Life Satisfaction } \\
\text { Index-A }\end{array}$ & $\begin{array}{l}\text { Not } \\
\text { assessed }\end{array}$ & Not assessed & Not assessed \\
\hline $\begin{array}{l}\text { McEwan et al }{ }^{16} \\
\text { (UK) }\end{array}$ & 20 months & $151(145)$ & $\begin{array}{l}\text { No significant effects } \\
\text { on elicited health } \\
\text { problems, ADL', } \\
\text { energy, pain, sleep, } \\
\text { and mobility }\end{array}$ & $\begin{array}{l}\text { Significant favourable } \\
\text { effects on attitude to } \\
\text { own ageing, loneliness, } \\
\text { isolation, emotional } \\
\text { reaction; no significant } \\
\text { effects on agitation }\end{array}$ & $\begin{array}{l}\text { Not } \\
\text { assessed }\end{array}$ & Not assessed & Not significant \\
\hline $\begin{array}{l}\text { Pathy et al }{ }^{19} \\
\text { (UK) }\end{array}$ & 3 years & $369(356)$ & $\begin{array}{l}\text { Significant favourable } \\
\text { effects on self rated } \\
\text { health; no significant } \\
\text { effects on Townsend } \\
\text { score, and } \\
\text { Nottingham Health } \\
\text { Profile }\end{array}$ & $\begin{array}{l}\text { No significant effects } \\
\text { on Life Satisfaction } \\
\text { Index }\end{array}$ & $\begin{array}{l}\text { Not } \\
\text { assessed }\end{array}$ & $\begin{array}{l}\text { No significant effects on } \\
\text { admission to hospital, and } \\
\text { long-term institutional care }\end{array}$ & $\begin{array}{l}\text { Significant } \\
\text { favourable } \\
\text { effects: } 67(86)\end{array}$ \\
\hline
\end{tabular}




\begin{tabular}{|c|c|c|c|c|c|c|c|}
\hline Study (country) & $\begin{array}{l}\text { Follow-up } \\
\text { period }\end{array}$ & Number & Physical function & $\begin{array}{l}\text { Psychosocial } \\
\text { function }\end{array}$ & $\begin{array}{l}\text { Effect on } \\
\text { falls }\end{array}$ & $\begin{array}{l}\text { Admissions to } \\
\text { institutions during } \\
\text { follow-up }\end{array}$ & $\begin{array}{l}\text { Mortality in } \\
\text { follow-up } \\
\text { period }\end{array}$ \\
\hline $\begin{array}{l}\text { van Rossum et al } \\
\text { (Netherlands) }\end{array}$ & 3 years & $292(288)$ & $\begin{array}{l}\text { No significant effects } \\
\text { on self rated health, } \\
\text { health complaints, } \\
I A D L \text {, and } A D L\end{array}$ & $\begin{array}{l}\text { No significant effects } \\
\text { on well-being, } \\
\text { loneliness, and } \\
\text { depressive complaints }\end{array}$ & $\begin{array}{l}\text { Not } \\
\text { significant }\end{array}$ & $\begin{array}{l}\text { No significant effects on } \\
\text { admissions to hospital" } \\
\text { and long-term } \\
\text { institutional care }\end{array}$ & Not significant \\
\hline $\begin{array}{l}\text { Sorensen et al }{ }^{25} \\
\text { (Danmark) }\end{array}$ & 3 years & $\begin{array}{l}585 \\
(777 / 140)\end{array}$ & $\begin{array}{l}\text { No significant effects } \\
\text { on subjective health } \\
\text { and functional ability }\end{array}$ & $\begin{array}{l}\text { No significant effects } \\
\text { on loneliness and } \\
\text { quality of life }\end{array}$ & $\begin{array}{l}\text { Not } \\
\text { assessed }\end{array}$ & $\begin{array}{l}\text { No significant effects on } \\
\text { admission to hospital and } \\
\text { institutional care }\end{array}$ & Not significant \\
\hline $\begin{array}{l}\text { Stuck et } a^{26} \\
\text { (USA) }\end{array}$ & 3 years & 215 (199) & $\begin{array}{l}\text { Significant favourable } \\
\text { effects on basic } A D L \\
\text { No significant effects } \\
\text { on instrumental ADL }\end{array}$ & Not assessed & $\begin{array}{l}\text { Not } \\
\text { assessed }\end{array}$ & $\begin{array}{l}\text { Significant favourable } \\
\text { effects on admissions to } \\
\text { permanent nursing home: } \\
9(20) \text {; no significant } \\
\text { effects on admission to } \\
\text { hospital and short term } \\
\text { nursing home }\end{array}$ & Not significant \\
\hline $\begin{array}{l}\text { Tinetti et al }{ }^{29} \\
\text { (USA) }\end{array}$ & 1 year & $153(148)$ & $\begin{array}{l}\text { Significant favourable } \\
\text { effects on } \\
\text { impairments in } \\
\text { balance, toilet } \\
\text { transfer skills, and } \\
\text { gait; no significant } \\
\text { effects on SIP, } \\
\text { postural hypotension, } \\
\text { impairment in leg } \\
\text { strength or motion, } \\
\text { and arm strength or } \\
\text { motion }\end{array}$ & Not assessed & $\begin{array}{l}\text { Significant } \\
\text { favourable } \\
\text { effects: } 52 \\
(68)^{\prime}\end{array}$ & $\begin{array}{l}\text { No significant effects on } \\
\text { admissions to hospital }\end{array}$ & Not significant \\
\hline
\end{tabular}




\begin{tabular}{|c|c|c|c|c|c|c|c|}
\hline Study (country) & $\begin{array}{l}\text { Follow-up } \\
\text { period }\end{array}$ & Number & Physical function & $\begin{array}{l}\text { Psychosocial } \\
\text { function }\end{array}$ & $\begin{array}{l}\text { Effect on } \\
\text { falls }\end{array}$ & $\begin{array}{l}\text { Admissions to } \\
\text { institutions during } \\
\text { follow-up }\end{array}$ & $\begin{array}{l}\text { Mortality in } \\
\text { follow-up } \\
\text { period }\end{array}$ \\
\hline $\begin{array}{l}\text { Vetter et al }{ }^{31} \\
\text { (Gwent, UK) }\end{array}$ & 2 years & $296(298)$ & $\begin{array}{l}\text { No significant effects } \\
\text { on physical disability } \\
\text { and mobility }\end{array}$ & $\begin{array}{l}\text { No significant effects } \\
\text { on anxiety scores, } \\
\text { depression, quality of } \\
\text { life, and social contacts }\end{array}$ & $\begin{array}{l}\text { Not } \\
\text { assessed }\end{array}$ & Not assessed & $\begin{array}{l}\text { Significant } \\
\text { favourable } \\
\text { effects: } 35(60)\end{array}$ \\
\hline $\begin{array}{l}\text { Vetter et al }{ }^{31} \\
\text { (Powys, UK) }\end{array}$ & 2 years & $281(273)$ & $\begin{array}{l}\text { No significant effects } \\
\text { on physical disability } \\
\text { and mobility }\end{array}$ & $\begin{array}{l}\text { No significant effects } \\
\text { on anxiety scores, } \\
\text { depression, quality of } \\
\text { life, and social contacts }\end{array}$ & $\begin{array}{l}\text { Not } \\
\text { assessed }\end{array}$ & Not assessed & Not significant \\
\hline $\begin{array}{l}\text { Vetter et al }{ }^{32} \\
\text { (UK) }\end{array}$ & 4 years & $350(324)$ & Not assessed & Not assessed & $\begin{array}{l}\text { Not } \\
\text { significant }\end{array}$ & Not assessed & Not significant \\
\hline $\begin{array}{l}\text { Wagner et } \mathrm{al}^{33} \\
\text { (USA) }\end{array}$ & 2 years & $\begin{array}{l}635 \\
(317 / 607)\end{array}$ & $\begin{array}{l}\text { No significant effects } \\
\text { on restricted activity } \\
\text { days }{ }^{9} \text {, bed days, and } \\
\text { Medical Outcomes } \\
\text { Study Physical } \\
\text { Limitations Scale }\end{array}$ & Not assessed & $\begin{array}{l}\text { Not } \\
\text { significant }\end{array}$ & Not assessed & Not significant \\
\hline
\end{tabular}

a) Number of falls in month before interview.

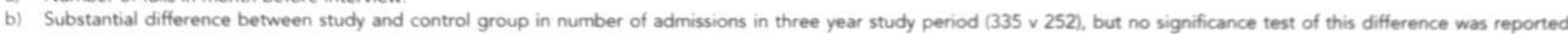
there were, however, significantly more long term (> 6 months) admissions in control group.

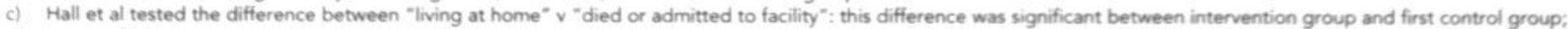

d) In one of 10 measured ADL activities a significant reduction in experienced problems was observed: this difference, however, was also present at baseline.

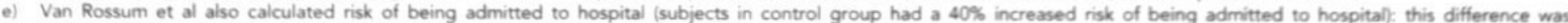
significant.

f) Number of falls during one year follow-up.

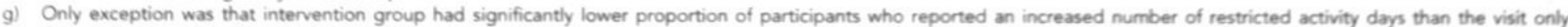
group. 
Secondly, because some of the trials seem to be underpowered $11,13,17$, it is possible that we slightly underestimated the effectiveness of the visits. Pooling the data of the trials could have shed more light on this issue, but owing to the considerable heterogeneity of the interventions we thought this was not justified.

\section{Implications}

To improve the effectiveness of preventive home visits it is important to gain a better understanding of the relation between specific characteristics of the home visits and favourable outcomes. Based on the information available, however, we could not reliably assess this mainly because of the multidimensional character of the interventions, which makes it difficult to distinguish the active elements from the total set of programme elements.

Several other factors complicate the analysis of the relation between specific intervention characteristics and favourable outcomes. Firstly, most trials provide only general information about the characteristics of the intervention. Secondly, most trials provide little or no information about the extent to which the intervention programmes were implemented according to plan. Unsuccessful implementation of the intervention protocol could have diminished the effects of (potentially effective) interventions. Thirdly, in most trials sufficient information was lacking about the compliance of the subjects to the interventions. A low compliance can negatively influence the effectiveness of the interventions and can also be an indicator of poor tailoring of the interventions to the needs of the subjects. Finally, the selection of the target populations could also have played a role in determining the level of success of the interventions. Fourteen of the trials in our review were targeted at the general population of elderly people living in the community. Only one intervention was aimed at the selection of elderly people with specific risk factors for health problems (falls) ${ }^{29}$. This short term intervention showed some promising results in reducing the number of falls and risk factors for falls, especially among subjects with impairment in balance or transfer skills and those who took four or more prescription drugs at baseline. This stresses the importance of choosing the right target populations in future programmes for home visits.

Considering the lack of insight into the predictors of programme success, we expect that it will be a difficult task to make improvements in the effectiveness of preventive home visits to elderly people living in the community.

\section{References}

1. Stuck AE, Siu AL, Wieland GD, Adams J, Rubenstein LZ. Comprehensive geriatric assessment: a meta-analysis of controlled trials. Lancet 1993;342:1032-6.

2. Cook DJ, Sackett DL, Spitzer WO. Methodologic guidelines for systematic reviews or randomized control trials in health care from the Potsdam consultation on meta-analysis. J Clin Epidemiol 1995;48:167-71.

3. Moher D, Olkin I. Meta-analysis of randomized controlled trials: a concern for standards. JAMA 1995;274:1962-3.

4. Dickersin K, Scherer R, Lefebvre C. Identifying relevant studies for systematic reviews. Br Med J 1994;309:1286-91. 
5. van Tulder MW, Assendelft WJJ, Koes BW, Bouter LM, the Editorial Board of the Cochrane Collaboration Back Review Group. Method guidelines for systematic reviews in the Cochrane Collaboration back review group for spinal disorders. Spine 1997;22:2323-30.

6. Alessi CA, Stuck AE, Aronow HU, et al. The process of care in preventive in-home comprehensive geriatric assessment. J Am Geriatr Soc 1997;45:1044-50.

7. Balaban DJ, Goldfarb NI, Perkel RL, Lepidus Carison B. Follow-up study of an urban familiy medicine home visit program. J Fam Pract 1988;26:307-12.

8. Black ME, Ploeg J, Walter SD, Hutchison BG, Scott EAF, Chambers LW. The impact of a public health nurse intervention on influenza vaccine acceptance. Am J Public Health 1993;83:1751-3.

9. Carpenter GI, Demopoulos GR. Screening the elderly in the community: controlled trial of dependency surveillance using a questionnaire administered by volunteers. $\mathrm{Br}$ Med J 1990;300:1253-6.

10. Clarke M, Clarke SJ, Jagger C. Social intervention and the elderly: a randomized controlled trial. Am J Epidemiol 1992;136:1517-23.

11. Fabacher D, Josephson K, Pietruszka F, Linderborn K, Morley JE, Rubenstein LZ. An in-home preventive assessment program for independent older adults: a randomized controlled trial. J Am Geriatr Soc 1994;42:630-8.

12. Gallagher EM, Brunt $\mathrm{H}$. Head over heels: impact of a health promotion program to reduce falls in the elderly. Can J Aging 1996;15:84-96.

13. Hall N, De Beck P, Johnson D, Mackinnon K, Gutman G, Glick N. Randomized trial of a health promotion program for frail elders. Can J Aging 1992;11:72-91.

14. Hendriksen C., Lund E, Stromgard E. Hospitalization of elderly people: a 3-year controlled trial. J Am Geriatr Soc 1989:37:117-22.

15. Hendriksen $C$, Lund $E$, Stromgard $E$. Consequences of assessment and intervention among elderly people: a three year randomised controlled trial. Br Med J 1984;289:1522-4.

16. Hornbrook MC, Stevens VJ, Wingfield DJ, Hollis JF, Greenlick MR, Ory MG. Preventing falls among community-dwelling older persons: results from a randomized trial. Gerontologist $1994 ; 34: 16-23$.

17. Luker KA. Health visiting and the elderly. Nurs Times 1981;77:137-40.

18. McEwan RT, Davison N, Forster DP, Pearson P, Stirling E. Screening elderly people in primary care: a randomized controlled trial. Br J Gen Pract 1990;40:94-7.

19. Pathy MSJ, Bayer A, Harding K, Dibble A. Randomised trial of case finding and surveillance of elderly people at home. Lancet 1992;340:890-3.

20. Ploeg J, Black ME, Hutchinson BG, Walter SD, Scott EAF, Chambers LW. Personal, home and community safety promotion with community-dwelling elderly persons: response to a public health nurse intervention. Can J Publ Health 1994;85:188-91.

21. Reuben DB, Hirsch SH, Chernoff JC, et al. Project safety net: a health screening outreach and assessment program. Gerontologist 1993;33:557-60.

22. Rizzo JA, Baker DI, McAvay G, Tinetti ME. The cost-effectiveness of a multifactorial targeted prevention program for falls among community elderly persons. Med Care 1996;34:954-69

23. van Rossum E, Frederiks C.M.A., Philipsen H, Portengen K, Wiskerke J, Knipschild P. Effects of preventive home visits to elderly people. Br Med J 1993;307:27-32.

24. Rubenstein LZ, Aronow HU, Schloe M, et al. A home-based geriatric assessment, follow-up and health promotion program: Design, methods, and baseline findings from a 3-year randomized clinical trial. Aging Clin Exp Res 1994;6:105-20.

25. Sorensen $\mathrm{KH}$, Sivertsen J. Follow-up three years after intervention to relieve unmet medical and social needs of old people. Compr Gerontol B 1988;2:85-91.

26. Stuck AE, Aronow HU, Steiner A, et al. A trial of annual in-home comprehensive geriatric assessments for elderly people living in the community. N Engl J Med 1995;333:1184-9.

27. Stuck AE, Gafner Zwahlen H, Neuenschwander BE, Meyer Schweizer RA, Bauen G, Beck JC. Methodologic challenges of randomized controlled studies on in-home comprehensive geriatric assessment: the Eiger project. Aging Clin Exp Res 1995;7:223.

28. Tinetti ME, Baker DI, Garrett PA, Gottschalk M, Koch ML, Horwitz RI. Yale Ficsit: risk factor abatement strategy for fall prevention. J Am Geriatr Soc 1993:41:315-20. 
29. Tinetti ME, Baker DI, McAvay G, et al. A multifactorial intervention to reduce the risk of falling among elderly people living in the community. N Engl J Med 1994;331:821-7.

30. Tulloch A., Moore V. A randomized controlled trial of geriatric screening and surveillance in general practice. J R Col Gen Pract 1979;29:733-42.

31. Vetter NJ, Jones DA, Victor CR. Effect of health visitors working with elderly patients in general practice: a randomised controlled trial. Br Med J 1984;288:369-72.

32. Vetter NJ, Lewis PA, Ford D. Can health visitors prevent fractures in elderly people? $\mathrm{Br}$ Med J 1992;304:888-90.

33. Wagner EH, LaCroix AZ, Grothaus L, et al. Preventing disability and falls in older adults: a population-based randomized trial. Am J Public Health 1994;84:1800-6. 


\section{Appendix I: Details of the preventive home visits}

\begin{tabular}{|c|c|}
\hline Reference & Intervention \\
\hline 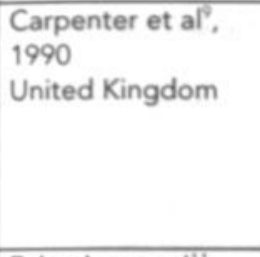 & $\begin{array}{l}\text { Volunteers completed a scored activity of daily living questionnaire. } \\
\text { Individuals with an increase in score }>5 \text { were referred to their general } \\
\text { practitioner. Subjects with no disability were visited every six months, and } \\
\text { those with some or severe disability every three months for a period of } \\
\text { about } 3 \text { years. Controls received usual care. } \\
\begin{array}{l}\text { Main objective: reducing medical, functional, mental, and so- } \\
\text { cial/environmental problems. }\end{array}\end{array}$ \\
\hline $\begin{array}{l}\text { Fabacher et al", } \\
1994 \\
\text { USA }\end{array}$ & $\begin{array}{l}\text { A home visit by a physician's assistant or nurse, to screen for medical, } \\
\text { functional, and psychosocial problems, followed by a letter describing } \\
\text { findings and recommendations, and follow-up visits by trained volunteers } \\
\text { at } 4 \text {-month intervals for one year. Controls received only telephone } \\
\text { interviews at } 4 \text { month intervals to collect outcome data. } \\
\text { Main objective: improving health and functional status. }\end{array}$ \\
\hline $\begin{array}{l}\text { Hall et al'3, } \\
1992 \\
\text { Canada }\end{array}$ & $\begin{array}{l}\text { The intervention and control group all received standard long term care } \\
\text { (LTC) services, which included screening and pre-admission assessment, } \\
\text { arrangement/purchase of needed services and review at } 3 \text { months and at } \\
\text { least yearly thereafter. In addition the intervention group, received visits } \\
\text { from the project nurse, who helped each subject to devise a personal } \\
\text { health plan based on his or her needs in the areas of health care, } \\
\text { substance use, exercise, nutrition, stress management, emotional } \\
\text { functioning, social support and participation, housing. finances and } \\
\text { transportation. The frequency of visits to individual clients depended on } \\
\text { their needs (duration three years). } \\
\text { Main objective: assisting older adults in maintaining their total well-being. }\end{array}$ \\
\hline $\begin{array}{l}\text { Hendriksen et } \mathrm{al}^{15} \text {, } \\
1984 \\
\text { Denmark }\end{array}$ & $\begin{array}{l}\text { An interview was carried out by a nurse using a structured questionnaire, } \\
\text { and information on social and health conditions was collected. } \\
\text { Corresponding visits were made every three months throughout the study } \\
\text { (maximum twelve visits during a period of three year). Controls received } \\
\text { usual care. } \\
\text { Main objective: reduction of mortality, and medical consumption. }\end{array}$ \\
\hline $\begin{array}{l}\text { Luker }^{17} \text {, } \\
1981 \\
\text { United Kingdom }\end{array}$ & $\begin{array}{l}\text { The intervention group received focused health visitor intervention once } \\
\text { monthly for four months from a health visitor. The focus of the visits was } \\
\text { generated by the subject's health problems which are subsumed under } 10 \\
\text { headings: weight maintenance, mobility, dentition, sensory function, } \\
\text { elimination, loneliness, performance of personal or household tasks, rest, } \\
\text { medication, miscellaneous. Controls received usual care. } \\
\text { Main objective: improvement of health problems and life satisfaction. }\end{array}$ \\
\hline $\begin{array}{l}\text { McEwan et al' } \\
1990 \\
\text { United Kingdom }\end{array}$ & $\begin{array}{l}\text { The test group received a home visit from a nurse at which an assessment } \\
\text { lasting } 45 \text { minutes was made of: activities of daily living, social function- } \\
\text { ing, sensory function, mental and emotional problems, current medical } \\
\text { problems, blood pressure, uri-analysis, haemoglobin level and compliance } \\
\text { with medication. Controls received usual care. } \\
\text { Main objective: resolve health and related problems and improve quality } \\
\text { of life. }\end{array}$ \\
\hline $\begin{array}{l}\text { Pathy et al }{ }^{19} \text {, } \\
1992 \\
\text { United Kingdom }\end{array}$ & $\begin{array}{l}\text { A screening questionnaire was sent to the participants. Depending on the } \\
\text { answers and other information the health visitor would arrange home } \\
\text { visits and give any practical advice and health education that might be } \\
\text { needed or arrange referral to the GP or community service. The duration } \\
\text { of the intervention period was three years. Controls received usual care. } \\
\text { Main objective: improving quality of life and health status, and reducing } \\
\text { mortality and use of all services. }\end{array}$ \\
\hline
\end{tabular}




\begin{tabular}{|c|c|}
\hline $\begin{array}{l}\text { van Rossum et al23, } \\
1993 \\
\text { The Netherlands }\end{array}$ & $\begin{array}{l}\text { The intervention group was visited four times a year over a period of } \\
\text { three years with extra visits if necessary by a community nurse. The nurse } \\
\text { discussed health topics in a broad sense with the participants and gave } \\
\text { information and advice. Controls received usual care. } \\
\text { Main objective: improving the state of health (functional and mental state, } \\
\text { well-being and mortality). }\end{array}$ \\
\hline $\begin{array}{l}\text { Sorensen et } \mathrm{al}^{35} \text {, } \\
1988 \\
\text { Denmark }\end{array}$ & $\begin{array}{l}\text { During a home visit a social worker assessed housing conditions, } \\
\text { economy, social support, and social network. In addition the need for } \\
\text { health intervention was estimated by a physician based on a general } \\
\text { medical examination. Those found to need further treatment were } \\
\text { referred to their general practitioner. Controls received usual care. } \\
\text { Main objective: relieving unmet medical and social needs. }\end{array}$ \\
\hline $\begin{array}{l}\text { Stuck et } \mathrm{a}^{26} \text {, } \\
1995 \\
\text { USA }\end{array}$ & $\begin{array}{l}\text { The people in the intervention group were seen at home by gerontologic } \\
\text { nurse practitioners who, in collaboration with geriatricians, evaluated } \\
\text { problems and risk factors for disability, gave specific recommendations } \\
\text { and provided health education. During a period of three years, follow-up } \\
\text { visits were performed every three months. Controls received usual care. } \\
\text { Main objective: preventing disability. }\end{array}$ \\
\hline $\begin{array}{l}\text { Tinetti et } \mathrm{al}^{20} \text {, } \\
1994 \\
\text { USA }\end{array}$ & $\begin{array}{l}\text { After a baseline assessment in their homes by the study nurse practitioner } \\
\text { and physical therapist, based on the results of the assessment the subjects } \\
\text { received the following interventions: behavioural recommendations, } \\
\text { education about use of sedative-hypnotic agents, training in transfer skills, } \\
\text { changes in environmental hazards, gait training, balance exercises, etc. } \\
\text { The intervention phase lasted three months. Controls received usual care } \\
\text { plus social visits. } \\
\text { Main objective: reducing the risk of falling. }\end{array}$ \\
\hline $\begin{array}{l}\text { etter et } \mathrm{al}^{31} \text {. } \\
984 \\
\text { iwent and Powys, } \\
\text { nited Kingdom }\end{array}$ & $\begin{array}{l}\text { Subjects were visited at home by a health visitor. The health visitors were } \\
\text { instructed to interview patients and to keep notes according to usual } \\
\text { health visiting practice. The health visitors were restricted to making one } \\
\text { unsolicited visit a year (for a period of two years). They followed up } \\
\text { patients who were in trouble at that visit. Controls received usual care. } \\
\text { Main objective: improving well-being, and physical, mental, and social } \\
\text { functioning. }\end{array}$ \\
\hline $\begin{array}{l}\text { Vetter et } \mathrm{al}^{32} \\
1992 \\
\text { United Kingdom }\end{array}$ & $\begin{array}{l}\text { During a period of four years a health visitor visits the household at least } \\
\text { once a year, for those not presenting any problems. Those elderly who } \\
\text { had problems were visited as often as was thought necessary by the } \\
\text { health visitor. The health visitor first obtained a history of illness and than } \\
\text { concentrated on four factors: nutrition, medical conditions, environment, } \\
\text { assessment and improvement of general muscle tone and fitness. Controls } \\
\text { received usual care. } \\
\text { Main objective: reduce the number of fractures. }\end{array}$ \\
\hline $\begin{array}{l}\text { lagner et } \mathrm{al}^{33} \text {, } \\
994 \\
\text { SA }\end{array}$ & $\begin{array}{l}\text { Intervention 1: subjects received a visit from a specially trained } \\
\text { nurse/educator aimed at reviewing risk factors for disability and falls, } \\
\text { resulting in a tailored intervention plan to address identified risk factors, } \\
\text { and motivate seniors to increase physical and social activity. } \\
\text { Intervention 2: a nurse visit focused on assessments and counselling } \\
\text { relevant to cardiovascular disease prevention, breast and cervical cancer } \\
\text { detection, influenza vaccination and seat belt use. Controls received usual } \\
\text { care. } \\
\text { Main objective: to reduce days of restricted activity due to illness. }\end{array}$ \\
\hline
\end{tabular}




\section{3}

\section{Intervention and design}

This chapter is an elaborated version of:

van Haastregt JCM, van Rossum E, Diederiks JPM, Voorhoeve PM, de Witte LP, Crebolder HFJM. Preventing falls and mobility problems in communitydwelling elders: the process of creating a new intervention. Geriatr Nurs 2000;21:309-314. 


\section{Summary}

The first part of this chapter describes the development, contents and implementation of a multifactorial home visit intervention, aimed at preventing falls and mobility impairments among elderly people at risk. The intervention consists of five preventive home visits performed by a community nurse, over a period of one year. Participants were screened for medical, functional, psychosocial, and environmental factors causing falls and mobility impairments, followed by recommendations, referrals and other actions aimed at dealing with the observed hazards.

In the second part of this chapter the design of the evaluation study accompanying the intervention is presented. This evaluation study in the form of a randomised controlled trial, consists of an effect evaluation, economical evaluation and process evaluation. The outcome measures that are considered in the three components of the study are presented. 


\section{Introduction}

Falls and mobility impairments are common problems among elderly people. Mobility impairments and the consequences of falls can have a considerable impact on independent functioning and quality of life of elderly people living in the community. Therefore there is a strong need for effective interventions aimed at the prevention of falls and mobility impairments in this group of elderly people.

In the first part of this chapter the development, contents and implementation of a multifactorial home visit programme aimed at preventing falls and mobility impairments in elderly people, is described. In the second part of the chapter the design of the accompanying evaluation study is presented.

\section{Development, contents and implementation of the intervention}

\section{Background}

Falls and mobility impairments are common problems among elderly people. Falls are associated with increasing morbidity, mortality and health care utilisation ${ }^{1,2}$. Approximately $30 \%$ of the people aged 65 years or over report one or more falls in the previous year ${ }^{3.7}$. About $5-10 \%$ of falls result in major injury, such as fractures, and approximately $20 \%$ of falls require medical attention ${ }^{8-10}$. The incidence of falls rises with age. Ageing is also characterised by an increasing prevalence of mobility impairments ${ }^{11,12}$. Falls and mobility impairments are interrelated problems. In the literature a considerable number of overlapping and interacting causes have been reported, such as balance problems, muscular weakness, neurological disorders, cardiovascular disease, cognitive impairment, depressive mood, and medication ${ }^{3,6,8,13-15}$. Mobility impairment is a strong predictor of recurrent falls ${ }^{16}$. In turn, fall accidents can have drastic, sometimes permanent consequences for mobility in the elderly, especially when they result in serious injuries like hip-fractures.

During the past years the prevention of falls in the elderly has received much attention. Gillespie et al $^{17}$ systematically reviewed randomised controlled trials of programs designed to reduce the number of falls in community-living, institutionalised, or hospitalised elderly people. The authors conclude that in the field of fall prevention exercise interventions alone do not seem to be very effective, and that multidimensional interventions targeted at both intrinsic and environmental risk factors of individual patients seem to be preferable ${ }^{17}$. Multidimensional interventions in the form of preventive home visits, including assessment by a health professional of medical problems and environmental hazards, have shown promising results in the prevention of falls among elderly people living in the community ${ }^{10,17.18}$.

In contrast to the evidence regarding the effects on falls, little evidence is yet available about the effects of risk assessment by a health professional on the prevention and reduction of mobility impairments. Many preventive programs aimed at improving mobility have focused on the effects of exercise interven- 
tions on mobility-related factors. In general, these exercise interventions have shown modest positive effects ${ }^{19-2 r}$. The disadvantage of these unidimensional exercise interventions, however, is that they are almost exclusively aimed at improving mobility-related factors like muscle strength, balance, and endurance, while less attention is paid to "functional mobility" (in terms of daily activities people actually perform or want to perform). Another disadvantage of these interventions is that little attention is paid to physical, psychological, social and environmental factors directly or indirectly influencing mobility, like chronic illness, depressive feelings, and the use of appropriate devices. Therefore we expect that multidimensional interventions including general risk assessment will be at least as effective in the prevention and reduction of mobility impairment in community-living elderly as exercise interventions. Because of the close relationship between falls and mobility impairments and because both problems have overlapping and interrelated causes, we decided to develop a multifactorial intervention consisting of multifactorial home visits by community nurses, aimed at both the reduction of falls and mobility impairments.

\section{Target population}

Previous studies in the field of preventive home visits suggested that these programmes tend to be more effective among elderly people at risk, than among the general population of elderly people $\mathrm{e}^{22,23}$. It was therefore decided to target the intervention to a subgroup of community-living elderly people who are already moderately impaired in their mobility and/or have an increased risk of falling. People who have severe mobility impairments (bedridden, fully dependent on a wheelchair) or who are terminally ill were excluded, since it is likely that most of them already receive professional care and regular supervision. One of the main advantages of preventive home visits is the opportunity to screen and advise people who are not already under regular supervision of professional caregivers. Moreover, the further reduction of mobility impairment in a group of severely mobility impaired elderly would probably require a substantially different approach.

\section{Development of the intervention}

The initiative for developing the home visit intervention originally came from a group of researchers from Maastricht University and the Institute for Rehabilitation Research (iRv). This group invited the staff of a primary care health centre and the home nursing service of an agglomeration in the south of the Netherlands to participate in the development, implementation and evaluation of the intervention. Both organisations agreed to co-operate. The following objectives for the intervention were formulated:

- obtaining a significant reduction in the number of falls and mobility impairments in the elderly receiving the intervention compared to a group of elderly receiving usual care (primary aim) 
- improving general physical, social and psychological functioning and reducing health care utilisation and associated costs (secondary aim).

A project team consisting of a general practitioner (health centre), an experienced community nurse (home care service) and a health scientist (iRv) was made responsible for the development of the intervention. A protocol for the intervention was developed, based on the literature and the practical and theoretical experience of the members of the project team, research group and other experts in the field.

The core component of the intervention developed by the project team is comprehensive geriatric assessment, resulting in specific recommendations and interventions aimed at tackling medical, functional, psychosocial, and environmental risk factors for falls and mobility impairments. The intervention consists of five preventive home visits performed by a community nurse, during a period of approximately one year. In the first six months subjects receive three visits (every two months), followed by two visits in the last six months (every three months). Each visit lasts about one hour.

\section{The intervention protocol}

A protocol for the home visits was developed, serving as a guideline for the nurses. This protocol consists of the following elements:

1. Basic guidelines for preventive home visits

2. Checklist for preventive home visits

3. Home-safety checklist

4. Report of problems and process

The four elements of the protocol are discussed in detail below.

\section{Basic guidelines for preventive home visits}

The "Basic guidelines for preventive home visits" are divided into five sections: (1) physical health, (2) devices, care and medication, (3) mobility, activities of daily living and social functioning, (4) falls and fear of falling, and (5) cognitive and psychological functioning. Each section is subdivided in an "assessment" and a "solutions" part. The "assessment part" contains questions relevant to the patient, points of special interest for the nurse, and practical guidelines for physical examinations. In the "solutions part" suggestions for possible solutions to the problems and risks identified are offered.

- Section 1, "Physical health", assesses the problems associated with impairments to the extremities, the heart and lungs, the central nervous system, vision, hearing as well as other physical problems. If problems are observed, participants are asked by the nurse as to how they are coping with the problems. The nurse provides specific recommendations regarding ways in which the problems observed might be dealt with, and to improve the participant's ability to cope with the problem. If necessary, the nurse will recommend the participant to visit their general practitioner to discuss their problem. 
- Section 2, "Devices, care and medication", assesses the use of assistive devices and health care services, and provides recommendations on how specific problems that have been observed can be improved. The nurse also lists the medication used by the participants, and discusses this list with the participant's general practitioner. If changes in medication are necessary, the nurse recommends that the participants visit their general practitioner to discuss these changes.

- Section 3, "Mobility, activities of daily living and social functioning", makes an assessment of impairments in gait and mobility, and the participant's ability to perform daily activities. Safety hazards in the home are assessed by means of a home-safety checklist (described below). In addition nutritional aspects of the participant's diet and social functioning are discussed. The nurse provides advice on how to improve mobility, and ways in which to perform daily activities. If necessary, home alterations are recommended, and the nurse will help the participant find ways of having these alterations made. If participants report problems in social functioning, the nurse will discuss the possible ways of strengthening the social network, and supports the participant in taking action.

- Section 4, "Falls and fear of falling", assesses the number, nature, and causes of falls in the previous year. The nurse will discuss ways in which future falls might be prevented, and provides specific advice with respect to this subject. In addition, participants are asked about their fear of falling and whether they avoid certain activities as a result of this fear. In cases where there is a serious fear of falling and/or avoidance, the nurse will discuss with participants the level to which this fear and avoidance seems real and justified, and tries to help participants overcome any irrational thoughts.

- Section 5, "Cognitive and psychological functioning", assesses cognitive and psychological functioning based on observation and specific questions regarding psychiatric symptoms. Specific recommendations, based on the problems assessed, are given or participants are referred to mental health care.

\section{Checklist for preventive home visits}

After each home visit the nurse marks in the "Checklist for preventive home visits" which of the main topics described in the "Basic guidelines" she discussed with the participant during the home visit, and which topics need extra attention in the following visits. This checklist provides the nurse with a brief overview of the preceding visits and can function as a guideline for the subsequent visits (see figure 3.1 ).

\section{Home-safety checklist}

Stalenhoef et $\mathrm{al}^{25}$ developed a checklist of indoor fall risk. The checklist contains 6 categories of risks (floors, lighting, walking space, stairs, obstacles 
and various), divided in 8 locations of the home (entrance, stairs, kitchen, bathroom, toilet, bedroom, living room, ceiling and cellar).

The nurse uses the checklist to check the home on safety hazards, and based on the results of this check, she makes recommendations to the participant on how to improve the situation.

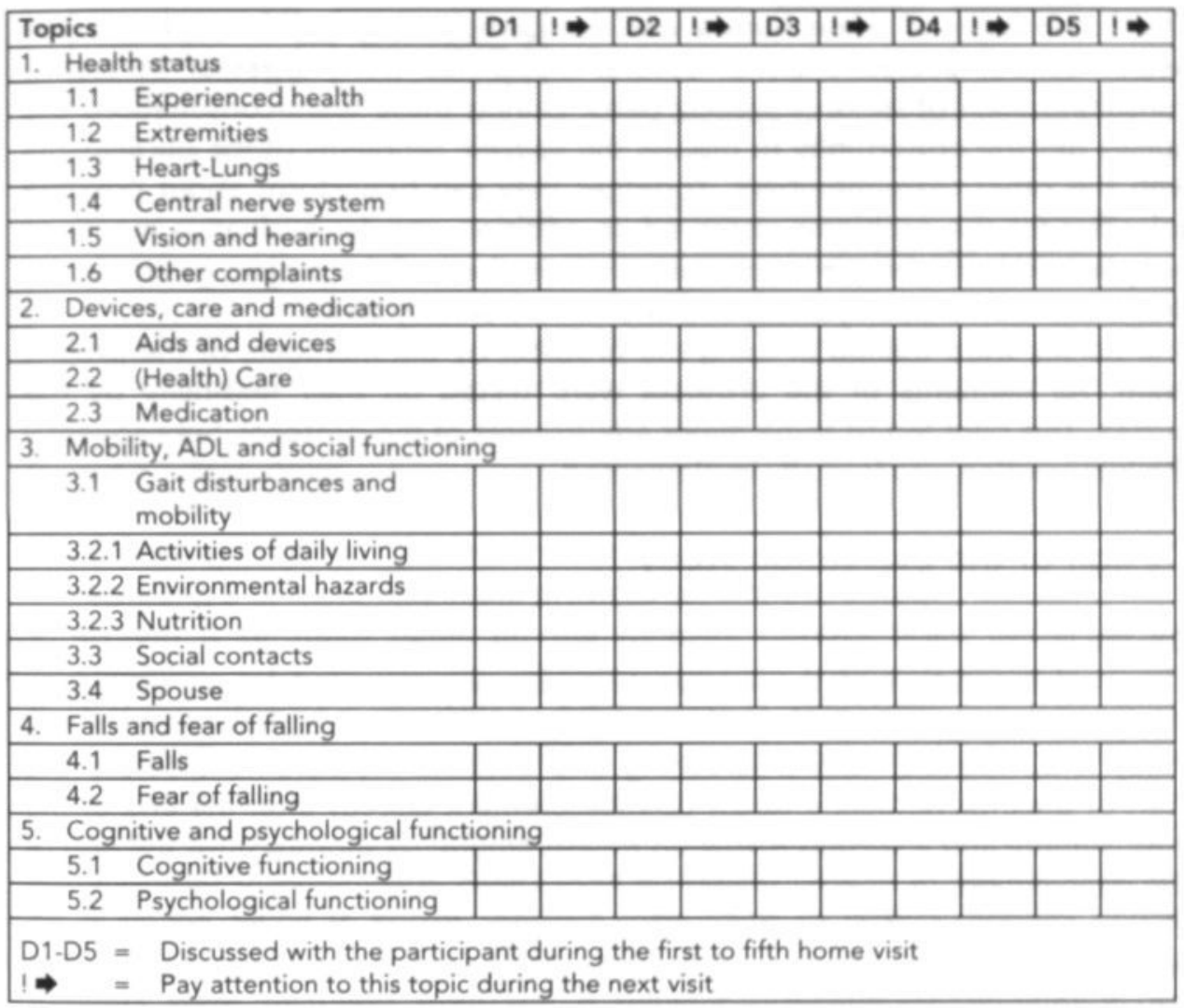

Figure 3.1 Checklist for preventive home visits.

\section{Report of problems and process}

For each participant the problems identified, the (potential) solutions, actions discussed with the participant, and other activities directly related to the home visits are registered by the nurse in a structured report. In addition referrals of the participant to other disciplines are registered.

\section{Implementing the intervention}

Two Dutch subsidisers ("ZorgOnderzoek Nederland" and "Stichting Onderzoek en Ontwikkeling Maatschappelijke Gezondheidszorg") agreed to finance the implementation of the intervention and its effect evaluation.

In the Netherlands community-living people can qualify for a home care allowance if they become (partially) dependent on home care assistance from 
professionals as a result of physical or psychosocial impairments. This home care can vary from housekeeping to specialised home nursing care from community nurses. It was possible therefore to integrate this newly developed intervention programme within the "infrastructure" of the Dutch home care system.

Four experienced community nurses were invited to perform the home visits. The home base of these nurses was the participating health centre. In this health centre, professionals of several disciplines work together in teams, consulting each other on a weekly basis. During these team-consultations the nurses get the opportunity to discuss the specific problems of the participants with the other team-members. Together they can brainstorm about possible solutions for the problems observed. In addition, regular evaluative meetings are planned between the nurses, and the members of the project group, in the first months on a weekly basis, and later on a 3-weekly basis.

The nurses were trained in using the protocol by the members of the project team. All elements of the protocol were tested on their feasibility by the nurses. This pilot led to some minor adjustments of the protocol. Subsequently the intervention was formally implemented.

\section{Design of the evaluation study}

\section{Design}

The implementation of the intervention was accompanied by an evaluative study, the design of which is shown in figure 3.2. The total duration of the study is 22 months, with a screening and baseline measurement before the start of the intervention, a follow-up measurement directly after the end of the intervention, and a second follow-up measurement, six months after the end of the intervention.

The key question of our trial is: What are the effects of multifactorial home visits by community nurses on falls and mobility impairments among community-living elderly people at risk?

We divided the evaluation study into three parts: effect evaluation, economical evaluation, and process evaluation. The effect evaluation is aimed at assessing the effects of the intervention on falls, mobility impairments and eight secondary outcome measures. The economical evaluation is aimed at assessing the effects of the intervention on health care utilisation and associated costs. The process evaluation is aimed at assessing the feasibility of the home visit programme for the persons receiving and performing the intervention.

\section{Study population}

In order to select a group of elderly people with moderate mobility impairmens and/or an increased risk of falling, a screening-questionnaire was developed. 
continuous registration of health care utilisation

continuous registration of falls

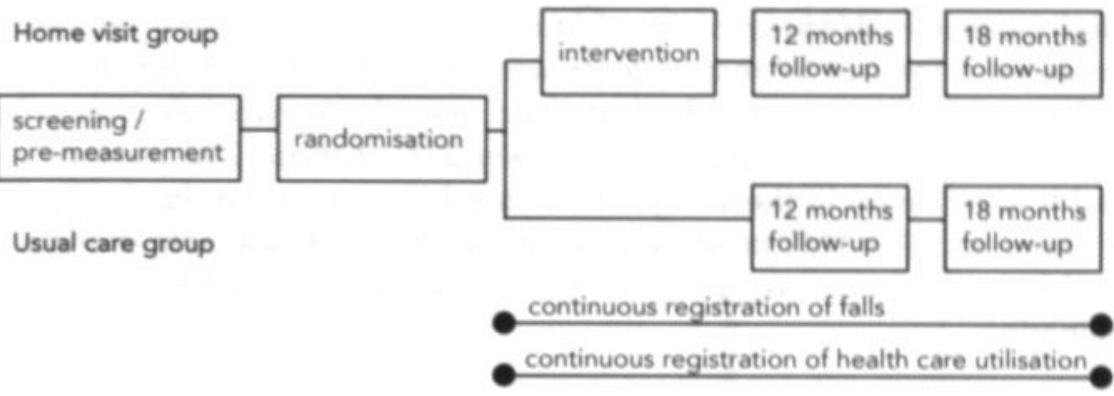

September ' 97

Figure 3.2 Study design.

The following selection criteria were used:

- reporting 2 or more falls in the previous six months, and/or

- scoring 3 or more items on the Mobility Control Scale (MCS) of the SIP68 26,27 .

Both the number of recent falls and the presence of mobility impairments are strong predictors of (recurrent) falls ${ }^{3,16}$. In contrast to several other predictors of falls, such as postural hypotension and poor cognitive functioning, these two variables are suited for large scale screening by means of a short selfadministered questionnaire. Apart from screening people at risk for falls, the MCS of the SIP68 is also a sensitive instrument to detect mobility impairments $^{28}$.

Patients were recruited from the 6 general practices cooperating in the participating health centre. Of the total number of 1459 elderly patients $(70+)$ in the centre, 1310 received the screenings-questionnaire. This questionnaire also contained questions regarding several background variables and baseline measurements of the relevant outcome measures. A covering letter was added, informing the patients about the study and requesting them to sign the informed consent form, also enclosed, if they were willing to participate in the trial. Beforehand, patients who where known by their general practitioner as severely mobility impaired (i.e. bedridden or fully dependent on a wheelchair), or terminally ill, were excluded. People residing in nursing homes or other institutions were excluded from participation in the study. People living in senior centres were considered to be community-living and could therefore participate in the study.

The response to the questionnaire was $68 \%(n=896)$. Informed consent for participation in the trial was given by 761 respondents. The questionnaire 
contained a second check for severe mobility impairment. In addition, respondents already receiving home care from a community nurse on a regular basis were excluded, in order to prevent contamination in the control group. Respondents on the waiting list for admission to a nursing home were also excluded, because our study is aimed at community-living elderly people. For these reasons a total of 59 respondents were excluded. Of the remaining 702 respondents, 392 persons matched at least one of the two selection criteria (risk of falls and mobility impairment). Finally 316 of these 392 persons were selected to participate in the study. The 316 subjects were randomly allocated to the home visit $(N=159)$ or usual care group $(N=157)$. Subjects sharing one household were always assigned to the same group in order to prevent contamination.

\section{Outcome measures}

For each of the three components of the study the main outcome measures are discussed below.

\section{Effect evaluation}

Table 3.1 shows the outcome variables that are measured during the course of the study. The number of falls and the level of mobility impairment are the primary outcome measures of the effect study. However, because the intervention is multidimensional and includes assessment of a large variety of factors potentially causing falls and mobility, we also measure whether our intervention has effects on fear of falling, perceived health, physical complaints, perceived gait problems, daily activity, mental health, loneliness, and social functioning. The number of falls are registered continuously during the course of the study by means of a fall diary. The other outcome measures are measured by means of a self-administered questionnaire at baseline, and after 12 and 18 months of follow-up.

\section{Economical evaluation}

Costs of the home visit programme that are considered include costs of the nurses who performed the visits, costs of consultation of general practitioners by the nurses, and additional costs (training session nurses, initial screening of potential participants, materials and supervision). The number of hours spent by the nurses on the home visit programme are registered by the nurses on a structured registration form.

The other direct health care costs considered are costs of hospitalisation, visits to health care providers (medical specialist, general practitioner, and physiotherapist), professional home care (domestic help and community nursing care), medical aids and medication. Costs regarding hospitalisation, hospital admissions, contacts with physiotherapists and medical specialists, and medical aids and medication, are provided by the main National Health Service Company in the study region. The number of contacts of the participants with general practitioners is registered by the general practitioners. 
Table 3.1 Variables measured during the course of the study.

\begin{tabular}{|c|c|c|c|c|c|}
\hline Variables measured & Number of items (further details) & Pre & IP & Fu1 & Fu2 \\
\hline \multicolumn{6}{|l|}{ Background variables } \\
\hline sex & 1 item & Q & - & - & - \\
\hline Age & 1 item & Q & - & - & - \\
\hline composition of household & 1 item & Q & - & - & - \\
\hline Income & 1 item & Q & - & - & - \\
\hline educational level & 1 item & Q & - & - & . \\
\hline exclusion criteria & $\begin{array}{l}4 \text { items (bedridden, dependent on wheelchair, on waiting list for admission to } \\
\text { nursing home, or receiving home care on a regular basis) }\end{array}$ & Q & - & - & - \\
\hline \multicolumn{6}{|l|}{ Primary outcome measures } \\
\hline \multirow[t]{2}{*}{ mobility } & 12 items (Mobility Control, SIP68 $8^{26,27}$ ) & Q & - & Q & Q \\
\hline & 10 items (Mobility Range, SIP68 ${ }^{26.27}$ ) & Q & - & Q & Q \\
\hline \multirow[t]{3}{*}{ falls } & 2 items (number of falls in the previous year) & Q & - & - & - \\
\hline & continuous registration of indoor and outdoor falls in a fall diary & $\cdot$ & $D>$ & $>$ & $>$ \\
\hline & 2 items (injurious falls and falls resulting in medical care) & - & - & Q & Q \\
\hline \multicolumn{6}{|l|}{ Secondary outcome measures } \\
\hline fear of falling & 10 items (Falls Efficacy Scale 20.30 ) & Q & - & Q & Q \\
\hline perceived health & 2 items (item 1 and 2 , RAND- $36^{31}$ ) & Q & - & Q & Q \\
\hline physical complaints & 18 items (a list of 17 mobility-related physical complaints, plus one open category) & Q & - & Q & Q \\
\hline perceived gait problems & 2 items & Q & - & Q & Q \\
\hline daily activity & 13 items (Frenchay Activities Index, items 14 and 15 were deleted ${ }^{33.34}$ ) & Q & - & Q & Q \\
\hline mental health & 5 items (Mental Health, Rand- $36^{31.37}$ ) & Q & - & Q & Q \\
\hline Loneliness & 1 item & Q & - & Q & Q \\
\hline social functioning & 2 items (adjusted version of item 4 and 5 of the Social Activities Battery ${ }^{15}$ ) & $\mathrm{Q}$ & - & Q & Q \\
\hline
\end{tabular}

Pre - pre-measurement / screening (month 0 )

IP - intervention period ( 0 to 12 months)

FU1 - follow-up 1 (12 months)

FU2 - follow-up 2 (18 months)

Q - questionnaire

D $>$ - fall diary (continuous registration) 
Hours of professional home care (excluding hours spent on the home visit programme) are registered by the main home care organisation of the study region.

\section{Process evaluation}

We assess the following aspects of the intervention process: the extent to which the home visit programme was performed according to protocol; the number of home visits that were performed and the time spent on the visits; the main topics discussed during the visits; the recommendations given to the participants; the compliance of the participants to these recommendations; the opinion of participants and nurses about the intervention; and the differences in approach between the nurses.

Data regarding the topics mentioned above were collected by using the following measurement methods: structured registration forms and questionnaires administered by the nurses during the intervention period; interviews with the participants at the end of the last home visit performed by the nurses; participation of members of the research team in the three weekly meetings of the nurses in which the intervention programme was discussed; and interviews with nurses and participants at the end of the intervention period, performed by member of the research team.

\section{Course of the study}

The intervention is developed and pilot tested from May to August 1997. In September/October 1997 the screening questionnaire is sent to all eligible patients of the participating health centre. In November/December 1997 the home visits are started. In November/December 1998 the intervention period is finished and the participants receive their first follow-up questionnaire. In May/June 1999 the participants receive the second follow-up questionnaire.

\section{References}

1. Sattin RW. Falls among older persons: a public health perspective. Annu Rev Publ Health 1992;13:489-508.

2. Sattin RW, Lambert Huber DA, DeVito CA, Rodriquez JG, Ros A, Bacchelli S, et al. The incidence of fall injury events among the elderly in a defined population. Am J Epidemiol 1990;131:1028-1037.

3. O'Loughlin JL, Robitaille Y, Boivin J, Suissa S. Incidence of risk factors for falls and injurious falls among the community-dwelling elderly. Am J Epidemiol 1993;137:342-54.

4. Luukinen H, Koski K, Hiltunen L, Kivela SL. Incidence rates of falls in an aged population in northern Finland. J Clin Epidemiol 1994;8:843-50.

5. Blake AJ, Morgan K, Bendall MJ, Dallosso H, Ebrahim SBJ, Arie THD, et al. Falls by elderly people at home: prevalence and associated factors. Age Ageing 1988;17:365-72.

6. Campbell AJ, Borrie MJ, Spears GF, Jackson SL, Brown J, Fitzgerald JL. Circumstances and consequences of falls experienced by a community population 70 years and over during a prospective study. Age Ageing 1990;19:136-141.

7. Stalenhoef PA, Crebolder HFJM, Knottnerus JA, van der Horst FGEM. Incidence, risk factors and consequences of falls among elderly subjects living in the community: a criteria-based analysis. Eur J Publ Health 1997; 7:328-34.

8. Tinetti ME, Speechley M, Ginter SF. Risk factors for falls among elderly persons living in the community. N Engl J Med 1988;319:1701-7. 
9. Reinsch S, MacRae P, Lachenbruch PA, Tobis JS. Attempts to prevent falls and injury: a prospective community study. Gerontol 1992:32:450-6.

10. Tinetti ME, Baker DI, McAvay G, Claus EB, Garrett P, Gottschalk M, et al. A multifactorial intervention to reduce the risk of falling among elderly people living in the community. N Engl J Med 1994;331:821-7.

11. Lundgren-Lindquist B, Jette AM. Mobility disability among elderly men and women in Sweden. Int Disabil Studies 1990;12:1-5.

12. Odding E, Valkenburg HA, Grobbee DE, Hofman A, Pols HAP. Locomotore beperkingen bij ouderen; het ERGO-onderzoek. Ned Tijdschr Geneeskd 1995;139:2096-2100.

13. Cunha UV. Diffential diagnosis of gait disorders in the elderly. Geriatrics 1988;43:33-42.

14. Cwikel J, Fried AV. The social epidemiology of falls among community-dwelling elderly: guidelines for prevention. Dis Rehabil 1992;14:113-21.

15. Wickham C, Cooper C, Margetts BM, Barker DJP. Muscle strength, activity, housing and the risk of falls in elderly people. Age Ageing 1989:18:47-51.

16. Graafmans WC, Ooms ME, Hofstee HMA, Bezemer PD, Bouter LM, Lips P. Falls in the elderly: a prospective study of risk factors and risk profiles. Am J Epidemiol 1996;143:1129-36.

17. Gillespie LD, Gillespie WJ, Cumming R, Lamb SE, Rowe BH. Interventions to reduce the incidence of falling in the elderly. Cochrane Library 1997:4:1-29.

18. Wagner EH, LaCroix AZ, Grothaus L, Leveille SG, Hecht JA, Arta K, et al. Preventing disability and falls in older adults: a population-based randomised trial. Am J Public Health $1994 ; 84: 1800-6$.

19. Hu MH, Woollacott MH. Multisensory training of standing balance in older adults: I. Postural stability and one-leg stance balance. J Geront: Med Sci 1994:M52-61.

20. Lord SR, Ward JA, Williams P, Strudwick M. The effect of a 12-month exercise trial on balance, strength, and falls in older women: a randomised controlled trial. J Am Geriatr Soc 1995; 43:1198-1206.

21. Hopkins Dr, Murrah B, Hoeger WWK, Rhodes RC. Effect of low-impact aerobic dance on the functional fitness of elderly women. Gerontol 1990;30:189-92.

22. van Rossum E, Frederiks CMA, Philipsen H, Portengen K, Wiskerke J, Knipschild P. Effects of preventive home visits to elderly people. Br Med J 1993;307:27-32.

23. Tinetti ME, Baker DI, McAvay G, Claus EB, Garrett P, Gottschalk m, et al. A multifactorial intervention to reduce the risk of falling among elderly people living in the community. N Engl J Med 1994:331:821-7.

24. Rubenstein LZ, Stuck AE, Siu AL, Wieland D. Impacts of geriatric evaluation and management programs on defined outcomes: overview of the evidence. J Am Geriatr Soc 1991;39:8S-15.

25. Stalenhoef P, Diederiks J, Knottnerus A, de Witte L, Crebolder H. How predictive is a homesafety checklist of indoor fall risk for the elderly living in the community? Eur J Gen Pract 1998;4:114-20.

26. de Bruin AF, Diederiks JPM, de Witte LP, Stevens JA, Philipsen H. The development of a short generic version of the Sickness Impact Profile. J Clin Epidemiol 1994;47:407-18.

27. de Bruin AF, Buys M, de Witte LP, Diederiks JPM. The Sickness Impact Profile:SIP68, a short generic version; First evaluation of the reliability and reproducibility. J Clin Epidemiol 1994:47:863-871.

28. Jannink-Nijlant JMM, Diederiks JPM, Brouwers MAH, Metsemakers JFM. Screening for mobility disorders by the mobility control subscale of the short version of the Sickness Impact Profile. Clin Rehabil 1999;13:492-7.

29. Tinetti ME, Richman D, Powell L. Falls efficacy as a measure of fear of falling. J Gerontol 1990; $45: 239-43 P$.

30. Buchner DM, Hornbrook MC, Kutner NG, Tinetti ME, Ory ME, Mulrow CD, et al. Development of the common data base for the FICSIT trials. J Am Geriatr Soc 1993;41:297-308.

31. Rand 36-item Health Survey. Rand Health Science program, Santa Monica, CA, Rand, 1992.

32. van der Zee I, Sanderman R. Het meten van de algemene gezondheidstoestand met de RAND-36: een handleiding. Groningen, Noordelijk Centrum voor Gezondheidsvraagstukken, 1993.

33. Holbrook M, Skilbeck CE. An activities index for use with stroke patients. Age Ageing 1983;12:166-70. 
34. Schuling J, de Haan R, Limburg M, Groenier KH. The Frenchay Activities Indez; Assessment of functional status in stroke patients. Stroke 1993;24:1173-77.

35. Donald CA, Ware JE, Brook RH, Davies-Avery A. Conceptualization and measurement of health for adults in the Health Insurance Study, Santa Monica, CA, The Rand Corporation, 1978. 


\section{4}

\section{Effects of a multifactorial home visit programme on falls and mobility impairments in elderly people at risk: randomised controlled trial}

This chapter is published as:

van Haastregt JCM, Diederiks JPM, van Rossum E, de Witte LP, Voorhoeve PM, Crebolder HFJM. Effects of a programme of multifactorial home visits on falls and mobility impairments in elderly people at risk: randomised controlled trial. Br Med J 2000;321:994-8. 


\section{Summary}

Objective. To evaluate whether a multifactorial home visit programme reduces falls and mobility impairments in elderly people living in the community. Design: Randomised controlled trial with 18 months of follow-up. Setting: Six general practices in Hoensbroek, the Netherlands. Participants: 316 people aged 70 and over living in the community, with moderate impairments in mobility or a history of recent falls.

Intervention: Five home visits by a community nurse over a period of one year. Visits consisted of screening for medical, functional, psychosocial, and environmental factors causing falls and mobility impairments, followed by specific advice, referrals, and other actions aimed at dealing with the observed hazards.

Main outcome measures: Falls and mobility impairments.

Results: No differences were found in falls and mobility outcomes between the home visit and usual care groups.

Conclusion: Multifactorial home visits had no effects on falls and mobility impairments in elderly people at risk who were living in the community. Because falls and mobility impairments remain a serious problem among elderly people, alternative strategies should be developed and evaluated. 


\section{Introduction}

Falls and mobility impairments are a common problem among elderly people $e^{1,2}$. In the past two decades the prevention of falls has received much attention. Gillespie et $\mathrm{al}^{3}$ systematically reviewed randomised controlled trials studying the effects of fall prevention programmes among elderly people. They concluded that multifactorial intervention programmes (such as preventive home visits) seem to be effective when targeted to specific risk factors identified in individuals by screening. Although a recent systematic review ${ }^{4}$ showed no clear evidence for the effectiveness of preventive home visits in the general population of elderly people, home visit programmes that target specific risk factors among particular people at risk seem to be more promising $^{3.5}$.

Because falls and mobility impairments are strongly interrelated problems that show many overlapping and interacting causes $^{6-9}$, we developed a multifactorial home visit programme targeted at both preventing falls and reducing mobility impairments in elderly people who are at risk of falls or have moderately impaired mobility. We aimed to determine if people receiving this home visit programme had better outcomes than people receiving usual care.

\section{Methods}

\section{Design}

We carried out a randomised controlled trial (with ethical approval) to assess the effectiveness of the home visit programme. In calculating the required sample size, we chose as the main outcome measure the proportion of people sustaining any fall in the previous year. We considered our intervention clinically successful if it reduced the number of people having a fall among people aged 70 or over to that of people aged 55 to 70 years (respectively $34 \%$ and $18 \%$ yearly, among elderly Dutch people ${ }^{10}$ ). We calculated that a sample size of 115 per group would provide a power of 0.80 at $5 \%$ significance" 11 . With an expected drop out rate of about $25 \%$ during 18 months of follow-up, this indicated that we would need to enrol about 150 participants per group.

\section{Selection criteria and randomisation}

We recruited participants from six general practices in Hoensbroek, the Netherlands, by means of a screening questionnaire. Participants had to be aged 70 years or over, be living in the community, and have reported two or more falls in the previous six months or have scored three or more on the Mobility Control Scale of the short version of the Sickness Impact Profile (SIP68) $^{12,13}$.

We excluded people who were bedridden, fully dependent on a wheelchair, terminally ill, on the waiting list for admission to a nursing home, or receiving home care from a community nurse on a regular basis. Eligible patients were randomised to the home visit group or usual care group by means of computer 
generated random numbers directly after screening. Persons sharing a household were always allocated to the same group.

\section{Intervention}

\section{Intervention group}

Participants in the intervention group received five home visits from a community nurse over a period of one year. During the home visits they were screened for several medical, functional, psychosocial, and environmental factors potentially influencing falls and mobility. The screening was followed by advice, referrals and other actions aimed at dealing with the hazards observed. The nurses followed a structured protocol for the home visits, which focused on falls, fear of falling, mobility, physical health, medication, activities of daily living, social functioning, cognitive functioning, and psychosocial functioning. The protocol also included a checklist for home safety ${ }^{14}$.

\section{Usual care}

Participants in the usual care group did not receive any special attention or intervention on prevention of falls and impairments in mobility. The general practitioners and health care staff dealing with the participants were not told which patients were allocated to the usual care group.

\section{Outcome measures}

\section{Primary outcome measures}

The primary outcome measures were falls (the number of individuals sustaining any fall, more than one fall, any injurious fall, and any fall resulting in medical care) and mobility impairments as assessed by the Mobility Control Scale and Mobility Range Scale of the short version of the Sickness Impact Profile $(\mathrm{SIP} 68)^{12,13}$.

\section{Secondary outcome measures}

Secondary outcome measures were the number of physical complaints (out of a total of 18), perceived health (first item RAND-36) ${ }^{15,16}$, perceived gait problems (5-point Likert Scale), daily activity (13 item Frenchay Activities Index) ${ }^{17,18}$, fear of falling (Falls Efficacy Scale) ${ }^{19,20}$, mental health (Mental Health, Rand-36) ${ }^{15.16}$, social functioning (adjusted version of item 4 and 5 of the Social Activities Battery) ${ }^{21}$, and loneliness (6-point Likert Scale).

The trial was conducted from September 1997 to June 1999. Participants were assessed by means of self-administered questionnaires before the start of the intervention programme and after 12 and 18 months of follow-up. During follow-up participants recorded falls in a weekly diary. 


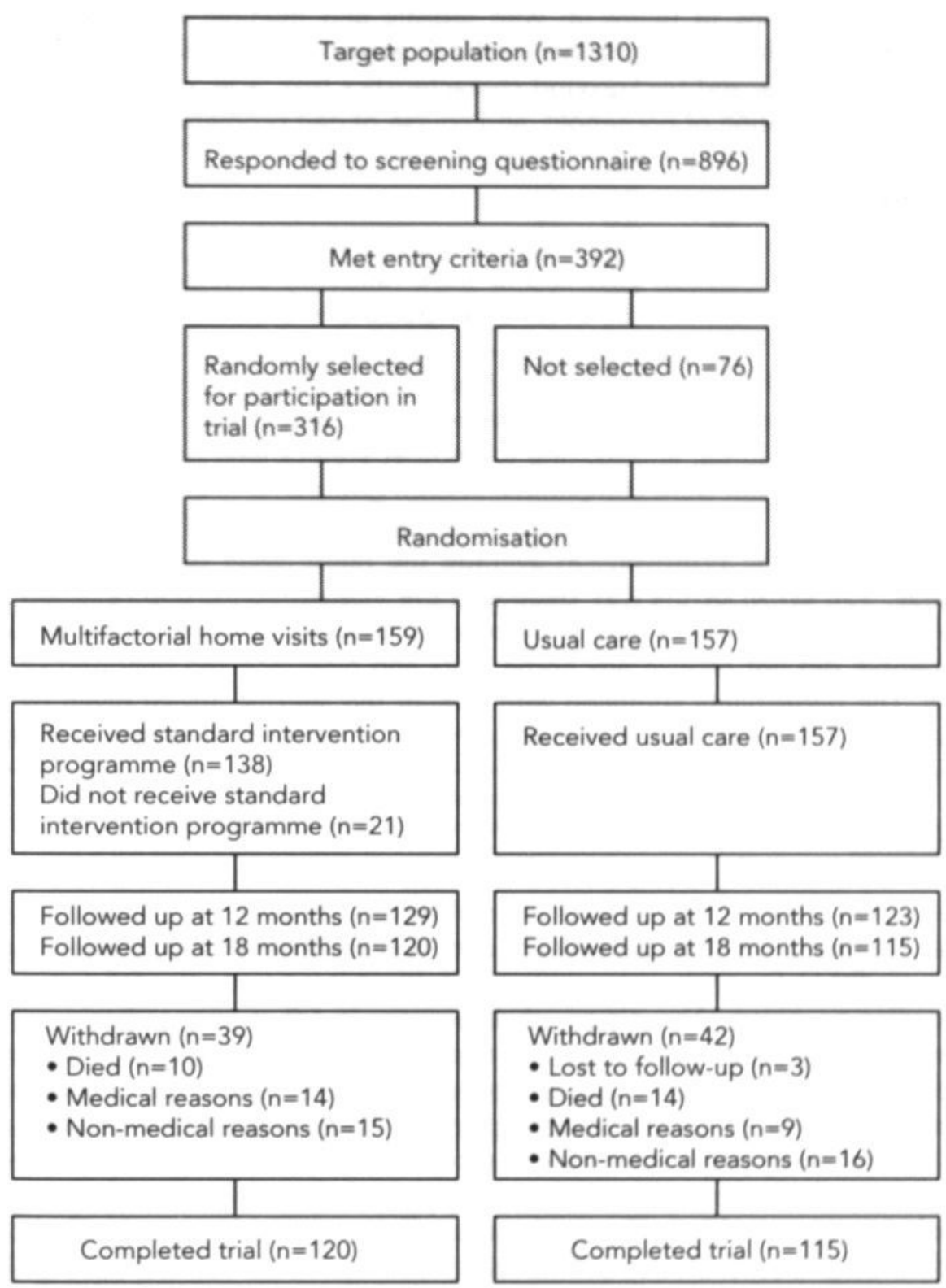

Figure 4.1 Progress of participants through trial.

\section{Statistical analysis}

We analysed data according to a preplanned protocol by using an intention to treat approach. Differences in baseline characteristics between the home visit and usual care groups were tested with the independent samples t-test, Mann 
Whitney U-test, or chi-square test. We analysed differences in outcomes after 12 and 18 months of follow-up with logistic and multiple linear regression (hierarchical backward elimination method), adjusting for possible differences in baseline scores and background characteristics (sex, age, educational level, income, composition of household, and course of gait problems experienced).

\section{Results}

Figure 4.1 shows the progress of the participants through the trial. Overall, 316 people met the inclusion criteria and were randomly allocated to either the home visit group $(n=159)$ or usual care group $(n=157)$. Twenty four people died during the 18 months of follow-up, three were lost to follow-up, and 23 withdrew from the study because of illness or admission to institutional care. Non-medical reasons for withdrawal were lack of motivation $(n=18)$, illness or death of spouse $(n=6)$, and moving to another area or long holiday $(n=7)$. The reasons for drop out were comparable in both groups.

The home visits were implemented according to plan, and no adjustments were made to the protocol. On average the home visits lasted 51 minutes. Overall, $138(87 \%)$ of the 159 people in the intervention group received the complete intervention. Owing to drop out in the first 12 months of the study, 12 people did not receive any home visits and nine received only part of the visits. The participants complied with $46 \%$ of the specific advice given by the nurses regarding referrals, home adjustments, medication, exercise and other preventive measures.

\section{Outcomes}

Table 4.1 shows the distribution of baseline characteristics of the two study groups. No significant differences were observed between the groups.

After 12 and 18 months of follow-up, data on $252(80 \%)$ and 235 people (74\%) were available for analysis respectively. Table 4.2 presents the fall outcomes according to group. The observed differences in fall outcomes between the home visit group and usual care group were not statistically significant. In addition no significant differences between the groups were found on mobility control, mobility range (table 4.3), physical complaints, mental health, and social functioning (table 4.4). After 12 months of follow-up, people in the home visit group showed significantly less decline in daily activity than those in the usual care group. After 18 months this effect was no longer significant. In addition, significant effects of the intervention were observed on fear of falling after 12 and 18 months of follow-up; people in the home visit group were less afraid of falling than those receiving usual care. No significant effects were detected on perceived health, perceived gait problems, and loneliness (table 4.4). Owing to the large number of secondary outcome measures, there is a considerable risk of type I error. When using Bonferroni correction (alpha = $0.05 / 8=0.006$ ), the favourable effects for daily activity and fear of falling are still significant after 12 months of follow-up, but the effect on fear of falling after 18 months no longer reaches significance. 


\begin{tabular}{|c|c|c|c|c|c|}
\hline & \multicolumn{2}{|c|}{$\begin{array}{c}\text { Home visits } \\
(n=159)\end{array}$} & \multicolumn{2}{|c|}{$\begin{array}{c}\text { Usual care } \\
(n=157)\end{array}$} & P-value \\
\hline & & & & & \\
\hline mean (sd) age & 77 & $(5.1)$ & 77 & $(5.0)$ & .926 \\
\hline no $(\%)$ female & 104 & (65) & 105 & (67) & .782 \\
\hline no $(\%)$ s elementary school education & 73 & (46) & 88 & (56) & .071 \\
\hline no $(\%)$ below average income & 99 & (62) & 104 & (66) & .461 \\
\hline no $(\%)$ living alone & 79 & (50) & 79 & (50) & .910 \\
\hline no $(\%)$ deteriorated course of gait disorders & 95 & (60) & 93 & (59) & .926 \\
\hline \multicolumn{6}{|l|}{ Falls } \\
\hline no $(\%)$ at least one fall & 60 & (38) & 57 & (36) & .792 \\
\hline no $(\%)$ more than one fall & 36 & (23) & 25 & (16) & .130 \\
\hline \multicolumn{6}{|l|}{ Mobility impairment (range) } \\
\hline mean (sd) mobility control $\left(Q\right.$ to $\left.12^{*}\right)$ & 5.4 & $(2.5)$ & 5.7 & $(2.4)$ & .282 \\
\hline mean (sd) mobility range ( 0 to 10$)$ & 2.0 & $(2.4)$ & 2.4 & (2.9) & $.149^{\prime}$ \\
\hline \multicolumn{6}{|l|}{ Secondary outcomes (range) } \\
\hline mean (sd) physical complaints $(Q$ to 18$)$ & 6.8 & $(3.3)$ & 7.0 & (3.5) & 677 \\
\hline mean (sd) daily activity (13 to 52 ) & 33.0 & $(7.5)$ & 31.8 & (7.6) & .159 \\
\hline mean (sd) fear of falling (10 to 40 ) & 18.5 & $(7.7)$ & 17.5 & $(7.0)$ & .244 \\
\hline mean (sd) mental health ( 5 to 30 ) & 22.4 & $(5.1)$ & 21.5 & (5.5) & .137 \\
\hline mean (sd) social functioning (2 to 12 ) & 6.5 & $(1.9)$ & 6.4 & (1.9) & .550 \\
\hline median perceived health ( 1 to $\underline{5}$ ) & 2 & & 2 & & .142 \\
\hline median perceived gait problems ( 1 to 5 ) & 3 & & 4 & & .732 \\
\hline median loneliness ( 1 to 6 ) & 2 & & 2 & & .403 \\
\hline
\end{tabular}

- The underlined scores indicate the most favourable scores.

$t \quad$ This had moderate negative skewness, so independent samples $t$ test was performed with transformed versions of this measure (square root).

\section{Drop outs}

The 81 people who dropped out of the study during the 18 months of followup were on average older than those who completed the study (78.6 versus 76.7, $p=.011$ ) and had a lower educational level (elementary school education or less: $49(61 \%)$ versus $112(48 \%), p=.046)$. Also, the number of people having any fall or more than one fall was higher among those who dropped out (at least one fall: $39(48 \%)$ versus $78(33 \%), p=.016)$; more than one fall: $25(31 \%)$ versus $36(15 \%), p=.002)$, and they also had more impairments in mobility range at baseline ( 3.5 versus $1.8, p=.000$ ). After both 12 and 18 months of follow-up, however, those participants remaining in the home visit and usual care groups did not differ significantly for background characteristics and fall and mobility outcomes measured at baseline. 
Table 4.2 Effects on falls after 12 and 18 months of follow-up according to treatment.

\begin{tabular}{|c|c|c|c|c|c|c|c|c|}
\hline \multirow[b]{2}{*}{ Outcome measures } & \multicolumn{4}{|c|}{12 months follow-up } & \multicolumn{4}{|c|}{18 months follow-up } \\
\hline & $\begin{array}{l}\text { Home visits } \\
(n=129)\end{array}$ & & $\begin{array}{l}\text { care } \\
123)\end{array}$ & & & $\begin{array}{l}\text { ne visits } \\
=120 \text { ) }\end{array}$ & $\begin{array}{l}\text { Usual care } \\
(n=115)\end{array}$ & \\
\hline & number $(\%)$ & num & er $(\%)$ & odds ratio* $(95 \% \mathrm{Cl})$ & nur & ber $(\%)$ & number (\%) & odds ratio* $(95 \% \mathrm{Cl})$ \\
\hline at least one fall & $63 \quad(50)$ & 53 & $(44)$ & $1.2(0.7$ to 2.0$)$ & 68 & $(57)$ & $58 \quad(52)$ & $1.3(0.7$ to 2.1$)$ \\
\hline more than one fall & $34 \quad(27)$ & 29 & (24) & $1.0(0.5$ to 1.8$)$ & 43 & (36) & $35 \quad(31)$ & $1.0(0.6$ to 1.9$)$ \\
\hline injurious fall" & $26 \quad(20)$ & 21 & (17) & $1.2(0.6$ to 2.3$)$ & 33 & $(28)$ & $25 \quad(22)$ & $1.4(0.8$ to 2.6$)$ \\
\hline fall resulting in medical care' & $15 \quad(12)$ & 11 & (9) & $1.3(0.6$ to 3.1$)$ & 21 & (18) & 14 (12) & $1.6(0.7$ to 3.2$)$ \\
\hline
\end{tabular}

- As assessed by logistic regression analysis.

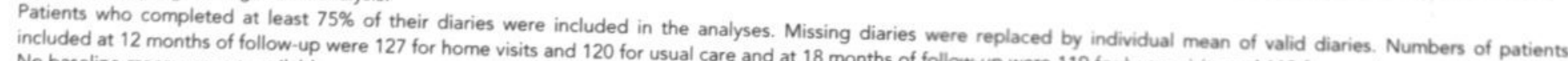

"No baseline measurement available.

Table 4.3 Effects on mobility impairments after 12 and 18 months of follow-up according to treatment.

\begin{tabular}{|c|c|c|c|c|c|c|}
\hline \multirow[b]{2}{*}{ Outcome measures } & \multicolumn{3}{|c|}{12 months follow-up } & \multicolumn{3}{|c|}{18 months follow-up } \\
\hline & $\begin{array}{l}\text { Home visits } \\
\qquad(n=129)\end{array}$ & $\begin{array}{l}\text { Usual care } \\
(n=123)\end{array}$ & & $\begin{array}{l}\text { Home visits } \\
(n=120)\end{array}$ & $\begin{array}{l}\text { Usual care } \\
(n=115)\end{array}$ & \\
\hline & mean (sd) & mean (sd) & adj. differ. $(95 \% \mathrm{Cl})^{*}$ & mean (sd) & mean (sd) & adj. differ. $(95 \% \mathrm{Cl})^{*}$ \\
\hline mobility control ( $\left(\underline{0}\right.$ to $\left.12^{\dagger}\right)$ & $5.1 \quad(2.8)$ & $5.3(2.7)$ & $-0.0 \quad(-0.6$ to 0.5$)$ & $5.5 \quad(2.8)$ & $5.5 \quad(2.7)$ & $0.0 \quad(-0.6$ to 0.6$)$ \\
\hline mobility range" $(0$ to 10$)$ & $2.0 \quad(2.5)$ & $2.6 \quad(3.0)$ & $-0.1 \quad(-0.3$ to 0.1$)$ & $2.2 \quad(2.4)$ & $2.3 \quad(2.7)$ & $0.0 \quad(-0.2$ to 0.2$)$ \\
\hline
\end{tabular}

The underined scores are the most favourable score

1. This had morlined scores are the most favourable scores.

This had moderate negative skewness, so the multiple regression analyser were performed on transformed versions of this measure (square root). 
Table 4.4 Effects on secondary outcome measures after 12 and 18 months follow-up according to treatment.

\begin{tabular}{|c|c|c|c|c|c|c|c|c|c|c|}
\hline \multirow[b]{2}{*}{ Outcome measures } & \multicolumn{5}{|c|}{12 months follow-up } & \multicolumn{5}{|c|}{18 months follow-up } \\
\hline & \multicolumn{2}{|c|}{$\begin{array}{l}\text { Home visits } \\
\quad(n=129)\end{array}$} & \multicolumn{2}{|c|}{$\begin{array}{l}\text { Usual care } \\
(n=123)\end{array}$} & & \multicolumn{2}{|c|}{$\begin{array}{l}\text { Home visits } \\
\qquad(n=120)\end{array}$} & \multicolumn{2}{|c|}{$\begin{array}{c}\text { Usual care } \\
(n=115)\end{array}$} & \\
\hline & mean & (sd) & mean & (sd) & adj. differ. $(95 \% \mathrm{Cl})^{*}$ & mean & (sd) & mean & (sd) & adj. differ. $(95 \% \mathrm{Cl})^{*}$ \\
\hline physical complaints ( 0 to $18^{\prime}$ ) & 6.1 & $(3.2)$ & 6.2 & $(3.6)$ & $0.2(-0.4$ to 0.8$)$ & 6.2 & (3.2) & 6.4 & $(3.4)$ & $-0.2 \quad(-0.9$ to 0.4$)$ \\
\hline daily activity (13 to 52$)$ & 33.5 & $(6.9)$ & 30.9 & $(8.0)$ & $1.6 \quad(0.6$ to 2.7$)$ & 33.1 & (7.3) & 31.5 & (7.7) & $1.0 \quad(-0.2$ to 2.2$)$ \\
\hline fear of falling (10 to 40$)$ & 16.5 & $(6.1)$ & 17.9 & (7.9) & $-2.5(-4.0$ to -1.0$)$ & 16.1 & $(5.7)$ & 17.6 & (7.3) & $-1.9(-3.3$ to -0.5$)$ \\
\hline mental health $(5$ to $\underline{30})$ & 22.0 & $(5.3)$ & 22.2 & (5.3) & $-0.7 \quad(-1.7$ to 0.3$)$ & 22.0 & $(4.8)$ & 21.9 & $(5.4)$ & $-0.1 \quad(-1.0$ to 0.8$)$ \\
\hline \multirow[t]{2}{*}{ social functioning ( 2 to 12$)$} & 6.4 & $(2.0)$ & 6.5 & $(1.9)$ & $-0.3 \quad(-0.7$ to 0.1$)$ & 6.4 & (1.9) & 6.3 & $(2.0)$ & $0.0 \quad(-0.4$ to 0.4$)$ \\
\hline & \multicolumn{2}{|c|}{ median } & \multicolumn{2}{|c|}{ median } & odds ratio $(95 \% \mathrm{CI})^{*}$ & \multicolumn{2}{|c|}{ median } & \multicolumn{2}{|c|}{ median } & odds ratio $(95 \% \mathrm{Cl})$ \\
\hline perceived health & \multicolumn{2}{|c|}{3} & \multicolumn{2}{|c|}{2} & $1.2(0.6$ to 2.2$)$ & \multicolumn{2}{|r|}{2} & \multicolumn{2}{|r|}{2} & $1.3 \quad(0.7$ to 2.3$)$ \\
\hline perceived gait problems & \multicolumn{2}{|r|}{3} & \multicolumn{2}{|r|}{3} & $1.0 \quad(0.5$ to 1.8$)$ & \multicolumn{2}{|r|}{4} & \multicolumn{2}{|r|}{4} & $0.8 \quad(0.4$ to 1.5$)$ \\
\hline loneliness & \multicolumn{2}{|r|}{1} & \multicolumn{2}{|r|}{2} & $0.9 \quad(0.4$ to 2.0$)$ & \multicolumn{2}{|r|}{2} & \multicolumn{2}{|r|}{2} & $0.9 \quad(0.4$ to 2.1$)$ \\
\hline
\end{tabular}

- As assessed by multiple linear regression analyses.

1. The underlined scores indicate the most favourable scores.

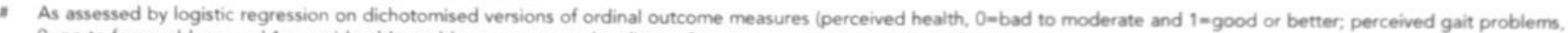
$0=$ no to few problems and 1 -considerable problems or greater; loneliness, 0 -never to sometimes and $1=$ often or more. 


\section{Discussion}

Multifactorial home visits by community nurses did not reduce falls and mobility impairments among a group of elderly people at risk. Furthermore, the home visits had no effects on physical complaints, perceived health, perceived gait problems, mental health, social functioning, and loneliness. The home visits did have favourable effects on fear of falling and daily activity after 12 months of follow-up, but these effects diminished after 18 months of followup.

There may be several explanations for the fact that we observed no effects of our intervention on falls and mobility impairments. Firstly, because people in the home visit group showed less fear of falling and higher levels of daily activity than those in the usual care group at follow-up, it is possible that the risk abatement was partly counterbalanced by an increase in risk behaviour in the home visit group, leading to a slightly increased number of people falling. Secondly, our intervention programme may not have added enough extra elements to the range of care and services already available for elderly people in the Netherlands.

Thirdly, a lack of adherence by the participants with the intervention programme, might have influenced the outcomes of our study. The fact that 138 persons completed the whole programme, and a further nine completed part of the programme, however, does not indicate that lack of adherence was a large problem. Compliance with the advice given by the nurses also seemed reasonable.

Fourthly, the drop out rate during follow-up could have influenced the outcomes of our trial. It turned out that those people who were expected to benefit most from the intervention (people at higher risk for falls and with more mobility impairments) dropped out of the study. We therefore performed subgroup analyses among a selection of people with the highest baseline scores for falls and mobility range. The results were comparable to those of our main analyses, which makes it highly unlikely that selective drop out negatively influenced the internal validity of our trial.

The results of our study contrast with those of the meta-analysis of Gillespie et $\mathrm{al}^{3}$ in which they concluded that multifactorial interventions for screening followed by targeted interventions resulted in a notable reduction in falls in elderly people. This conclusion was, however, primarily based on the results of four trials performed in the United States ${ }^{5,22-24}$. It is likely that the observed differences in effectiveness between our intervention and those undertaken in the United Stated are related to differences in health care settings. Other explanations may be differences between components of the programmes. Owing to the multifactorial character and diversity of the interventions, however, it was not possible to isolate the effective components of the interventions undertaken in the United States ${ }^{3}$.

We conclude that a multifactorial home visit programme aimed at reducing falls and mobility impairments in elderly people at risk who live in the commu- 
nity is not effective in the Dutch health care setting. This may also apply to comparable health care settings in other European countries. Because falls and mobility impairments remain a serious problem among elderly people, alternative strategies to prevent falls and reduce mobility impairments need to be developed and tested in different health care settings.

\section{References}

1. Sattin RW. Falls among older persons: a public health perspective. Annu Rev Publ Health 1992;13:489-508.

2. Lundgren-Lindquist B, Jette AM. Mobility disability among elderly men and women in Sweden. Int Disabil Studies 1990;12:1-5.

3. Gillespie LD, Gillespie WJ, Cumming R, Lamb SE, Rowe BH. Interventions to reduce the incidence of falling in the elderly. Cochrane Library 1997;4:1-29.

4. van Haastregt JCM, Diederiks JPM, van Rossum E, de Witte LP, Crebolder HFJM. Effects of preventive home visits to elderly people living in the community: systematic review. $\mathrm{Br} \mathrm{Med} J$ 2000;320:754-8.

5. Tinetti ME, Baker DI, McAvay G, Claus EB, Garrett P, Gottschalk M, et al. A multifactorial intervention to reduce the risk of falling among elderly people living in the community. $N$ Engl J Med 1994;331:821-7.

6. O'Loughlin JL, Robitaille Y, Boivin J, Suissa S. Incidence of and risk factors for falls and injurious falls among the community-dwelling elderly. Am J Epidemiol 1993;137:342-54.

7. Stalenhoef PA, Crebolder HFJM, Knottnerus JA, van der Horst FGEM. Incidence, risk factors and consequences of falls among elderly subjects living in the community. Eur $\mathrm{J}$ Publ Health $1997 ; 7: 328-34$.

8. Cunha UV. Differential diagnosis of gait disorders in the elderly. Geriatrics 1988;43:33-42.

9. Wickham C, Cooper C, Margetts BM, Barker DJP. Muscle strength, activity, housing and the risk of falls in elderly people. Age Ageing 1989;18:47-51.

10. Schiricke, K. and Vloet, M. Mobiliteit bij ouderen. Institute for Rehabilitation Research, Hoensbroek, The Netherlands, Thesis, 1993.

11. Pocock SJ. The size of a clinical trial. In: Clinical trials; A practical approach. Chichester, New York, Brisbane, Toronto, Singapore: John Wiley \& Sons, 1983;123-41.

12. de Bruin AF, Diederiks JPM, de Witte LP, Stevens JA, Philipsen H. The development of a short generic version of the Sickness Impact Profile. J Clin Epidemiol 1994;47:407-18.

13. de Bruin AF, Buys M, de Witte L.P., Diederiks JPM. The Sickness Impact Profile: SIP68, a short generic version; First evaluation of the reliability and reproducibility. J Clin Epidemiol 1994;47:863-71.

14. Stalenhoef P, Diederiks J, Knottnerus A, de Witte L, Crebolder H. How predictive is a homesafety checklist of indoor fall risk for the elderly living in the community? Eur J Gen Pract 1998:4:114-20.

15. Rand 36-item Health Survey. Rand Health Science program. Santa Monica, CA: Rand, 1992.

16. van der Zee I, Sanderman R. Het meten van de algemene gezondheidstoestand met de RAND-36: een handleiding. Groningen: Noordelijk Centrum voor Gezondheidsvraagstukken, 1993.

17. Holbrook M, Skilbeck CE. An activities index for use with stroke patients. Age Ageing 1983;12:166-70.

18. Schuling J, de Haan R, Limburg M, Groenier KH. The Frenchay Activities Index; Assessment of functional status in stroke patients. Stroke 1993;24:1173-7.

19. Tinetti ME, Richman D, Powell L. Falls efficacy as a measure of fear of falling. J Gerontol 1990;45:P239-P243.

20. Buchner DM, Hornbrook MC, Kutner NG, Tinetti ME, Ory MG, Mulrow CD, et al. Development of the common data base for the FICSIT trials. J Am Geriatr Soc 1993:41:297-308.

21. Donald CA, Ware JE, Brook RH, Davies-Avery A. Conceptualization and measurement of health for adults in the Health Insurance Study. Santa Monica, CA: The Rand Corporation, 1978. 
Chapter 4

22. Fabacher D, Josephson K, Pietruszka F, Linderborn K, Morley JE, Rubenstein LZ. An in-home preventive assessment programme for independent older adults. J Am Geriatr Soc 1994;42:630-638.

23. Rubenstein LZ, Robbins AS, Josephson KR, Schulman BL, Osterweil D. The value of assessing falls in an elderly population. A randomized clinical trial. Ann Intern Med 1990;113:308-316. 


\section{5}

\section{Cost-effectiveness analysis of a multifactorial home visit programme among elderly people at risk: randomised controlled trial}

This chapter is submitted as:

van Haastregt JCM, Goossens MEJB, van Rossum E, Voorhoeve PM, Diederiks JPM, de Witte LP, Crebolder HFJM. Cost-effectiveness analysis of a multifactorial home visit programme among elderly people at risk: randomised controlled trial. 


\section{Summary}

Objective: To assess the cost-effectiveness of a multifactorial home visit programme aimed at reducing falls and mobility impairments in elderly people living in the community.

Design: Randomised controlled trial with 18 months of follow-up

Participants: 316 community-living people aged 70 and over, with moderate mobility impairments or a history of recent falls

Intervention: Five preventive home visits by a community nurse, over a period of one year. Visits consisted of screening for medical, functional, psychosocial, and environmental factors causing falls and mobility impairments, followed by recommendations, referrals and other actions aimed at dealing with the observed hazards.

Main outcome measures: Direct health care costs consisting of costs of the home visit programme, hospitalisation, visits to medical specialists, general practitioners and physiotherapists, professional home care, medical aids and medication. Clinical outcome measures were falls and mobility impairments.

Results: After 18 months of follow-up, mean total direct health care costs of persons in the usual care group exceeded those of the home visit group with 608 Euro. This difference in favour of the home visit group was not statistically significant. No effects of the intervention were observed for falls and mobility impairments.

Conclusion: Our home visit programme was not cost-effective. At the moment there seem to be no convincing arguments in favour of adding multifactorial home visits on a structural basis to regular care. 


\section{Introduction}

The prevention and reduction of health problems among elderly people living in the community has received a wide degree of attention in the past two decades $^{1-3}$. One of the widely used intervention strategies in this regard is the preventive home visit by a health visitor or community nurse. Preventive home visit programmes can be characterised by the following elements: a) they are aimed at prevention and reduction of problems and risks related to ageing; $b$ ) they consist of a multidimensional evaluation of medical, functional, psychosocial, and environmental problems and resources, and c) they result in specific recommendations and actions aimed at reducing or treating the observed problems and preventing new ones ${ }^{1,2}$.

In several European countries preventive home visits among elderly people are part of regular health care. A considerable number of randomised controlled trials have been performed to examine the effectiveness of preventive home visit programmes ${ }^{4.17}$. A recent review of these trials showed no clear evidence in favour of the effectiveness of home visit programmes on physical function, psychosocial function, falls, admissions to institutions and mortality ${ }^{2}$. Therefore additional information regarding the cost-effectiveness of these programmes might prove to be very relevant for health policy purposes. When preventive home visit programmes appear to lead to a reduction in health care utilisation and associated costs, this might form an important argument in favour of the continuation of these programmes, merely because the costs associated with the care for elderly people are high. Such a reduction in costs could possibly be caused by substitution of care and early detection and treatment of health problems.

Until now only little attention has been paid to the economic evaluation of preventive home visit programmes. After searching Medline for the period January 1980 to December 2000 and checking the papers included in the systematic review of home visit trials mentioned above ${ }^{2}$, five trials were found which reported about the costs of health care utilisation associated with multifactorial home visit programmes ${ }^{7,11,13,18,19}$. Hendriksen et $\mathrm{al}^{7}$, van Rossum et $\mathrm{al}^{11}$. Stuck et al (1995) ${ }^{13}$, and Stuck et al $(2000)^{18}$ presented a rough calculation of expenses and financial gains of the home visit programme. Rizzo et al ${ }^{19}$ presented a more detailed economical evaluation. Van Rossum et al "', Stuck et al $(1995)^{13}$, and Stuck et al (2000) ${ }^{18}$ assessed that the expenses associated with the intervention programme exceeded the financial gains when compared to usual care. Subgroup analyses in the study of Stuck et al $(2000)^{18}$, however, revealed that favourable effects on long-term costs of health care utilisation were observed among a subgroup of low risk elderly. The studies of Hendriksen et $\mathrm{al}^{7}$ and Rizzo et $\mathrm{al}^{18}$ revealed that the financial gains of the intervention programme exceeded the costs when compared to usual care.

Because there seems to be considerable inconsistency in the results and methods of the available economical evaluations, a need exists for acquiring 
additional detailed evidence regarding expenses and gains associated with home visit programmes.

Recently we developed and tested a multifactorial home visit programme which was specifically aimed at preventing falls and reducing mobility impairment among elderly people at risk. As is described in more detail elsewhere ${ }^{20}$, after 18 months of follow-up, our programme showed no significant favourable effects on falls and mobility impairments (primary outcome measures) compared to usual care. Short-term favourable effects were observed for daily activity and fear of falling (secondary outcome measures), after 12 months of follow-up. These effects diminished after 18 months of follow-up. No effects were observed for six other physical and psychosocial (secondary) outcome measures.

Because adding multifactorial home visits to usual care had no effect on the primary outcome measures, the objective of the present study is to assess whether the costs of health care utilisation of people receiving home visits differ from the costs of people receiving usual care.

\section{Methods}

\section{Design}

A randomised controlled trial was carried out to assess health care utilisation and associated costs of people receiving the home visits compared to people receiving usual care. Randomisation of the eligible subjects to home visit or usual care group was done by means of computer generated random numbers.

\section{Participants}

Patients were recruited from six general practices of a health centre in Hoensbroek, the Netherlands, by means of a screening questionnaire. Participants had to match the following inclusion criteria: aged 70 years or over; living in the community; reporting two or more falls in the previous six months or scoring three or more on the Mobility Control Scale of the short version of the Sickness Impact Profile (SIP68) ${ }^{21,22}$; and giving informed consent to participate in the study. People who were bedridden, fully dependent on a wheelchair, terminally ill or on the waiting list for admission to a nursing home were excluded from participation in the study. In addition respondents already receiving home care from a community nurse on a regular basis were excluded, in order to prevent contamination.

\section{Intervention}

The persons in the intervention group received five home visits from a community nurse over a period of one year. During the home visits participants were screened for a number of medical, functional, psychosocial, and environmental factors potentially influencing falls and mobility. The screening was followed by recommendations, referrals and other actions aimed at dealing 
with the hazards observed. A more detailed description of the intervention is published elsewhere ${ }^{23}$.

The persons in the usual care group did not receive any special attention or intervention with respect to the prevention of falls and mobility impairments. General practitioners and other health care staff working with the participants were not informed about the study group to which their patients were allocated.

\section{Costs}

Costs in guilders have been converted into Euro's ( 1 guilder is 0.45 Euro).

\section{Costs of home visit programme}

Costs of the home visit programme that were considered included costs of the nurses who performed the visits (preparation, travel expenses, visits and activities resulting form the visits), costs of consultation of general practitioners by the nurses (to discuss medication and specific health problems of the participants); and additional costs (training session nurses, initial screening of potential participants, materials and supervision). The number of hours spent by the nurses on the home visit programme were registered by the nurses on a structured registration form. The time spent by the general practitioner on advising the nurses was estimated to be one consultation per person in the home visit group.

Costs of the nurses ( 31 Euro per hour) were based on the 1998 charges of the "College voor Zorgverzekeringen" (National Board of Health Care Insurances) ${ }^{24}$ as were the costs of consultation of the general practitioners by the nurses (16 Euro per consultation). Additional costs were calculated by adding up the costs of materials used, initial screening of persons at risk, training of the nurses and supervision during the intervention period. These additional costs were estimated at 84 Euro per person in the home visit group.

\section{Direct health care costs}

The direct health care costs considered are costs of: hospitalisation, visits to health care providers (medical specialist, general practitioner, and physiotherapist), professional home care (domestic help and community nursing care), medical aids and medication.

Data regarding days of hospitalisation, number of hospital admissions, and number of contacts with physiotherapists were provided by the main National Health Service Company in the study region. The number of contacts of the participants with general practitioners was registered by the general practitioners. Hours of professional home care (excluding hours spent on the home visit programme) were registered by the main home care organisation of the study region. They were able to provide complete data for hours of domestic help but, owing to a (partial) change to a new registration system, data regarding community nursing care could only be provided for the last six months of follow-up. Based on the data of these last six months, extrapolations were 
made for the entire follow-up period by multiplying the hours of community nursing by three.

Direct health care costs were based on the 1998 charges of the "National Board of Health Care Insurances" 24 for the following services: hospitalisation (223 Euro per day excluding costs of specialist contacts), contacts with physiotherapists (18 Euro per contact), contacts with general practitioners (16 Euro per contact), domestic help (17 Euro per hour) and community nursing (31 Euro per hour). Costs for contacts with medical specialists (in and out-patient), medical aids and medication were directly retrieved from the databases of the main National Health Service Company in the study region.

\section{Procedure}

Programme costs and direct health care costs were registered prospectively during 18 months of follow-up (December 1997 till the end of May 1999). Because our intervention was a multifactorial programme which focused on a wide range of medical, functional, psychosocial, and environmental aspects directly or indirectly influencing falls and mobility, the overall costs of health care utilisation were assessed instead of focusing specifically on the costs of

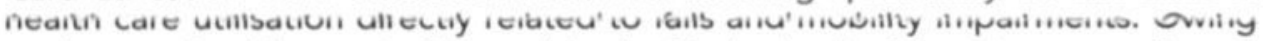
to the way health care is financed in the Netherlands, it is rather complicated to retrieve reliable cost data of those participants with private health care insurance (people with an income above the National Health Service income limit). Therefore the participants with private health care insurance $(13 \%)$ were not included in this economical evaluation.

\section{Baseline characteristics}

The following baseline characteristics of the participants were considered in our analysis: sex, age, educational level, income, composition of household (living alone versus living not alone), experienced course of gait problems in the year preceding baseline (deteriorated versus not deteriorated), number of physical complaints at baseline (out of 18 items) and perceived health status at baseline (first item Rand-36 $36^{25}$.

\section{Statistical analyses}

No power calculations were performed for costs. Power calculations were based on the expected clinical outcomes ${ }^{20}$. Data were analysed according to a pre-planned protocol, using an intention to treat approach, including participants in the analyses regardless whether they did or did not adhere to the intervention programme. Both costs by category and total direct health care costs were assessed. Owing to the fact that the cost data are skewed to the right, we both present mean and median costs of health care utilisation. Univariate differences in costs between the home-visit and the usual care group were tested for their statistical significance using the Mann Whitney $U$ test. In addition a multiple linear regression analysis was performed with the total health care costs as the dependent variable. Because the distribution of 
this variable is skewed to the right, the transformed version (square root) of the total health care costs was used as dependent variable. In the regression analysis we adjusted for differences between the groups in baseline characteristics. A hierarchical backward elimination method was used, forcing "treatment" (usual care $=0$ versus home visits $=1$ ) into the equation while removing other independent variables with a p-value above 0.10 on a stepwise basis. Missing data with regard to one or more categories of direct health care costs were imputed by using the mean from the treatment group (home visit or usual care).

A sensitivity analysis was performed to test the impact of deleting the costs of community nursing care (of which only six months of data were available) from the analyses.

\section{Results}

A total number of 316 persons were selected for participation in the study. These 316 persons were randomly allocated to home visit $(n=159)$ or usual care group ( $n=157)$. Of this group of 316 persons, 42 persons $(13 \%)$ had private health care insurance and were therefore excluded from the cost-effectiveness analysis, because no cost-data could be retrieved. The remaining 274 participants were all included in the analysis (home visits $n=134$, usual care $n=140$ ). Of this group of 274 persons, 31 persons had one or more missing data (home visit $n=16$, and usual care $n=15$ ). Reasons for missing data were: being insured with other insurance companies than the co-operating company $(n=15)$; receiving home care from an organisation in the neighbour region $(n=13), n o$ data regarding contacts with the general practitioner could be retrieved $(n=1)$ or a combination of these reasons $(n=2)$. Because these reasons were unlikely to be related to health care utilisation, the missing data for these 31 persons were imputed by the mean of the relevant cost category of their group.

\section{Baseline characteristics}

For the 274 persons included in the analyses, the distribution of baseline characteristics are presented in table 5.1. No significant differences between the home visit and usual care group were observed for the baseline characteristics.

\section{Home visit programme}

The home visits were implemented according to plan and no protocol adjustments were made during the intervention period ${ }^{20}$. Of the 134 persons in the home visit group, 115 received the complete intervention, and 8 received part of the intervention. Table 5.2 shows that on average a total of 5.9 hours per person was spent on the home visit programme by the nurses: 3.8 hours on the visits themselves and 2.1 hours on preparation, transportation and actions following from the visits. Table 5.3 shows the costs associated with the intervention programme. On average the programme costs were 287 Euro per person. 
Table 5.1 Baseline characteristics according to group.

\begin{tabular}{|c|c|c|c|c|c|}
\hline \multirow[t]{2}{*}{ Baseline characteristics } & \multicolumn{2}{|c|}{$\begin{array}{l}\text { Home visits } \\
\qquad(n=134)\end{array}$} & \multicolumn{2}{|c|}{$\begin{array}{l}\text { Usual care } \\
(n=140)\end{array}$} & \multirow[b]{2}{*}{ p-value } \\
\hline & mean & (sd) & mean & (sd) & \\
\hline age & 77.2 & (5.2) & 76.9 & (4.8) & .652 \\
\hline perceived health status ( 1 to 5$)^{*}$ & 2.4 & $(0.7)$ & 2.3 & (0.6) & .547 \\
\hline physical complaints $(Q$ to 18$)$ & 7.0 & (3.4) & 6.8 & (3.4) & .548 \\
\hline & number & (\%) & number & (\%) & \\
\hline female & 91 & (68) & 94 & (67) & .892 \\
\hline$\leq$ elementary school education & 70 & (52) & 86 & (61) & .125 \\
\hline below average income & 99 & (74) & 104 & (74) & .939 \\
\hline living alone & 71 & (53) & 74 & (53) & .983 \\
\hline deteriorated course of gait disorders & 80 & (60) & 83 & (59) & .944 \\
\hline
\end{tabular}

- Underlined scores are the most favourable scores.

\section{Health care utilisation}

Table 5.2 shows the health care utilisation of the people in the home visit and usual care group during 18 months of follow-up. The number of days spent in hospital is lower for the home visit group than for the usual care group. The mean number of contacts with the general practitioner was comparable in both groups. The mean number of contacts with the physiotherapist was significantly higher in the home visit group. Persons in the home visit group received less hours of domestic help. In addition they received considerably less hours of community nursing care.

Table 5.2 Health care utilisation during 18 months of follow-up, in non-monetary terms.

\begin{tabular}{|c|c|c|c|c|c|}
\hline \multirow[t]{2}{*}{ Health care utilisation } & \multicolumn{2}{|c|}{$\begin{array}{l}\text { Home visits } \\
(n=134)\end{array}$} & \multicolumn{2}{|c|}{$\begin{array}{l}\text { Usual care } \\
(n=140)\end{array}$} & \multirow[b]{2}{*}{ p-value } \\
\hline & mean* & (sd) & mean* & (sd) & \\
\hline \multicolumn{6}{|l|}{ Home visit program } \\
\hline hours spent by nurses on home visits & 3.8 & $(1.7)$ & 0 & $(0.0)$ & - \\
\hline hours spent by nurses on preparation, etc. & 2.1 & $(0.9)$ & 0 & $(0.0)$ & - \\
\hline \multicolumn{6}{|l|}{ Hospitalisation } \\
\hline admissions & 0.5 & $(0.9)$ & 0.6 & $(1.0)$ & .516 \\
\hline days in hospital & 6.6 & (13.5) & 8.4 & $(19.7)$ & .715 \\
\hline \multicolumn{6}{|l|}{ Health care professionals } \\
\hline general practitioner consultations & 10.1 & (7.1) & 0.1 & $(9.4)$ & .302 \\
\hline physiotherapy contacts & 12.4 & $(21.8)$ & 8.8 & $(18.2)$ & .030 \\
\hline \multicolumn{6}{|l|}{ Home care facilities } \\
\hline hours of domestic help & 71.4 & $(144.7)$ & 80.0 & $(141.6)$ & .283 \\
\hline hours of community nursing care & 2.5 & $(11.6)$ & 11.9 & $(56.6)$ & .280 \\
\hline
\end{tabular}

- means are calculated for the total group, including the persons who did not use the services.

* Mann Whitney U test. 
Table 5.3 presents the direct health care costs during 18 months of follow-up. Mean costs of hospitalisation, domestic help, community nursing care, and medical aids are lower, and costs for specialist care and physiotherapy are higher in the home visit group compared to the usual care group. Mean costs of general practitioners contacts are almost identical in the two groups. None of the differences in health care utilisation between home care and usual care group reaches statistical significance, except for physiotherapy contacts.

\section{Total direct health care costs}

After 18 months of follow-up, mean total direct health care costs are 608 Euro and median costs are 180 Euro less for the home visit group compared to the usual care group. This difference in total health care costs is not statistically significant. Multiple linear regression analyses with the square root transformed total direct health care costs as the dependent variable while adjusting for differences in baseline characteristics, confirms that the observed differences in costs between home visit and usual care group are not statistically significant (adjusted difference $=-1.7 ; 95 \% \mathrm{Cl}=-12.9$ to 9.6 ).

An additional multiple regression analyses including only the 243 persons with complete data-sets also confirmed these findings (adjusted difference $=-3.0$; $95 \% \mathrm{Cl}=-15.5$ to 9.5$)$.

\section{Sensitivity analysis}

By extrapolating the data regarding community nursing care of the last six months to the entire follow-up period there is a risk that the intervention group is unintentionally favoured, because they had a relatively low use of community nursing care in this six months compared to the people in the usual care group. It is not evident that this large difference also existed in the preceding 12 months. Therefore we performed an additional analysis in which we deleted the costs for community nursing care in both groups. This analysis revealed that the differences in mean total direct health care costs was reduced to 314 Euro in favour of the home visit group (home visit: mean 5155 Euro, standard deviation 5179 Euro, median 3580 Euro; usual care: mean 5469, standard deviation 6012, median 3643). Results of multiple regression analysis with total direct health care costs as dependent variable were comparable to those of the main analysis (adjusted difference $=-0.8 ; 95 \% \mathrm{Cl}=-11.9$ to 10.4 ).

\section{Discussion}

Based on the results of our study we can conclude that the mean total direct health care costs for people receiving home visits are 608 Euro less than the costs for people receiving usual care. This difference is not statistically significant. 


\begin{tabular}{|c|c|c|c|c|c|c|c|}
\hline \multirow{2}{*}{$\begin{array}{l}\text { Costs } \\
\text { Costs of home visit program } \\
\text { community nurses }\end{array}$} & \multicolumn{3}{|c|}{ Home visits ( $n=134$ ) } & \multicolumn{3}{|c|}{ Usual care $(n=140)$} & \multirow[b]{2}{*}{ p-value } \\
\hline & mean & (sd) & median & mean & (sd) & median & \\
\hline home visits & 119 & (53) & 129 & 0 & (0) & 0 & \\
\hline preparation, etc. & 67 & (29) & 70 & 0 & (0) & 0 & \\
\hline consulting general practitioners & 16 & $(0)$ & 16 & 0 & (0) & 0 & \\
\hline other & 84 & (0) & 84 & 0 & (0) & 0 & \\
\hline Subtotal I & 287 & (75) & 302 & 0 & (0) & 0 & \\
\hline \multicolumn{8}{|l|}{ Other direct health care costs } \\
\hline hospitalisation & 1473 & (3009) & 0 & 1870 & $(4389)$ & 0 & .715 \\
\hline medical specialists & 740 & (1188) & 381 & 668 & (1025) & 318 & .553 \\
\hline general practitioners & 165 & $(115)$ & 147 & 166 & (153) & 131 & .302 \\
\hline Physiotherapists & 219 & (385) & 0 & 155 & (321) & 0 & .030 \\
\hline domestic help & 1231 & (2496) & 0 & 1380 & (2441) & 0 & .283 \\
\hline community nursing care & 78 & $(364)$ & 0 & 372 & (1771) & 0 & .280 \\
\hline medical aids & 242 & $(442)$ & 89 & 290 & $(471)$ & 58 & .927 \\
\hline Medication & 798 & (706) & 621 & 939 & (892) & 776 & .388 \\
\hline Subtotal II & 4945 & (5306) & 3334 & 5841 & $(6572)$ & 3760 & .388 \\
\hline Total direct health care costs & 5233 & $(5302)$ & 3580 & 5841 & $(6572)$ & 3760 & .939 \\
\hline
\end{tabular}

- Mann Whitney U test. 
Because effect evaluation revealed that there were no effects of the home visit programme on falls and mobility outcomes and only short term effects on fear of falling and daily activity, we conclude that at the moment there are no convincing arguments in favour of adding multifactorial home visits on a structural basis to regular care. Caution should be used in generalising these results to participants with private health care insurance, because the results of the present study apply to those participants with National Health Service insurance $(87 \%)$.

Our findings are not in line with those of Rizzo et $\mathrm{al}^{19}$, who concluded that their home visit programme was associated with lowered total mean health care costs (but higher median costs) and a reduction of falls, and was therefore costeffective. The cost categories considered in the study of Rizzo et al ${ }^{19}$ were fairly comparable to those used in our study. In contrast to our study, however, in the trial of Rizzo et $\mathrm{al}^{19}$ the differences in costs between home visit and usual care group were not tested on their statistical significance. It is therefore possible that the differences in costs in favour of the intervention group in the study of Rizzo et $\mathrm{al}^{19}$ were caused entirely by chance in stead of being a consequence of the home visit programme.

A limitation in the present study is that we only assessed direct health care costs. In economical evaluations also the assessment of indirect costs (the value of production lost to society due to illness-related absence from work and days of inactivity), and direct non health care costs (costs borne by the patient and the family, such as paid and unpaid help, and travel costs) are important. Indirect costs were not assessed in the present study because they are of limited relevance in a population of retired elderly people. Direct non health care costs, on the contrary, can be of considerable relevance for an economical evaluation of an intervention aimed at elderly people (especially costs of unpaid help of family and friends). These direct non health care costs should preferably be gathered prospectively by means of a cost-diary ${ }^{26}$. However adding such a cost diary would, in our opinion, have been too burdensome for the participants (combined with the other measurements), and it was therefore decided not to assess direct non health care costs in the present study.

The general lack of evidence regarding the cost-effectiveness of preventive home visit programmes among elderly people stresses the importance of adding full economical evaluations to future trials in this field of study as a standard measure. Aggregation of the results of these economical evaluations could lead to well-founded conclusions regarding the costs of health care utilisation associated with these interventions. In addition the possibility of adding instruments to measure direct non health care costs to these studies should be explored. 


\section{References}

1. Stuck AE, Siu AL, Wieland GD, Adams J, Rubenstein LZ. Comprehensive geriatric assessment: a meta-analysis of controlled trials. Lancet 1993;342:1032-6.

2. van Haastregt JCM, Diederiks JPM, van Rossum E, de Witte LP, Crebolder HFJM. Effects of preventive home visits to elderly people living in the community: systematic review. $\mathrm{Br}$ Med J 2000;320:754-8.

3. Gillespie LD, Gillespie WJ, Cumming R, Lamb SE, Rowe BH. Interventions to reduce the incidence of falling in the elderly. Cochrane Library 1997;4:1-29.

4. Carpenter GI, Demopoulos GR. Screening the elderly in the community: controlled trial of dependency surveillance using a questionnaire administered by volunteers. $\mathrm{Br} \mathrm{Med} J$ 1990;300:1253-6.

5. Fabacher D, Josephson K, Pietruszka F, Linderborn K, Morley JE, Rubenstein LZ. An in-home preventive assessment program for independent older adults: a randomized controlled trial. J Am Geriatr Soc 1994:42:630-8.

6. Hall N, De Beck P, Johnson D, Mackinnon K, Gutman G, Glick N. Randomized trial of a health promotion program for frail elders. Can J Aging 1992;11:72-91.

7. Hendriksen $C$, Lund E, Stromgard $E$. Consequences of assessment and intervention among elderly people: a three year randomised controlled trial. Br Med J 1984;289:1522-4.

8. Luker KA. Health visiting and the elderly. Nurs Times 1981;77:137-40.

9. McEwan RT, Davison N, Forster DP, Pearson P, Stirling E. Screening elderly people in primary care: a randomized controlled trial. Br J Gen Pract 1990;40:94-7.

10. Pathy MSJ, Bayer A, Harding K, Dibble A. Randomised trial of case finding and surveillance of elderly people at home. Lancet 1992;340:890-3.

11. van Rossum E, Frederiks C.M.A., Philipsen H, Portengen K, Wiskerke J, Knipschild P. Effects of preventive home visits to elderly people. Br Med J 1993;307:27-32.

12. Sorensen KH, Sivertsen J. Follow-up three years after intervention to relieve unmet medical and social needs of old people. Compr Gerontol B 1988;2:85-91.

13. Stuck AE, Aronow HU, Steiner A, Alessi CA, Büla CJ, Gold MN, et al. A trial of annual in-home comprehensive geriatric assessments for elderly people living in the community. N Engl J Med 1995;333:1184-9.

14. Tinetti ME, Baker DI, McAvay G, Claus EB, Garrett P, Gottschalk M, et al. A multifactorial intervention to reduce the risk of falling among elderly people living in the community. N Engl J Med 1994;331:821-7.

15. Vetter NJ, Jones DA, Victor CR. Effect of health visitors working with elderly patients in general practice: a randomised controlled trial. Br Med J 1984;288:369-72.

16. Vetter NJ, Lewis PA, Ford D. Can health visitors prevent fractures in elderly people? Br Med J 1992;304:888-90.

17. Wagner EH, LaCroix AZ, Grothaus L, Leveille SG, Hecht JA, Arta K, et al. Preventing disability and falls in older adults: a population-based randomized trial. Am J Public Health 1994;84:1800-06.

18. Stuck AE, Minder CE, Peter-Wüest I, Gillmann G, Egli C, Kesselring A, et al. A randomized trial of in-home visits for disability prevention in community-dwelling older people at low and high risk for nursing home admission. Arch Intern Med 2000;160:977-986.

19. Rizzo JA, Baker DI, McAvay G, Tinetti ME. The cost-effectiveness of a multifactorial targeted prevention program for falls among community elderly persons. Med Care 1996;34:954-69.

20. van Haastregt JCM, Diederiks JPM, van Rossum E, de Witte LP, Voorhoeve PM, Crebolder HFJM. Effects of a programme of multifactorial home visits on falls and mobility impairments in elderly people at risk: randomised controlled trial. Br Med J 2000;321:994-8.

21. de Bruin AF, Diederiks JPM, de Witte LP, Stevens JA, Philipsen H. The development of a short generic version of the Sickness Impact Profile. J Clin Epidemiol 1994:47:407-18.

22. de Bruin AF, Buys M, de Witte L.P., Diederiks JPM. The Sickness Impact Profile: SIP68, a short generic version; First evaluation of the reliability and reproducibility. J Clin Epidemiol 1994:47:863-71.

23. van Haastregt JCM, van Rossum E, Diederiks JPM, Voorhoeve PM, de Witte LP, Crebolder HFJM. Preventing falls and mobility problems in community-dwelling elders: the process of creating a new intervention. Geriatr Nurs 2000;21:309-14. 
24. Oostenbrink JB, Koopmanschap MA, Rutten FFH. Handleiding voor kostenonderzoek, methoden en richtlijnprijzen voor economische evaluaties in de gezondheidszorg. Amstelveen: College voor zorgverzekeringen; 2000.

25. Rand health science program. Rand 36-item health survey. Santa Monica, CA: Rand; 1992.

26. Goossens MEJB, Rutten-van Mölken MPMH, Vlaeyen JWS, van der Linden SMJP. The cost diary: a method to measure direct and indirect costs in cost effectiveness research. J Clin Epidemiol 2000;53:688-95. 



\section{Process evaluation of a multifactorial home visit programme among elderly people at risk}

This chapter is accepted for publication as:

van Haastregt JCM, van Rossum E, Diederiks JPM, de Witte LP, Voorhoeve PM, Crebolder HFJM. Process-evaluation of a home visit programme to prevent falls and mobility impairments among elderly people at risk. Pat Educ Couns (in press) 


\section{Summary}

Objective: A recently published randomised controlled trial revealed that a multifactorial home visit programme aimed at preventing falls and mobility impairments among community-living elderly people at risk had no favourable effects on falls and mobility impairments. This paper describes the results of a detailed evaluation of the intervention process of this home visit programme. The aim of the study is to provide insight in factors related to the intervention process that may have influenced the effectiveness of the home visit programme.

Intervention: The programme consisted of five home visits performed by a community nurse over a period of one year. During the home visits the participants were screened for risk factors potentially influencing falls and mobility. The screening was followed by recommendations, referrals, and other actions aimed at dealing with the hazards observed.

Methods: Data regarding the intervention process were gathered by means of interviews with nurses and participants, and by means of structured forms and questionnaires administered by the nurses during the intervention period.

Results: The evaluation of the intervention process showed that the intervention was largely performed according to protocol. The nurses and the majority of the participants had a favourable judgement about the home visits. On average the nurses made three recommendations to each participant regarding preventive actions. The participants complied to $46 \%$ of these recommendations. The following factors may have hampered the effectiveness of the programme: psychosocial problems of the participants attracted relatively much attention during the home visits, possibly at the expense of other relevant topics; the nurses provided only a limited number of recommendations to the participants; compliance with these recommendations was reasonable but not optimal. Positive aspects of the home visits according to the nurses were: the intermediary function of the nurse; the provision of emotional support to the participants; the detection of previously untreated problems; and the fact that the repeated visits give the nurse the opportunity to build a trusting relationship with the participant, which may improve the compliance of participants with recommendations.

Conclusions: Our one-year multifactorial home visit programme consisting of five home visits seems to be feasible for nurses and participants. Despite this it seems to be an unsuitable intervention technique to reduce falls and mobility impairments among elderly people at risk. 


\section{Introduction}

Recently we published the results of a randomised controlled trial into the effects of a multifactorial preventive home visit programme on falls and mobility impairments among elderly people at risk' ${ }^{\prime}$. In contrast to our expectations the home visits showed no favourable effects on falls and mobility impairments'. Roughly there can be two reasons for these negative results: 1) the design and conduct of the trial had methodological flaws, or 2) the intervention was not effective. With regard to the methodological quality of our trial we have no indications that our trial had serious methodological flaws (details on the design and methodology are discussed in chapter 3 and 4). Therefore the second option that the intervention is not effective seems to be more plausible. This poses the following question: "Which factors related to the intervention process may have influenced the effectiveness of our preventive home visit programme?". In this paper we try to answer this question by presenting and discussing the results of a detailed evaluation of the intervention process which was performed during and directly after the intervention period.

There exists a considerable lack of information provided on the intervention process of trials in the field of preventive home visits. The majority of trials published in the past two decades provide only general information about the intervention process ${ }^{2-19}$ (see chapter 7). Only Stuck et $\mathrm{al}^{13}$ published a paper with the results of a detailed evaluation of the intervention process of their home visit programme ${ }^{20}$. This lack of information provided on the intervention process makes it difficult to assess which factors in general improve or hamper the quality and effectiveness of home visit programmes. The aim of this paper is to improve the insight in factors potentially influencing the effectiveness of preventive home visit programmes. More insight into these factors may be relevant to researchers and health professionals because there are several western European countries in which home visits to elderly people are part of regular health care, while there is still no convincing evidence in favour of the effectiveness of these visits ${ }^{19}$.

\section{Methods}

In this method section we focus on the methods of the process evaluation. For those interested in the design and results of the trial in which the effects of the home visits on falls and mobility were evaluated, a summary of the trial is presented in appendix I. A detailed report of the trial is presented in Chapter 4.

\section{Participants}

The process evaluation was performed among the four visiting nurses and the 159 elderly people aged 70 years and over, who were assigned to the home visit group. The selection of participants is described in appendix I. 


\section{Measurement instruments}

We evaluated the following aspects of the intervention process: the extent to which the home visit programme was performed according to protocol; the number of home visits that were performed and the time spent on the visits; the main topics discussed during the visits; the recommendations given to the participants; the compliance of the participants to these recommendations; the opinion of participants and nurses about the intervention; and the differences in approach between the nurses.

Data regarding the topics mentioned above were collected by using the following methods:

- structured registration forms and questionnaires administered by the nurses during the intervention period

- interviews with the participants at the end of the last home visit, performed by the visiting nurses

- participation of members of the research team in the three weekly meetings of the nurses in which the intervention programme was discussed (PV and $\mathrm{JvH}$ )

- interviews with nurses and participants at the end of the intervention period, performed by member of the research team (JvH).

Table 6.1 shows those aspects of the intervention process which were assessed and the methods that were used.

Table 6.1 Measurements regarding the intervention process.

\begin{tabular}{|c|c|}
\hline Aspects & Methods \\
\hline Protocol deviations & $\begin{array}{l}\text { - prospectively recorded by nurses on registration forms } \\
\text { qualitative data gathered by researcher during the three } \\
\text { weekly meetings with the nurses }\end{array}$ \\
\hline $\begin{array}{l}\text { Number of visits and time } \\
\text { spent on visits }\end{array}$ & - prospectively recorded by nurses on registration forms \\
\hline $\begin{array}{l}\text { Main topics discussed } \\
\text { during visits }\end{array}$ & - prospectively recorded by nurses on registration forms \\
\hline $\begin{array}{l}\text { Recommendations and } \\
\text { compliance }\end{array}$ & - prospectively recorded by nurses on registration forms \\
\hline $\begin{array}{l}\text { Opinion participants about } \\
\text { intervention }\end{array}$ & $\begin{array}{l}\text { - structured interview performed by nurses at the end of last } \\
\text { home visit }\end{array}$ \\
\hline $\begin{array}{l}\text { Opinion nurses about } \\
\text { intervention }\end{array}$ & $\begin{array}{l}\text { - qualitative data gathered by researcher during the three } \\
\text { weekly meetings } \\
\text { structured self-administered questionnaire in which the nurses } \\
\text { judged the relevance of the home visits for each individual } \\
\text { participant (filled in just before the last home visit to each } \\
\text { participant) } \\
\text { - group interview directly after intervention period } \\
\text { group interview with the nurses after nurses were informed } \\
\text { about clinical outcomes of the intervention programme }\end{array}$ \\
\hline
\end{tabular}




\section{Intervention programme as planned}

The multifactorial home visit programme consists of five visits performed by a community nurse, over a period of one year. In the first six months participants receive three visits (every two months) followed by two visits in the last six months (every three months). The nurses have to follow a structured protocol for the home visits, focusing on falls, fear of falling, mobility, physical health, medication, activities of daily living, social functioning, cognitive functioning, and psychological functioning. The protocol also includes a checklist for home safety $^{21}$. The first home visit consists of a comprehensive assessment, resulting in specific recommendations to the patient regarding preventive measures. In the subsequent visits the nurse evaluates the preceding period with the participants and asks whether they have complied with their recommendations. In addition, the nurse assesses whether any new (health) problems have emerged in the intervening months and provides additional recommendations, if necessary. A more detailed description of the development and contents of the intervention protocol is presented in chapter $3^{22}$. The complete intervention protocol can be obtained from the authors.

\section{Results}

\section{Participants}

The mean age of the participants was 77 years (range 70 to 96 ; $s d=5$ ), $65 \%$ was female, and $50 \%$ lived alone. The four nurses who performed the home visits were all experienced nurses. They performed the home visits in combination with (part of) their usual work. Three of them had a part-time and one had a full-time appointment.

\section{The intervention as implemented: protocol deviations}

The intervention programme was implemented in an urban setting in the south of the Netherlands. Four experienced community nurses from a health centre in Hoensbroek, the Netherlands were invited to perform the visits. According to plan the nurses were trained and instructed to use the intervention protocol, prior to the start of the intervention. In the first two months of the intervention period, weekly meetings took place, attended by the nurses, a member of the research team $(\mathrm{JvH})$, and one of the general practitioners of the health centre (PV). In the remaining months these meetings took place every three to four weeks. During these meetings the visits were evaluated and discussed.

No substantial protocol deviations were reported by the nurses. Minor deviations included the order in which topics were discussed, spreading the comprehensive assessment of the first visit over two visits (if it took too much time to finish it during the first visit), and not being able to check all rooms in the home for their safety when a participant refused to allow admittance. In addition to these meetings, the nurses also reported to have used the regular (weekly) team-meetings of the health centre, to ask general practitioners and other colleagues for advice about recommendations to specific participants (in case of doubt). This was also according to plan. A thorough assessment of the 
registration forms completed by the nurses during and after every home visit also confirmed that the home visits were performed according to protocol.

\section{Number and duration of visits}

Of the 159 participants in the home visit group, $138(87 \%)$ received the complete intervention programme. These 138 were allocated to one of the four nurses in the following way: nurse $A, n=19$; nurse $B, n=27$; nurse $C, n=33$; nurse $D, n=59$. The number of patients assigned to each nurse took into account the number of hours worked by the nurse.

Twelve persons $(8 \%)$ did not receive any home visit at all and nine $(6 \%)$ received part of the visits. Reasons for not receiving the (complete) intervention programme included: death $(n=6)$; illness $(n=4)$; lack of motivation to continue participation in the trial $(n=6)$; on holiday or moved to another region $(n=5)$. A total of 710 home visits were performed. The mean number of visits was 4.5 per person.

On average the nurses spent 80 minutes on each home visit (sd=17 minutes). This included preparation time ( 6 minutes, $s d=1$ minute), travel time ( 8 minutes, sd=3 minutes), the visit itself ( 51 minutes, $s d=14$ minutes) and time spent on other activities resulting from the visits ( 14 minutes, $s d=5$ minutes). On average the first visit was longer than the subsequent visits (109 versus 72 minutes).

Table 6.2 Main topics discussed during the home visits.

\begin{tabular}{lcc}
\hline Main topics discussed & N times mentioned to be main topic \\
\hline health problems & 598 & $(34 \%)$ \\
social functioning & 250 & $(14 \%)$ \\
psychological/ cognitive functioning & 185 & $(11 \%)$ \\
exercise and other leisure activities & 171 & $(10 \%)$ \\
medication & 150 & $(9 \%)$ \\
falls and fear of falling & 148 & $(8 \%)$ \\
aids, devices and home adjustments & 133 & $(8 \%)$ \\
activities of daily living and dependence & 74 & $(4 \%)$ \\
other & 33 & $(2 \%)$ \\
& 1742 & $(100 \%)$ \\
total & & \\
\hline
\end{tabular}

- After each home visit the nurses recorded the three topics they considered to be the most important discussed during that visit.

\section{Main topics discussed}

After every visit the nurses recorded three topics they considered to be the most important discussed during that visit. A total of 1742 topics were recorded. We subdivided those topics in nine categories which are presented in table 6.2. Frequently mentioned topics in the category "health problems" were gait disorders and locomotor problems. In the category "social functioning", loneliness and conflicts with important others were often discussed. In the category "psychological and cognitive functioning" frequently mentioned 
topics were depression, feelings of fear, and grief at the loss of a spouse, relative or friend.

\section{Recommendations and compliance}

The nurses made a wide range of recommendations to participants during the home visits. Part of these recommendations resulted in practical agreements with the participants about undertaking action. The nurses recorded these recommendations after each visit. The nurses also recorded during the next visit(s) whether or not the participants had complied with the proposed action. On average three of such recommendations were made to each participant.

Table 6.3 shows the main types of recommendations and the number of recommendations that the participants had actually complied with. A considerable number of recommendations related to home adjustments. These were often relatively small adjustments like the fitting of grab rails in the toilet or bathroom, putting down anti-slip bath mats, and mounting handrails. On average participants complied with $46 \%$ of the recommendations. The highest compliance was observed for recommendations regarding medication (medicine intake, change of dose, change of medication, stopping specific medication). For $35 \%$ of the recommendations provided, no information is available regarding compliance, the main reason being that when a recommendation was given during one of the last home visits it could often not be checked whether the participant had actually complied with it. In $19 \%$ of the cases the nurses recorded that the participant had not complied with the recommendations. The actual compliance rate therefore ranges from $46 \%$ to $81 \%$. The highest non-compliance rate was observed with respect to recommendations about applying for institutional care such as homes for the elderly or nursing homes.

Table 6.3 Recommendations and compliance.

Topics

Recommen-

Compliant Non-compliant

Unknown dations ( $n$ )

\begin{tabular}{lrrlrrrr}
\hline home adjustments & 102 & 46 & $(45 \%)$ & 30 & $(29 \%)$ & 26 & $(25 \%)$ \\
referral to general practitioner & 81 & 39 & $(48 \%)$ & 12 & $(15 \%)$ & 30 & $(37 \%)$ \\
aids and devices & 63 & 27 & $(43 \%)$ & 17 & $(27 \%)$ & 19 & $(30 \%)$ \\
referral to other care-providers & 51 & 25 & $(49 \%)$ & 4 & $(8 \%)$ & 22 & $(43 \%)$ \\
medication & 40 & 24 & $(60 \%)$ & 3 & $(8 \%)$ & 13 & $(33 \%)$ \\
referral to regular home care & 15 & 7 & $(47 \%)$ & 1 & $(7 \%)$ & 7 & $(47 \%)$ \\
referral to institutional care & 10 & 4 & $(40 \%)$ & 4 & $(40 \%)$ & 2 & $(20 \%)$ \\
other & 55 & 21 & $(38 \%)$ & 9 & $(16 \%)$ & 25 & $(45 \%)$ \\
\hline total & 417 & 193 & $(46 \%)$ & 80 & $(19 \%)$ & 144 & $(35 \%)$ \\
\hline
\end{tabular}

\section{Opinion of the participants about intervention programme}

Nine of the 138 participants found the home visits unnecessary or not useful, six had a neutral judgement. The other 123 participants $(89 \%)$ all had a 
favourable judgement. Nearly all participants (130) were content with the duration of the home visits. Four persons found the visits too short and four persons found the visits too long.

A total of 134 participants answered the question regarding the perceived benefits of the visits. Eighty-three percent $(n=111)$ reported to have benefited from the home visits. The answers varied from some $(n=33)$, quite a lot $(n=64)$, to a great deal $(n=14)$. Twenty-three persons reported not having experienced any benefit from the home visits. Participants reporting benefits had experienced most benefits from: "the opportunity to discuss problems, the opportunity to talk with the nurse, and the attention received from the nurse" $(n=48) ;$ "the advice given by the nurse in general" $(n=25) ;$ "the advice given by the nurse regarding aids, devices and home adjustments" $(n=21) ;$ and "a greater awareness of the risks of falling and mobility problems" ( $n=17)$.

Table 6.4 (column "Participants") shows that participants who reported having benefited from the visits differed from those who had not on the following baseline characteristics: a higher proportion lived alone; more physical complaints; worse mental health status; and a worse perceived health ( $p<$ 0.05 ). In addition women and persons who received secondary education also tended to perceive more benefits from the home visits.

\section{Opinion of nurses about the intervention programme}

Overall, the nurses had a positive judgement about the protocol for the home visits. They found the protocol both feasible and useful. Especially recommendations with regard to simple devices and home adjustment such as grab-rails in the toilet or bathroom were considered to be a positive aspect of the visits. Providing emotional support to the participants was also regarded to be an essential aspect of the visits. In addition, the fact that the nurse could function as an intermediary between participant and other health care professionals was considered important.

The nurses reported that through the home visits they were able to obtain a good picture of the functioning of the participants and were able to provide general practitioners with information on previously untreated health problems and problems with medication. The fact that there were five subsequent visits was considered to be important, because this way a trusting relationship could be developed with the participants, which appeared to make participants more receptive to recommendations.

For each participant, the nurses were asked to indicate whether they believed the participant actually benefited from their visits. According to the nurses, more than half of the participants had actually benefited from the visits $(n=74)$, the main reasons being: "participant received useful and practical advice and support" ( $n=51$ ); "participants received emotional support and had someone to discuss their problems with" ( $n=18)$; "increased awareness of risks of falling and decline in mobility" ( $n=5)$. 
Table 6.4 Relation between baseline characteristics and process factors.

\begin{tabular}{|c|c|c|c|c|c|c|}
\hline \multirow[b]{2}{*}{ Baseline characteristics } & \multicolumn{3}{|c|}{ Participants } & \multicolumn{3}{|c|}{ Nurses } \\
\hline & $\begin{array}{l}\text { Benefited } \\
(n=111)\end{array}$ & $\begin{array}{l}\text { Did not benefit } \\
\quad(n=23)\end{array}$ & P-value & $\begin{array}{l}\text { Participant } \\
\text { benefited } \\
(n=74)\end{array}$ & $\begin{array}{l}\text { Participant did } \\
\text { not benefit } \\
(n=62)\end{array}$ & P-value \\
\hline \multicolumn{7}{|l|}{ Background characteristics } \\
\hline $\begin{array}{l}\text { mean age } \\
\% \text { female sex }\end{array}$ & $\begin{array}{l}77 \\
68\end{array}$ & $\begin{array}{l}79 \\
48\end{array}$ & .12 & $\begin{array}{l}78 \\
68\end{array}$ & $\begin{array}{l}77 \\
61\end{array}$ & $\begin{array}{l}.43 \\
.45\end{array}$ \\
\hline $\begin{array}{l}\% \text { female sex } \\
\% \leq \text { elementary school education }\end{array}$ & $\begin{array}{l}00 \\
43\end{array}$ & 65 & .06 & 43 & 53 & .25 \\
\hline $\begin{array}{l}\% \leq \text { elementary school education } \\
\% \text { below average income }\end{array}$ & 60 & 57 & .79 & 58 & 61 & .71 \\
\hline$\%$ living alone & 51 & 22 & .01 & 53 & 42 & .21 \\
\hline$\%$ deteriorated course of gait disorders & 65 & 48 & .13 & 69 & 53 & .06 \\
\hline \multicolumn{7}{|l|}{ Primary outcome measures } \\
\hline$\%$ at least one fall in past 6 months & 35 & 39 & .72 & 39 & 31 & .30 \\
\hline$\%$ more than one fall in past 6 months & 20 & 26 & .50 & 26 & 15 & .11 \\
\hline mean mobility control $\left(0\right.$ to $\left.12^{*}\right)$ & 5.6 & 4.9 & .30 & 5.8 & 5.2 & .32 \\
\hline mean mobility range $(Q$ to 10$)$ & 1.8 & 1.7 & .77 & 1.9 & 1.9 & .99 \\
\hline \multicolumn{7}{|l|}{ Secondary outcome measures } \\
\hline mean physical complaints $(0$ to 18$)$ & 7.1 & 5.0 & .01 & 7.2 & 6.4 & .13 \\
\hline mean daily activity ( 13 to $\underline{52}$ ) & 33.6 & 32.1 & .32 & 33.4 & 33.0 & .55 \\
\hline mean fear of falling (10 to 40$)$ & 18.4 & 18.8 & .68 & 19.8 & 17.0 & .07 \\
\hline mean mental health $(5$ to $\underline{30})$ & 22.1 & 24.5 & .04 & 21.8 & 23.4 & .07 \\
\hline mean social functioning ( 2 to 12$)$ & 6.5 & 6.4 & .92 & 6.7 & 6.4 & .17 \\
\hline mean perceived health ( 1 to $\underline{5}$ ) & 2.4 & 2.7 & .02 & 2.5 & 2.4 & 26 \\
\hline mean perceived gait problems (1 to 5 ) & 3.6 & 3.7 & .81 & 3.9 & 3.4 & .02 \\
\hline mean loneliness (1 to 6 ) & 2.3 & 1.8 & .17 & 2.2 & 2.1 & .52 \\
\hline
\end{tabular}

- The underlined scores are the most favourable scores. 
With regard to the 62 participants who, in the opinion of the nurses, had benefited only very little or not at all from the home visits, the following explanations were given: "participant has a good functional level" ( $n=21)$; "participant is not motivated to make any changes" ( $n=14) ;$ "I could not make any recommendation to this patient" $(n=12)$; and "other" $(n=5)$. For two persons no judgement was given.

The opinion of the nurses overlap with the opinion of the participants in $70 \%$ of cases. In $29 \%$ of cases participants reported to have benefited, while the nurses thought they had not, and in one case the nurse reported that the participant had benefited while the participant reported not to have benefited. There are only minor differences between the participants who in the opinion of the nurses had benefited from the visits and those who had not. Persons who had benefited, more often experienced deteriorated gait, were more afraid to fall, had a poorer mental health status, and had more gait problems at baseline (table 6.4, column "Nurses"). Only the difference regarding perceived gait problems was statistically significant $(p<0.05)$.

After the nurses had been informed about the negative results of the trial (at the end of the study), they were asked to brainstorm on the possible causes of the lack of effectiveness. The following explanations were put forward by the nurses:

- During the home visits a relatively large amount of attention focused on psychosocial (emotional) problems of the participants. Only part of these problems are likely to be related to falls and mobility impairments. The need or wish of the participants to discuss psychosocial problems with the nurse may have gone at the expense of other relevant topics, such as problems with gait and balance and other medical problems. However, the nurses felt it was disrespectful and dysfunctional to ignore emotional problems, since persons experiencing such problems will not be very receptive to recommendations with respect to the prevention of falls and mobility impairment, if the nurse pays no attention to their problems.

- It was sometimes difficult to persuade participants to change specific behavioural patterns or to take any specific action, especially when they did not view themselves at risk for falls or mobility decline.

- Some participants were reluctant to follow recommendations because they seemed to associate certain interventions with "getting old", which was probably too confronting.

- Prolongation of visits over a longer period might have resulted in more favourable effects, because in the later stages of the intervention programme the nurses felt participants were willing to agree to undertake specific actions, which they were unwilling to undertake at the beginning of the programme.

- It was considered difficult to detect the reasons for falls, as many factors can play a role. 
- In retrospect it may not have been wise to exclude persons already receiving (regular) home nursing care from participating in the trial. It is possible that these persons in particular would have benefited from the additional preventive home visits, because they experience health problems and have already developed a measure of trust with the nurse.

- Especially frail elderly, who in theory could benefit the most from the support and recommendations provided by the nurses, are also the ones who are often difficult to persuade in taking preventive actions or changing their behaviour, which may be due to a low self-efficacy and limited skills.

- For people who lead an active life and for people living in homes for the elderly, the home visits do not appear to be very useful. The first group can manage well enough by themselves and for the second group the home visits do not add enough elements to the care these people already receive (about $5 \%$ of the participants lived in homes for the elderly).

\section{Differences between the nurses}

There are considerable differences between the nurses regarding the time spent on the visits. Nurse A spent on average 53 minutes on the visits $(n=19)$, nurse B 63 minutes ( $n=27)$, nurse C 59 minutes $(n=33)$, and nurse D 41 minutes $(n=59)$. Nurse $D$ who performed the largest number of visits spent the least time on each visit. Also, the number of recommendations made and the compliance to these recommendations differed considerably between the nurses. Nurse A made on average 2.2 recommendations with a $59 \%$ compliance rate, nurse B made 2.6 recommendations with a $39 \%$ compliance rate, nurse $C$ made 3.6 recommendations with a $43 \%$ compliance rate, and nurse $D$ made 3.2 recommendations with a $47 \%$ compliance rate. The participants attended to by nurses $B$ and $C$ seemed more positive about the benefits of the home visits than those seen by nurses $A$ and $D$. Of the clients of nurse $A 79 \%$ reported to have benefited, for nurse $B$ this was $96 \%$, for nurse $C 97 \%$, and for nurse $D 71 \%$. Nurses $A$ and $D$ also held a more negative judgment on the benefits their participants had had from the visits. Nurse A reported that $26 \%$ had benefited, nurse B $63 \%$, nurse C $73 \%$, and nurse D $49 \%$.

\section{Discussion}

\section{Conclusions}

In this paper we analysed those aspects of the intervention process that may have influenced the effectiveness of the intervention programme. Firstly, we assessed whether the intervention programme was performed according to protocol. We observed that the majority $(87 \%)$ of the people in the home visit group received the complete intervention. The average duration of the home visits (excluding travel time and preparation) was 51 minutes, which was according to plan. The nurses reported no substantial protocol deviations. In addition, evaluation of the registration forms also revealed no substantial protocol deviations. 
Secondly, we made an assessment of the main topics discussed during the home visits, as reported by the nurses. As expected health related risk factors, such as gait disorders and locomotor problems were perceived by the nurses to be important topics. In addition psychosocial problems attracted a relatively large amount of attention during the visits. The reason for the relatively large amount of time spent discussing these problems seems to be the fact that the participants expressed a clear need to discuss these problems, and that the nurses considered it disrespectful and dysfunctional to ignore this need. The fact that the protocol for the home visits allowed the nurses some degree of freedom in choosing which topics they would give most attention during the visits also may have contributed to this phenomenon.

It is possible that the large amount of attention paid to emotional problems which are not directly related to falls and mobility impairments has gone at the expense of attention paid to addressing factors which are more directly related to falls. Only the more serious psychosocial and cognitive problems are reported in the literature to be directly related to falls and mobility problems

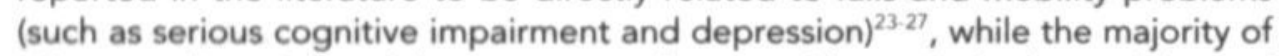
minor psychosocial problems seem to play no evident role in the aetiology of falls and mobility impairments.

Thirdly, we assessed whether a lack of compliance could have had a negative influence on effectiveness. The compliance rate of at least $46 \%$ was very much comparable to that reported in a home visiting trial by Stuck and colleagues ${ }^{13,20}$. Although reasonable, the compliance seems certainly liable to improvement.

The fact that for each person, on average, three recommendations were made regarding concrete preventive action indicates that, on average, the participants only complied with about two recommendations. When one bears in mind that compliance with a recommendation does not automatically mean that a risk factor for falls or mobility impairments is actually reduced, the lack of effectiveness of our intervention programme may partly be explained by the limited number of recommendations resulting of the programme. This conclusion seems to be confirmed by the fact that in the study of Stuck et al $\left.\right|^{13,20}$ on average 11.5 recommendations were made per year (divided over an average number of 3 to 4 visits a year) of which about half were complied with. This higher number of recommendations in the more successful programme of Stuck et $\mathrm{al}^{13,20}$ however may be partly explained by the fact that in our study the nurses registered only those recommendations that had resulted in practical agreements with the participant about undertaking action. In addition this difference may also have resulted from the fact that in the study of Stuck et $\mathrm{al}^{13,20}$ the nurse formulated the recommendations in consultation with a geriatrician. It is possible that this standard consultation of a geriatrician by the visiting nurse results in more recommendations than was the case in our programme in which the nurse only consulted a general practitioner in case of doubt about which recommendations to give. 
Fourthly, we assessed the subjective opinion of the participants and nurses regarding the home visits. The large majority of the participants had a positive judgement about the home visits and reported having benefited from the visits. The nurses also had a positive judgement about the home visits, but considered the home visits to be beneficial for only about half of the participants. In particular "frail elderly" (participants who reported to have problems with mental and physical health at baseline) appeared to have benefited more from the home visits, according to themselves and the nurses.

The nurses reported a number of strong aspects of the home visits: useful and practical recommendations and support could be provided to the participants; emotional support could be provided to the participants; the nurse could function as an intermediary between participants and other caregivers; detection of previously untreated problems; a trusting relationship between nurse and participant can be developed, because of the repeated visits.

Additional analyses, not presented in this paper, revealed that there was no relationship between perceived benefit of the home visits on the one hand and more improvement (or less deterioration) on falls and mobility impairment after 18 months of follow-up on the other. So it seems there is a discrepancy between the subjective judgement regarding benefits of the home visits and the observed effects on falls and mobility outcomes after 18 months of followup. However, this is not surprising because participants report having benefited mainly from the fact that they received attention from the nurse, and the fact someone listened to them. These "attention" aspects of the visits are unlikely to have had a substantial favourable effect on falls and mobility problems, and are more likely to have had effects on psychosocial outcome measures. However analysis of the secondary outcome measures of our trial (see appendix I) ${ }^{1}$ showed that no significant favourable effects of the home visits on psychosocial outcome measures (mental health, social functioning, and loneliness) were observed after 12 and 18 months of follow-up.

\section{Practice implications}

Although our one-year multifactorial home visit programme was considered feasible by nurses and participants, it seems to be an unsuitable intervention technique to reduce falls and mobility impairments among elderly people at risk. Possibilities to develop more effective intervention techniques to prevent falls and mobility impairments among community-living elderly people should be explored. In this regard the following recommendations may be helpful.

- The need or wish of elderly people to discuss psychosocial problems with an intervener may unintentionally go at the expense of discussing other relevant topics. This may decrease the effectiveness of an intervention programme. Strategies to prevent this phenomenon without ignoring the needs of participants may be explored. 
- The potential advantages of involving health professionals from different disciplines in an intervention programme aimed at preventing falls and mobility impairments, may be explored.

- With regard to compliance to recommendations special attention should be given to the fact that some recommendations may be confronting for the elderly people, which may have a negative influence on compliance. In addition, special attention must be paid to enhance the skills and abilities of elderly people to comply with recommendations. A more active use of compliance enhancing strategies should be advocated ${ }^{28}$. Special attention to enhancing compliance should be given with regard to recommendations in the field of referral to institutional care, the use of aids and devices, and home adjustments, which showed a below average level of compliance in our study.

- Strong aspect of preventive home visit may be used in new intervention programmes: the provision of useful and practical recommendations and support to the participants; the intermediary function of the nurse; detection of previously untreated problems; and using repeated visits to build a trusting relationship with the participant.

\section{References}

1. van Haastregt JCM, Diederiks JPM, van Rossum E, de Witte LP, Voorhoeve PM, Crebolder HFJM. Effects of a programme of multifactorial home visits on falls and mobility impairments in elderly people at risk: randomised controlled trial. Br Med J 2000;321:994-8.

2. Carpenter GI, Demopoulos GR. Screening the elderly in the community: controlled trial of dependency surveillance using a questionnaire administered by volunteers. $\mathrm{Br}$ Med J 1990;300:1253-6.

3. Dalby DM, Sellors JW, Fraser F, Fraser C, Ineveld C, Howard M. Effect of preventive home visits by a nurse on the outcomes of frail elderly people in the community: a randomised controlled trial. CMAJ 2000;162:497-500.

4. Fabacher D, Josephson K, Pietruszka F, Linderborn K, Morley JE, Rubenstein LZ. An in-home preventive assessment program for independent older adults: a randomized controlled trial. J Am Geriatr Soc 1994;42:630-8.

5. Hall N, De Beck P, Johnson D, Mackinnon K, Gutman G, Glick N. Randomized trial of a health promotion program for frail elders. Can J Aging 1992;11:72-91.

6. Hébert R, Robichaud L, Roy PM, Bravo G, Voyer L. Efficacy of a nurse-led multidimensional preventive programme for older people at risk of functional decline. A randomised controlled trial. Age Ageing 2001;30:147-53.

7. Hendriksen $C$, Lund $E$, Stromgard $E$. Consequences of assessment and intervention among elderly people: a three year randomised controlled trial. Br Med J 1984;289:1522-4.

8. Luker KA. Health visiting and the elderly. Nurs Times 1981;77:137-40.

9. McEwan RT, Davison N, Forster DP, Pearson P, Stirling E. Screening elderly people in primary care: a randomized controlled trial. Br J Gen Pract 1990;40:94-7.

10. Pathy MSJ, Bayer A, Harding K, Dibble A. Randomised trial of case finding and surveillance of elderly people at home. Lancet 1992;340:890-3.

11. van Rossum E, Frederiks C.M.A., Philipsen H, Portengen K, Wiskerke J, Knipschild P. Effects of preventive home visits to elderly people. Br Med J 1993;307:27-32.

12. Sorensen $\mathrm{KH}$, Sivertsen J. Follow-up three years after intervention to relieve unmet medical and social needs of old people. Compr Gerontol B 1988;2:85-91.

13. Stuck AE, Aronow HU, Steiner A, Alessi CA, Bula CJ, Gold MN, et al. A trial of annual in-home comprehensive geriatric assessments for elderly people living in the community. N Engl J Med 1995;333:1184-9. 
14. Stuck AE, Minder CE, Peter-Wüest I, Gillman G, Egli C, Kesselring A, et al. A randomised trial of in-home visits for disability prevention in community-dwelling older people at low and high risk for nursing home admission. Arch Intern Med 2000; 160:977-86.

15. Tinetti ME, Baker DI, McAvay G, Claus EB, Garrett P, Gottschalk M, et al. A multifactorial intervention to reduce the risk of falling among elderly people living in the community. N Engl $\mathrm{J}$ Med 1994;331:821-7.

16. Vetter NJ, Jones DA, Victor CR. Effect of health visitors working with elderly patients in general practice: a randomised controlled trial. Br Med J 1984;288:369-72.

17. Vetter NJ, Lewis PA, Ford D. Can health visitors prevent fractures in elderly people? $\mathrm{Br}$ Med J 1992;304:888-90.

18. Wagner EH, LaCroix AZ, Grothaus L, Leveille SG, Hecht JA, Arta K, et al. Preventing disability and falls in older adults: a population-based randomized trial. Am J Public Health 1994;84:1800-6.

19. van Haastregt JCM, Diederiks JPM, van Rossum E, de Witte LP, Crebolder HFJM. Effects of preventive home visits to elderly people living in the community: systematic review. $\mathrm{Br}$ Med J 2000:320:754-8.

20. Alessi CA, Stuck AE, Aronow HU, Yuhas KE, Bula CJ, Madison R, et al. The process of care in preventive in-home comprehensive geriatric assessment. J Am Geriatr Soc 1997:45:1044-50.

21. Stalenhoef $P$, Diederiks J, Knottnerus A, de Witte LP, Crebolder H. How predictive ia a homesafety checklist for indoor fall risk in the elderly living in the community? Eur J Gen Pract 1998:4:114-20.

22. van Haastregt JCM, van Rossum E, Diederiks JPM, Voorhoeve PM, de Witte LP, Crebolder HFJM. Preventing falls and mobility problems in community-dwelling elders: the process of creating a new intervention. Geriatr Nurs 2000;21:309-14.

23. Stalenhoef PA, Crebolder HFJM, Knottnerus JA, van der Horst FGEM. Incidence, risk factors and consequences of falls among elderly subjects living in the community: a criteria-based analysis. Eur J Publ Health 1997;7:328-34.

24. Tinetti ME, Speechley M, Ginter SF. Risk factors for falls among elderly persons living in the community. N Engl J Med 1988;319:1701-7.

25. American Geriatrics Society, British Geriatrics Society, and American Academy of Orthopaedic Surgeons Panel on Falls Prevention. Guideline for the prevention of falls in older persons. J Am Geriatr Soc 2001:49:664-72.

26. Tinetti ME, SK Inouye, Gill TM, Doucette JT. Shared risk factors for falls, incontinence, and functional dependence: unifying the approach to geriatric syndromes. JAMA 1995;273:134853.

27. Tromp AM, Smit JH, Deeg DJH, Bouter LM, Lips P. Predictors for falls and fractures in the longitudinal Aging Study Amsterdam. J Bone Min Res 1998;13:1932-9.

28. Aminzadeh F. Adherence to recommendations of community-based comprehensive geriatric assessment programmes. Age Ageing 2000;29:401-7. 


\section{Appendix I: Summary of trial into the effects of home visits to community-living elderly people}

\section{Objective}

To evaluate whether a programme of multifactorial home visits reduces falls and mobility impairments in elderly people living in the community.

\section{Design}

Randomised controlled trial with 18 months of follow-up.

\section{Participants}

Participants were recruited from six general practices cooperating in a health centre in Hoensbroek, the Netherlands by means of a screening questionnaire which was sent to 1,310 patients. Participants had to be aged 70 years or over, be living in the community and have reported two or more falls in the previous six months or have scored three or more on the mobility control scale of the short version of the Sickness Impact Profile. People who were bedridden, fully dependent on a wheelchair, terminally ill, on the waiting list for admission to a nursing home, or receiving home care from a community nurse on a regular basis, were excluded. Eligible patients were randomised to the home visit group $(n=159)$ or usual care group $(n=157)$ by computer generated random numbers directly after screening. People sharing a household were always allocated to the same group.

\section{Intervention}

The intervention programme consisted of five home visits by a community nurse, over a period of one year. Visits consisted of screening for medical, functional, psychosocial, and environmental factors causing falls and impairments in mobility, followed by specific advice, referrals and other actions aimed at the observed hazards and problems. People in the control group received usual care.

\section{Outcome measures}

The primary outcome measures were falls and mobility impairments (as assessed by the mobility control scale and mobility range scale of the Sickness Impact Profile). Secondary outcome measures were number of physical complaints (out of a total of 18), perceived health (first item RAND-36), perceived gait problems (five point Likert scale), daily activity (13 item Frenchay Activities Index), fear of falling (Falls Efficacy Scale), mental health (Mental Health, RAND-36), social functioning (adjusted version of item 4 and 5 of Social Activities Battery), and loneliness (six point Likert scale).

Participants were assessed by means of self-administered questionnaires before the start of the intervention programme and after 12 and 18 months of follow-up. During follow-up participants recorded falls in a weekly dairy.

\section{Results}

After 18 months of follow-up, data on 235 people (74\%) were available for analysis (home visit $n=120$; usual care $n=115$ ). No statistically significant differences were found in falls, mobility outcomes and the 8 secondary outcome measures between the intervention and usual care group, after 18 months of follow-up. 


\section{Lack of information on the intervention process in randomised controlled trials}

This chapter is submitted as:

van Haastregt JCM, van Rossum E, Diederiks JPM, de Witte LP, Voorhoeve PM, Crebolder HFJM. Lack of information on the intervention process in randomised controlled trials. 


\section{Summary}

Objective: This paper aims to describe the availability and quality of information provided on the intervention process in randomised controlled trials, in order to assess the magnitude of underreporting of process data. In addition, the possible causes and consequences of the observed gaps in process information in trial reports are discussed, and recommendations are made for improvements.

Design: A systematic review of 33 publications reporting the results of 15 randomised controlled trials in the field of preventive home visits to elderly people living in the community.

Results: More than half of the trials included did not describe the absence or presence of protocol deviations, the completion of the intervention programme, compliance to recommendations/interventions, and the opinion of the participants and home visitors about the programme. The information that was provided about other aspects of the intervention process was very general in most cases.

Conclusions: It is concluded that there is a serious lack of information provided on the intervention process in trials in the domain of preventive home visit. It seems likely that such a lack can also be observed in many other domains. We stress the importance of developing specific guidelines for the reporting of the intervention process of randomised controlled trials. Such guidelines should preferably be developed by an international consortium such as the CONSORT-group and could serve to supplement or enhance the existing CONSORT-checklist for the reporting of randomised controlled trials. 


\section{Introduction}

In order to be able to interpret the results of randomised controlled trials, it is essential that sufficient information is provided on the characteristics of the intervention under evaluation, as well as the success of its implementation. Our experience is that in papers presenting the results of trials, too little attention is paid to the reporting of the intervention process. This represents a serious problem because it seems almost irrelevant to know whether an intervention is effective or not, if information on the characteristics of the intervention and the success of its implementation is not available. In our opinion trials should always report details on the characteristics of the intervention, its protocol, the protocol deviations and the compliance of participants to the intervention. In addition, information on the subjective evaluation of the intervention by participants and interveners may provide useful information on the quality of the implementation and the mechanisms of the intervention.

A lack of detailed information on the intervention process can seriously hamper a valid interpretation of trial results. Without this information it is very difficult to ascertain whether the ineffectiveness of an intervention is caused by weaknesses in or unsuitability of the intervention, or as a result of unsuccessful implementation. For both researchers planning to replicate a trial, and health professionals planning to implement an intervention in regular care, it is essential to have detailed information on the intervention process. This information is also essential when trying to improve the effectiveness of less successful intervention programmes.

In order to substantiate and illustrate our observation of serious underreporting of information on the intervention process in trials, a systematic assessment was made of this reporting in one specific field of study: the field of preventive home visits to elderly people living in the community. The choice for this domain was an arbitrary and pragmatic one: obviously other fields of study could have been chosen as well. For the purpose of the present study a reassessment was made of the trials previously included in a systematic review' evaluating the effectiveness of preventive home visits to elderly people living in the community ${ }^{2 \cdot 15}$. A systematic search was made of additional publications relating to these trials, the search being limited to generally available Englishlanguage publications (i.e. articles published in indexed journals). Publications were screened for information on the intervention processes.

The aim of the present paper is threefold. Firstly, it aims to describe the availability and quality of information provided on the intervention process in the field of preventive home visits, in order to give an impression of the extent of underreporting of process data in trials. Secondly, the paper aims to discuss the possible causes and consequences of observed gaps in process information in research papers, and thirdly it aims to discuss ways in which the situation can be improved. 


\section{Methods}

\section{Search strategy}

All 15 trial reports ${ }^{2.15}$ previously included in a systematic review ${ }^{1}$ into the effectiveness of preventive home visit programmes, were included in the present review. In addition Medline (from 1975 to 2000) was searched for other publications on these trials. The strategy used for this search was: [name of first author OR name of second author OR etc.] AND [AGED/all subheadings (MESH-term)]. References in the publications identified were also screened for additional publications (in English).

\section{Criteria based analyses}

A ten-item checklist was developed for assessing the availability and quality of information on the intervention process (appendix I). Items were selected on the basis of their expected contribution to a better understanding of the intervention process for both researchers and health care professionals. The checklist consists of three categories: the intervention programme as planned (2 items); the intervention programme as implemented (6 items); and the intervention programme as evaluated by participants and visitors ( 2 items). The assessments of the publications included were performed independently by two reviewers (JD and $\mathrm{JvH}$ ). The minimum score a trial could obtain was 0 and the maximum score was 10 . Disagreement between reviewers was resolved by consensus.

Table 7.1 Availability and quality of information on the intervention process as indicated by score on the checklist.

\begin{tabular}{|c|c|c|c|c|c|}
\hline \multirow{2}{*}{$\begin{array}{l}\text { Trials } \\
\text { Carpenter et } \mathrm{al}^{2}\end{array}$} & \multirow{2}{*}{$\begin{array}{c}\begin{array}{c}\text { Intervention as } \\
\text { planned } \\
\text { (max. 2) }\end{array} \\
0.5\end{array}$} & \multirow{2}{*}{$\begin{array}{c}\begin{array}{c}\text { Intervention as } \\
\text { implemented } \\
\text { (max. 6) }\end{array} \\
2.0\end{array}$} & \multirow{2}{*}{$\begin{array}{c}\begin{array}{c}\text { Subjective } \\
\text { evaluation } \\
\text { (max. 2) }\end{array} \\
1.5\end{array}$} & \multicolumn{2}{|c|}{$\begin{array}{c}\text { Total score }(\%) \\
(\max .10)\end{array}$} \\
\hline & & & & 4.0 & $(40 \%)$ \\
\hline Fabacher et $\mathrm{al}^{3}$ & 2.0 & 3.5 & 0.0 & 5.5 & $(55 \%)$ \\
\hline Hall et all ${ }^{4}$ & 2.0 & 1.0 & 0.0 & 3.0 & $(30 \%)$ \\
\hline Hendriksen et $\mathrm{al}^{5,16-18}$ & 0.5 & 1.5 & 0.5 & 2.5 & $(25 \%)$ \\
\hline Luker $^{\mathrm{B}, 19.21}$ & 1.0 & 1.0 & 1.0 & 3.0 & $(30 \%)$ \\
\hline McEwan et al? & 0.5 & 1.0 & 0.0 & 1.5 & $(15 \%)$ \\
\hline Pathy et $a^{8}$ & 0.5 & 1.0 & 0.0 & 1.5 & $(15 \%)$ \\
\hline Van Rossum et al ${ }^{9,22}$ & 1.0 & 2.0 & 0.0 & 3.0 & $(30 \%)$ \\
\hline Sorensen et $\mathrm{al}^{10,23,24}$ & 0.5 & 2.5 & 0.0 & 3.0 & $(30 \%)$ \\
\hline Stuck et al $^{11,25-29}$ & 2.0 & 4.5 & 1.0 & 7.5 & $(75 \%)$ \\
\hline Tinetti et al ${ }^{12.30 \cdot 34}$ & 2.0 & 3.5 & 0.0 & 5.5 & $(55 \%)$ \\
\hline Vetter et al, Gwent ${ }^{13 a}$ & 0.5 & 1.5 & 0.0 & 2.0 & $(20 \%)$ \\
\hline Vetter et al, Powys ${ }^{136}$ & 0.5 & 1.5 & 0.0 & 2.0 & $(20 \%)$ \\
\hline Vetter et $a^{14}$ & 1.5 & 1.0 & 0.0 & 2.5 & $(25 \%)$ \\
\hline Wagner et al ${ }^{15}$ & 1.5 & 2.5 & 0.5 & 4.5 & $(45 \%)$ \\
\hline $\begin{array}{l}\text { Mean score } \\
\text { (\%) }\end{array}$ & $\begin{array}{r}1.1 \\
(55 \%)\end{array}$ & $\begin{array}{r}2.0 \\
(33 \%)\end{array}$ & $\begin{array}{r}0.3 \\
(15 \%)\end{array}$ & 3.4 & $(34 \%)$ \\
\hline
\end{tabular}




\section{Results}

\section{Search strategy}

In addition to the 14 papers reporting on the main effects of the 15 trials $^{2.15}$, 19 other publications addressing aspects of these trials were retrieved ${ }^{16.34}$. In the case of nine trials no additional publications were found ${ }^{2-4,7,8,13-15}$, for two trials $^{5,6}$ three additional publication were retrieved, for two trials ${ }^{11,12}$ five additional publications were identified, and for the remaining two trials one and two ${ }^{10}$ additional publications were retrieved, respectively.

\section{Assessment of availability and quality of information regarding the intervention process}

Table 7.1 presents the availability and quality of information provided on the intervention process as indicated by the score on the checklist. The mean score on the checklist was 3.4 out of a maximum of 10. The scores ranged from 1.5 to 7.5. The publications included tend to provide more information on the intervention as planned, than on the intervention as implemented. Very little information is provided on the intervention programmes as evaluated by participants and visitors. Table 7.2 shows that over half the trials failed to describe the absence or presence of protocol deviations, the completion of the intervention programme, compliance to recommendations/interventions, and the opinion of the participants and home visitors about the programme. All trials mentioned the contents of the intervention programme as planned and characteristics of home visitors. However, for the majority of trials this was restricted to a rather general description.

Table 7.2 Extent to which information is provided on the intervention process in the 15 trials.

\begin{tabular}{lccc}
\hline Aspects of intervention process & $\begin{array}{c}\text { N trials } \\
\text { no } \\
\text { description }\end{array}$ & $\begin{array}{c}\text { N trials } \\
\text { general } \\
\text { description }\end{array}$ & $\begin{array}{c}\text { N trials } \\
\text { detailed } \\
\text { description }\end{array}$ \\
\hline $\begin{array}{l}\text { The intervention programme as planned } \\
\text { a. details intervention programme }\end{array}$ & 0 & 9 & 6 \\
b. details protocol & 7 & 4 & 4 \\
The intervention programme as imple- & 15 & 0 & \\
mented & 1 & 10 & 4 \\
c. absence/presence of protocol deviations & 0 & 12 & 3 \\
d. timing, frequency, and duration visits & 11 & 2 & 2 \\
e. details home visitors & 7 & 4 & 4 \\
f. completion of programme & 11 & 2 & 2 \\
g. recommendations/interventions & & & \\
h. compliance to recommendations & 10 & 2 & 3 \\
The intervention as evaluated by participants & 14 & 1 & 0 \\
and visitors & & & \\
i. opinion participants & & & \\
j. opinion home visitors & & & \\
\hline
\end{tabular}




\section{Discussion}

The present review demonstrates that there is a serious lack of information on the intervention process in trials which evaluate the effects of preventive home visits to elderly people living in the community. Most trials presented a rather general and incomplete description of the intervention process. Important process factors such as the absence or presence of protocol deviations, completion of the programme, and compliance to the interventions were hardly reported. In addition, the subjective evaluation of the intervention process by participants and home visitors was not reported in the majority of trials.

Although we only assessed trials in the field of preventive home visits, it seems likely that a lack of information on the intervention process can also be observed in many other domains. Why does the evaluation of the intervention process of trials receive so little attention? One possible explanation is that many journals restrict the length of research articles. This often means that only limited space is available for the description of the intervention process. We have the impression that renowned international journals are not interested in publishing detailed reports of the intervention processes of trials. As such, these reports may remain unpublished or published as a separate paper in non-indexed journals, or other media less accessible to readers (e.g. nonEnglish journals and internal research reports).

Another possible explanation is that detailed process evaluations are simply not performed, owing to the qualitative and time-consuming nature of these evaluations. Also, the absence of measurement instruments for evaluating (aspects of) the intervention process probably discourages researchers from performing a detailed process evaluation. Furthermore, researchers may not be interested in gathering and reporting process data because they expect to receive less credits from a paper describing the process of the intervention, than for example from a paper describing its clinical effects.

Another important factor may be that no internationally accepted guidelines exist for reporting information on intervention processes. In the most recent version of the checklist of the "Consolidated Standards of Reporting Trials" (CONSORT), developed in order to help authors improve the reporting of randomised controlled trials, only two of the 22 items (partly) refer to aspects of the intervention process ${ }^{35}$. One of these two items (item 4) recommends reporting precise details of the interventions intended for each group and how and when they were actually administered, the other (item 13) recommends reporting a specification of the number of people receiving the intended treatment, and describing protocol deviations from the study as planned, together with the reasons. These two items do not seem to offer sufficient structure for guaranteeing a detailed and systematic description of the intervention process. 
How can the provision of information on the intervention process of field experiments be improved? In order to encourage researchers to gather, analyse and describe data on the intervention processes and to report it in a structured way, we consider it important to develop specific guidelines for describing the intervention process of randomised controlled trials. Such guidelines should preferably be developed by an international consortium such as the CONSORT-group and might function as a supplement to or elaboration of the current CONSORT checklist. Such guidelines should include specific instructions on the aspects of the intervention process that need to be reported, and the required level of detail. In developing these guidelines, it is important to make a clear distinction between aspects of the intervention as planned and aspects of the intervention as implemented, whilst it is at least as important to know how an intervention is actually implemented as to know how it was planned. This review shows a tendency amongst researchers for reporting how the intervention was planned, but not how it was actually implemented. In addition, it seems important that measurement instruments for the assessment of the quality of the intervention process are developed and standardised where possible.

Journals will probably not reconsider the limitations with regard to the length of research papers. Instead authors might be given the opportunity of publishing information about the intervention process on the journals' website, with the main clinical outcomes (including a summary of the process evaluation), appearing in the journal itself. Another option may be to encourage researchers to publish the results of process evaluations in more practiceoriented (indexed) journals, while summarising these results in the "main paper" in which the outcomes of the intervention are presented.

\section{References}

1. van Haastregt JCM, Diederiks JPM, van Rossum E, de Witte LP, Crebolder HFJM. Effects of preventive home visits to elderly people living in the community: systematic review. Br Med J 2000;320:754-8.

2. Carpenter GI, Demopoulos GR. Screening the elderly in the community: controlled trial of dependency surveillance using a questionnaire administered by volunteers. Br Med J 1990;300:1253-6.

3. Fabacher D, Josephson K, Pietruszka F, Linderborn K, Morley JE, Rubenstein LZ. An in-home preventive assessment program for independent older adults: a randomized controlled trial. J Am Geriatr Soc 1994;42:630-8.

4. Hall N, De Beck P, Johnson D, Mackinnon K, Gutman G, Glick N. Randomized trial of a health promotion program for frail elders. Can J Aging 1992;11:72-91.

5. Hendriksen $C$, Lund $E$, Stromgard $E$. Consequences of assessment and intervention among elderly people: a three year randomised controlled trial. Br Med J 1984;289:1522-4.

6. Luker KA. Health visiting and the elderly. Nurs Times 1981:77:137-40.

7. McEwan RT, Davison N, Forster DP, Pearson P, Stirling E. Screening elderly people in primary care: a randomized controlled trial. Br J Gen Pract 1990;40:94-7.

8. Pathy MSJ, Bayer A, Harding K, Dibble A. Randomised trial of case finding and surveillance of elderly people at home. Lancet 1992;340:890-3.

9. van Rossum E, Frederiks C.M.A., Philipsen H, Portengen K, Wiskerke J, Knipschild P. Effects of preventive home visits to elderly people. Br Med J 1993;307:27-32. 
10. Sorensen $\mathrm{KH}$, Sivertsen J. Follow-up three years after intervention to relieve unmet medical and social needs of old people. Compr Gerontol B 1988;2:85-91.

11. Stuck AE, Aronow HU, Steiner A, Alessi CA, Bula CJ, Gold MN, et al. A trial of annual in-home comprehensive geriatric assessments for elderly people living in the community. N Engl J Med 1995;333:1184-9.

12. Tinetti ME, Baker DI, McAvay G, Claus EB, Garrett P, Gottschalk M, et al. A multifactorial intervention to reduce the risk of falling among elderly people living in the community. $N$ Engl J Med 1994;331:821-7.

13. Vetter NJ, Jones DA, Victor CR. Effect of health visitors working with elderly patients in general practice: a randomised controlled trial. Br Med J 1984;288:369-72.

14. Vetter NJ, Lewis PA, Ford D. Can health visitors prevent fractures in elderly people? Br Med J 1992:304:888-90.

15. Wagner EH, LaCroix AZ, Grothaus L, Leveille SG, Hecht JA, Arta K, et al.. Preventing disability and falls in older adults: a population-based randomized trial. Am J Public Health $1994 ; 84: 1800-6$.

16. Hendriksen C, Lund E, Stromgard E. Hospitalization of elderly people: a 3 year controlled trial. J Am Geriatr Soc 1989;37:117-22.

17. Hendriksen C. An intervention study among elderly people: methodological and practical experiences. Scand J Prim Health Care 1986;4:39-42.

18. Hendriksen C, Lund E, Stromgard E. Use of social and health services by elderly people during the terminal 18 months of life. Scan J Soc Med 1987;3:169-74.

19. Luker KA. Goal attainment: a possible model for assessing the role of the health visitor. Nurs Times 1978;74:1257-9.

20. Luker KA. Measuring life satisfaction in an elderly female population. J Adv Nurs 1997;4:50311.

21. Luker K, Elderly women's opinions about the benefits of health visitor visits. Nurs Times 1981;77:suppl 9:33-5.

22. van Rossum E, Frederiks C, Philipsen H, Kil-van Lierop J, Mantel A, Portengen J, Knipschild P. Design of a Dutch study to test preventive home visits to the elderly. Nurs Res 1991;40:185-8.

23. Sorensen KH, Sivertsen J, Schroll M, Gjorup S. A socio-medical population study of the elderly in the city of Copenhagen 1978/79: General presentation and methodological aspects. Dan Med Bull 1982;29:274-80.

24. Sorensen KH, Pedersen HD. Quality of life in old age: a population study of elderly in Copenhagen. Compr Gerontol B 1988;2:31-5.

25. Rubenstein LZ, Aronow HU, Schloe M, Steiner A, Alessi CA, Yuhas KE, et al. A home-based geriatric assessment, follow-up and health promotion program: design, methods, and baseline findings from a 3-year randomized clinical trial. Aging Clin Exp Res 1994;6:105-20.

26. Büla CJ, Alessi CA, Aronow HU, Yuhas K, Gold M, Nisenbaum R, et al. Community physicians' cooperation with a program of in-home comprehensive geriatric assessment. J Am Geriatr Soc 1995; 43:1016-20.

27. Alessi CA, Stuck AE, Aronow HU, Yuhas KE, Bula CJ, Madison R. The process of care in preventive in-home comprehensive geriatric assessment. J Am Geriatr Soc 1997;45:1044-50.

28. Cho CY, Alessi CA, Cho M, Aronow HU, Stuck AE, Rubenstein LZ, Beck JC. The association between chronic illness and functional change among participants in a comprehensive geriatric assessment program. J Am Geriatr Soc 1998;46:677-82.

29. Bula CJ, Clerc Berod A, Stuck AE, Alessi CA, Aronow HU, Santos-Eggimann B, et al. Effectiveness of preventive in-home geriatric assessment in well functioning communitydwelling older people:secondary analysis of a randomised trial. J Am Geriatr Soc 1999;47:389-95.

30. Buchner DM, Hornbrook MC, Kutner NG, Tinetti ME, Ory MG, Mulrow CD, et al. Development of the common data base for the FICSIT trials. J Am Geriatr Soc 1993:41:297-308.

31. Tinetti ME, Baker DI, Garret PA, Gottschalk M. Koch ML, Horwitz RI. Yale Ficsit: risk factor abatement strategy for fall prevention. J Am Geriatr Soc 1993;41:315-20.

32. Koch M, Gottschalk M, Baker DI, Palumbo S, Tinetti ME. An impairment and disability assessment and treatment protocol for community-living elderly persons. Phys Ther 1994;74:28698. 
33. Rizzo JA, Baker DI, McAvay G, Tinetti ME. The cost-effectiveness of a multifactorial targeted prevention program for falls among community elderly persons. Med Care 1996;34:954-69.

34. Tinetti ME, McAvay G, Claus E. Does multiple risk factor reduction explain the reduction in fall rate in the Yale Fiscit trial. Am J Epidemiol 1996;144:389-99.

35. Moher D, Schulz KF, Altman DG, for the CONSORT Group. The CONSORT statement: revised recommendations for improving the quality of reports of parallel-group randomised trials. Lancet 2001;357:1191-4. 


\section{Appendix I: Criteria for assessing information provided on the intervention process}

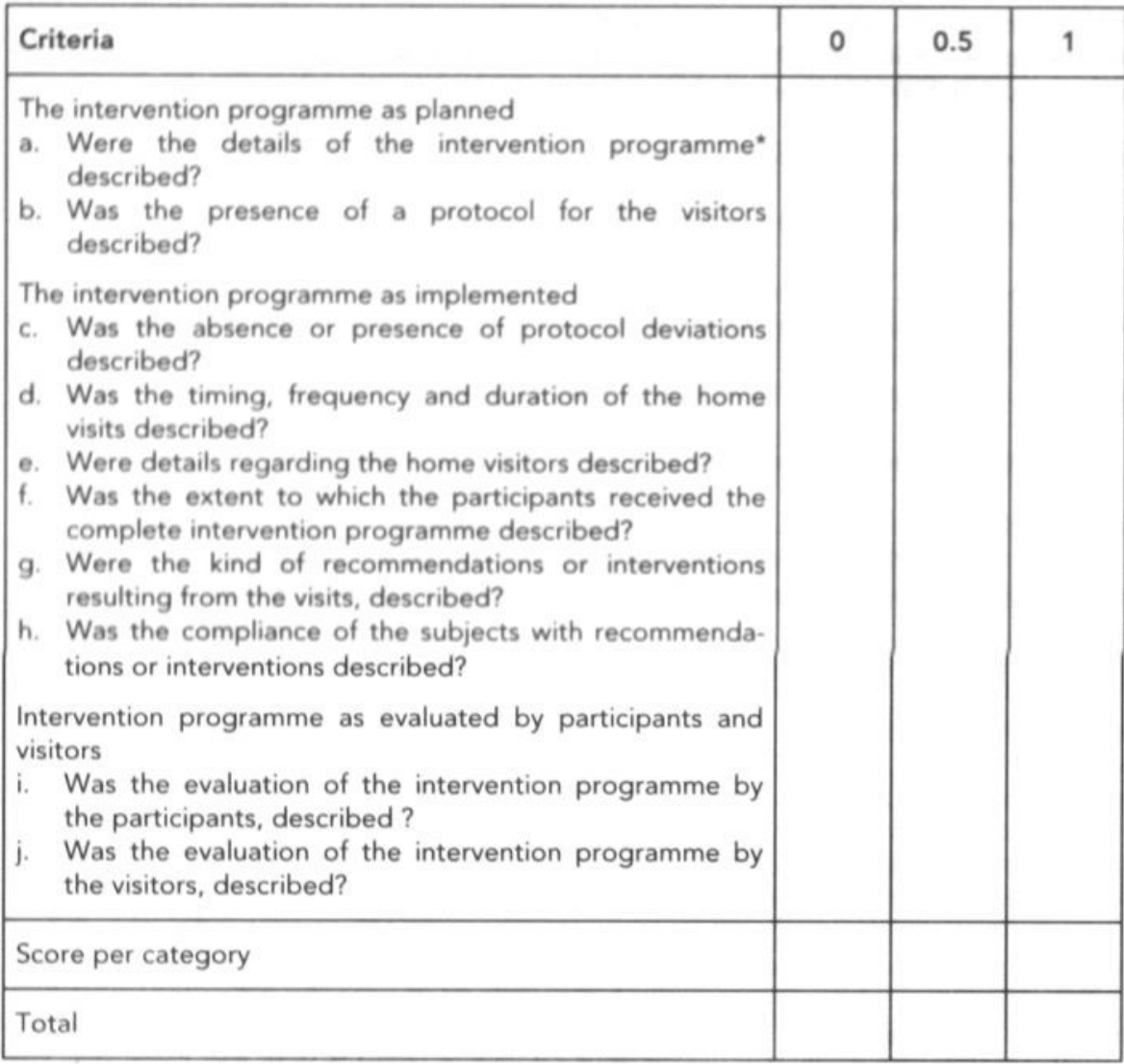

$0.0=$ no description

0.5 - general description

1.0 - detailed description

\section{Operationalisation of the criteria}

The intervention programme as planned

a. Were the details of the intervention programme described?

$0.5=$ Only a general description of the intervention programme was provided.

$1.0=$ The different components of the intervention programme were described in detail, with reference to the methods and instruments used.

b. Was the presence of a protocol for the visitors described?

$0.5=$ The presence of a protocol for the home visitors was mentioned.

$1.0=$ A description of the form and contents of the protocol is provided, referring to how the different components of the intervention programme were performed. 
The intervention programme as implemented

c. Was the absence or presence of protocol deviations described?

$0.5=$ The absence or presence of protocol deviations is described in general terms.

1.0 - The absence or presence of protocol deviations is described in specific terms, referring to systematically gathered information during the intervention period.

d. Was the timing, frequency and duration of the home visits described?

$0.5=$ Only a general description of timing, frequency and duration.

1.0 = At least the period between visits, mean number of home visits per participant and mean duration of home visits were described (or can be derived from numbers presented in the text).

e. Were details regarding the home visitors described?

$0.5=$ Only a general description of the visitors is provided (i.e. nurse, general practitioner, volunteer, etc.).

$1.0=$ In addition to this general description, at least the following details were provided: the number of different visitors performing the visits, the fact whether participants receive visits from one visitor or different visitors, and one or more background details on the visitors (like educational background, specialism, work experience, etc.).

f. Was the extent to which participants received the complete intervention programme described?

$0.5=$ Only the number of persons receiving the complete intervention programme were described.

$1.0=$ In addition to the number of persons receiving the complete intervention, reasons for not receiving the complete intervention programme were presented.

g. Were the kind of recommendations or interventions that resulted from the visits described?

$0.5=$ Only a general description of the recommendations and interventions.

$1.0=$ A detailed description of recommendations and interventions including nature and frequencies of recommendations and other interventions.

h. Was the compliance of the subjects to recommendations or interventions of the visitors described?

$0.5=$ Only a general description of compliance (such as good, moderate, bad).

$1.0=$ A detailed description of compliance with recommendations and interventions was described, based on prospectively gathered data.

Subjective evaluation of the intervention programme

i. Was the subjective evaluation of the intervention programme of the participants described?

$0.5=$ Only a general description of the subjective evaluation was described.

$1.0=$ A specific description of the subjective evaluation of the intervention was described, based on systematically gathered data among the participants.

j. Was the subjective evaluation of the intervention programme of the visitors described?

$0.5=$ Only a general description of the subjective evaluation was described

$1.0=$ A specific description of the subjective evaluation was described, based on systematically gathered data among the subjects. 



\section{Introduction}

The study described in this thesis consists of the following five elements:

- Systematic review of randomised controlled trials examining the effects of preventive home visits in elderly people living in the community.

- Evaluation of the effects of a multifactorial home visit programme on falls and mobility impairments in elderly people living in the community.

- Evaluation of the cost-effectiveness of this home visit programme.

- Evaluation of the intervention process of this home visit programme.

- Systematic review of the information provided on the intervention process in randomised controlled trials in the field of preventive home visits.

Before the start of the study we expected that our multifactorial home visit programme would prevent falls and reduce mobility impairments among elderly people, when compared to usual care. With regard to the economical effects of our intervention we expected that the costs of health care utilisation of people receiving the home visits would not differ from those of people receiving usual care. In addition we expected the intervention programme to be feasible for both nurses and participants.

This chapter starts with an overview of the main results of the study. Then we discuss some methodological and theoretical issues regarding the study. Finally, the conclusions of the study and recommendations for health care practice and further research are presented.

\section{Main results}

The systematic review of the effectiveness of preventive home visit programmes to elderly people (chapter 2), showed that statistically significant favourable effects of preventive home visits were observed in 5 out of 12 randomised controlled trials measuring physical functioning, 1 out of 8 measuring psychosocial function, 2 out of 6 measuring falls, 2 out of 7 measuring admissions to institutional care, and 3 out of 13 measuring mortality. None of the 15 included trials reported negative effects of the home visits. There were relatively large differences in the methodological quality of the included trials. Overall, however, the methodological quality of the trials was considered to be adequate.

The effect evaluation presented in chapter 4 showed that our multifactorial home visit programme had no favourable effects on falls and mobility impairments of the participants after 12 and 18 months of follow-up. These findings were in contrast with our expectations. With regard to the secondary outcome measures, favourable effects were observed for fear of falling and daily activities after 12 months of follow-up. These effects diminished after 18 months of follow-up. No favourable effects were observed for the other secondary outcome measures (physical complaints, mental health, social functioning, perceived health, perceived gait problems, and loneliness) after 12 and 18 months of follow-up. 
The cost-effectiveness analysis presented in chapter 5 revealed that the mean total direct health care costs per person in the usual care group exceeded those of the home visit group with 608 Euro over a period of 18 months. These direct health care costs consisted of costs of the home visit programme, hospitalisation, visits to medical specialists, general practitioners, and physiotherapists, professional home care, medical aids, and medication. Costs of the home visit programme were on average 287 Euro per person per year. The difference in total direct health care costs between the usual care and home visit group was not statistically significant.

The evaluation of the intervention process presented in chapter 6 showed that the home visits were largely performed according to protocol. The majority of the participants and nurses had a favourable judgement about the visits. With regard to the topics discussed during the visits it was observed that health related risk factors, such as gait disorders and locomotor problems were important topics according to the nurses. In addition, the nurses reported that psychosocial problems attracted relatively much attention during the visits. On average the nurses made three recommendations to each participant regarding preventive actions. Overall, the participants complied with $46 \%$ of these recommendations.

The following factors may have hampered the effectiveness of the programme: psychosocial problems of the participants attracted relatively much attention during the home visits, possibly at the expense of other relevant topics; the nurses provided only a limited number of recommendations to the participants; compliance with these recommendations was reasonable, but not optimal. Positive aspects of the home visits may be the intermediary function of the nurse, the provision of practical recommendations and support to the participants, the detection of previously untreated problems, and the fact that the repeated visits give the nurse the opportunity to build a trusting relationship with the participant, which may improve the compliance of participants with recommendations.

The systematic review of the availability of information about the intervention process in 15 trials examining the effects of preventive home visits (chapter 7) revealed that more than half of the included trials did not describe the absence or presence of protocol deviations, the completion of the intervention programme, compliance to recommendations/interventions, and the opinion of the participants and home visitors about the programme. The information provided about other aspects of the intervention process was in most cases very general.

\section{Methodological and theoretical considerations}

Below we discuss a number of methodological and theoretical issues regarding the study presented in this thesis. First, we discuss the methodology of our randomised controlled trial and possible explanations for the fact that our 
home visit intervention did not have the expected favourable effects on falls and mobility impairments. Next we discuss the methodology of the two systematic reviews.

\section{The randomised controlled trial}

\section{Selection of study population}

We selected a group of elderly people at risk for falls or with moderate mobility impairments for participation in our trial. Two questions may be posed with regard to this choice: 1 ) Is the choice for a group of elderly people at risk a good one? and 2) Did we indeed select people with an increased risk for falls or moderate mobility impairments?

With regard to the first question it can be concluded that at present there is a considerable lack of clarity with regard to the population home visit programmes should be aimed at. We based our choice for people at risk on studies that suggested that these home visit programmes should preferably be aimed at elderly people at risk ${ }^{1,2}$. Recent studies of Büla et $\mathrm{al}^{3}$ and Stuck et $\mathrm{al}^{4}$, however, point in the opposite direction. The study of Büla et $\mathrm{al}^{3}$ revealed that preventive home visits delay the onset of disability in people without initial impairments in basic activities of daily living (BADL), but not among those with initial BADL-impairment. Stuck et $\mathrm{al}^{4}$ concluded that home visits for disability prevention in community-living elderly people can reduce disability among elderly people at low risk but not among those at high risk for nursing home admission. In contrast with these two latter studies a recent study of Close et $\mathrm{al}^{5}$ revealed that a medical and occupational therapy intervention (performed partly at home) showed convincing effects on the number of falls among people who had sustained an injurious fall (which can be considered as a high risk group for further falls).

The fact that different researchers report conflicting conclusions about the most suitable target populations of home visit programmes, indicates that the effectiveness of home visits for a specific population is hard to predict and seems to depend on many factors, such as the specific characteristics of the programme, the outcomes which one aims to influence with the intervention, the health care system in the study setting, and underlying characteristics of the participants (compliance, self-efficacy, etceteras). So the question whether our choice of a risk group is a good one remains unanswered. The choice of the optimal target population(s) in home visit programmes and other preventive programmes among community-living elderly people therefore needs further study.

The question whether we have indeed selected the people that we wanted to select (i.e. people at increased risk for falls or moderately mobility impaired), is easier to answer. We selected elderly people who had experienced at least two falls in the previous six months, and/or persons who scored three or more on the mobility control scale of the short version of the Sickness Impact Profile 
(SIP68) ${ }^{6,7}$. When we compare the fall rate of our study population, with the fall rate in the general population of elderly people, it is obvious that we have selected a group of people with a higher risk for falls. On average, $47 \%$ of the persons participating in the first twelve months of our study fell at least once. This is considerably higher than the percentages of fallers reported in the general population of those aged 70 and over (approximately 30 to $35 \%$ ). With regard to mobility impairment the average score on the mobility control scale of the SIP68 at baseline was 6, while in the total population of nearly 900 elderly people $(70+)$ which we had screened before our trial, this score was 3.5 . This indicates that we have selected a group of elderly people for our trial with substantially more mobility impairments than the general population of community-living elderly people.

In addition, a previous study among people with a chronic disease (mean age 57) revealed that persons with chronic diseases such as rheumatoid arthritis, ankylosing spondilitis, and osteoporosis had a mean score of 4.0 on the mobility control scale of the SIP68 7 . So also when compared with persons with a chronic disease, our population seems to be indeed mobility impaired.

\section{Drop out}

After 18 months of follow-up $26 \%$ of the participants had dropped out of the study. Drop out rates and reasons for drop out were comparable in the home visit and usual care group. Drop out analysis showed that especially persons at relatively high risk for falls and with more mobility impairments dropped out of the study. As reported in chapter 4 we therefore performed subgroup analysis among a selected group of people with the highest baseline scores for falls and mobility impairment. The results in this subgroup analysis were comparable to our findings in the total group: no difference in falls and mobility impairment was observed between persons receiving home visits and persons receiving usual care. This indicates that it is unlikely that selective drop out biased the results of our trial.

\section{Outcome measurement}

The question can be posed whether we used the appropriate measurement instruments to measure falls and mobility impairments. We used a fall diary to assess the percentage of people sustaining one or more falls. A fall diary is a commonly used method for measuring falls. The strong advantage of a diary is that falls are registered continuously, which minimises the risk of recall bias. The percentage of injurious falls and falls needing medical attention were measured retrospectively by means of a self administered questionnaire (after 12 and 18 months of follow-up). With regard to these two outcomes it can not be excluded that recall bias has occurred. However one may expect that these more serious falls are unlikely to be forgotten by the participants.

The mobility control and mobility range scales of the SIP $68^{6,7}$ were chosen because they are valid and reliable scales, and relatively easy to administer. They measure those aspects of mobility that we aimed to measure and 
intervene on: problems in control over whole body movements and difficulties in executing mobility activities.

The fact that both the questionnaire and diary were self-administered instruments is unlikely to have led to substantial selective drop out of those people not able to administer the questionnaires, because persons who had problems with administering the questionnaires and/or diaries were offered assistance. The persons who gave this assistance were not aware of group assignment. Not being able to administer the questionnaires or diaries was not reported to be a reason for drop out by the participants. A study of van Rossum et al' $^{\prime}$ in which results obtained from personal interviews among community-living elderly people were compared with results obtained from self-administered questionnaires, indicates that self-administered questionnaires seem an acceptable alternative to personal interviews among community-living elderly people.

\section{Confounding and intervening factors}

One of the possible explanations for the absence of effects of the home visits on falls may be that positive effects on daily activities and fear of falling after 12 months of follow-up increased the risk of falling in the home visit group. Such a mechanism of an increased fall rate owing to an increased activity level has been reported in a trial by Rubenstein et $\mathrm{al}^{8}$. In order to adjust for this mechanism we repeated our analysis on falls and recurrent falls after 12 and 18 months of follow-up, while adjusting for activity levels and fear of falling at follow-up. The results of these analyses were comparable to those of the original analyses, indicating that the increased level of activity and decreased level of fear of falling can not explain the absence of favourable effects on falls.

\section{Intervention}

The intervention programme consisted of five home visits by a community nurse, over a period of one year. Visits consisted of screening for medical, functional, psychosocial, and environmental factors causing falls and mobility impairments, followed by specific recommendations, referrals and other actions aimed at the observed hazards and problems.

The nurses followed a structured protocol for the home visits, focusing on falls, mobility, fear of falling, physical health, medication, activities of daily living, social functioning, and psychological/cognitive functioning. Process evaluation revealed that the home visits were largely performed according to protocol.

The protocol for the home visits allowed the nurses some degree of freedom in choosing the topics to be discussed during the visits. The amount of attention paid to a specific topic also depended on the needs of the participants. When a participant, for example, wanted to discuss specific emotional problems, this was possible, provided that the other topics scheduled for that visit were also discussed. Process evaluation revealed that there was a clear need among participants to discuss psychosocial problems such as loneliness, conflicts with 
important others, grief about the loss of an important other, and feelings of fear. This need of the participants resulted in a relatively large portion of the visits spent on discussing these topics. This attention may have gone at the expense of attention to topics that are more strongly related to falls and mobility impairments.

In addition, according to the registration of the nurses, on average only three recommendations were made to the participants (such as home adjustments, referral to general practitioners, and the use of aids and devices). Compared to a study of Stuck et $\mathrm{al}^{9,10}$, this number of three recommendations seems to be relatively low. Stuck et $\mathrm{al}^{9,10}$ reported that the nurses in their home visit programme on average provided 11.5 recommendations per year divided over 3 to 4 visits. Obviously this large difference in the number of recommendations may be related to differences in the way the nurses registered them, and differences in the definition of a recommendation in both studies. The higher rate of recommendations registered in the study of Stuck et $\mathrm{al}^{9.10}$ may also be caused by the fact that in their study the nurse formulated the recommendations in consultation with a geriatrician. It is possible that these consultations resulted in more and better recommendations than was the case in our programme in which the nurse formulated the recommendations without standard consultation of a geriatrician or general practitioner. However, the nurses in our study used the weekly team-meetings to ask general practitioners and other colleagues for advice about recommendations they should give to specific participants.

Another factor that may have influenced the effectiveness of the intervention programme is the reluctance of participants to take measures to prevent falls. Most participants did not seem to regard themselves to be at serious risk for falls and may therefore have decided not to comply to (part of) the recommendations. This observation is in accordance with the results of a study by Braun". She reported that community-living elderly participants considered falls to be preventable and were aware of the importance of fall-related risk factors, but they did not consider themselves to be susceptible to falling. Those persons who did consider falls to be an important health care concern attributed higher levels of importance to nearly all personal fall-related risk factors, particularly exterior environmental factors and physical factors, compared to participants who did not consider falls to be an important health concern. Braun stated that fall prevention programs may benefit from inclusion of methods to enhance understanding of personal susceptibility to fall-related risk factors ${ }^{11}$.

In addition, low levels of self-efficacy with regard to undertaking specific actions recommended by the nurses may also have influenced the effectiveness of the home visits especially among frail elderly people with limited social networks. Although we instructed the nurses to always assess possible barriers 
to comply to recommendations, we did not assess whether this had the desired effects on self-efficacy of the participants.

\section{The systematic reviews}

\section{Effectiveness of preventive home visit programmes}

The main conclusion of our first systematic review was that there is a lack of convincing evidence in favour of the effects of preventive home visits on physical function, psychosocial function, falls, admissions to institutions, and mortality. This is partly in contrast with the conclusion of a recent meta-analysis performed by Elkan et $\mathrm{al}^{12}$. They concluded that home visits to elderly people reduce mortality and admission to long term institutional care. No significant favourable effects were found for hospital admissions, health status, and daily functioning.

There are several explanations possible for the fact that our findings with regard to mortality and admissions to institutional care differed from those of Elkan et $\mathrm{al}^{12}$. One possible explanation is that their study included 15 studies, of which only $9^{1,9,13 \cdot 19}$ overlapped with the 15 studies included in our review. This difference in included studies was a consequence of differences in selection criteria. In the study of Elkan et al ${ }^{12}$ also non-randomised studies were included, the intervention had to be focussed on a wide range of preventive outcomes, and the intervention had to be performed by nurses specialised in health visiting (not by volunteers or other professional disciplines).

Another, more likely, explanation for the difference in conclusions between our review and that of Elkan et $\mathrm{al}^{12}$, is that they performed meta-analyses while we did not. In our opinion, statistically pooling of data is inappropriate because there are considerable differences between characteristics of the home visit programmes, participants, outcome measures, timing of outcome measurements and health care settings. Another concern with regard to meta-analysis is that even very small effects may turn out to be statistically significant when the size of the pooled sample is large. Statistical significance is obviously not identical to clinical significance. Elkan et $\mathrm{al}^{12}$ do not discuss the clinical significance of their findings regarding mortality and admission to long-term institutional care. They also do not discuss the fact that none of the included studies had the reduction of mortality as the primary goal. The rationale behind the supposed favourable effects of home visits on mortality and long term institutional care therefore remains unclear. Based on the considerations described above, the meta-analysis of Elkan et $\mathrm{al}^{12}$ did not convince us that home visits have a favourable effect on mortality and admissions to long-term institutional care. We therefore do not change the conclusion based on our review.

Because our review covered the period between 1966 and March 1999, we searched the literature for new trials published after March 1999. Three 
additional trials were found. Stuck et $\mathrm{al}^{4}$ performed a study in Switzerland revealing that after 3 years of home visits, participants at low baseline risk for nursing home admission, were less dependent in instrumental activities of daily living (ADL) compared to control persons. Among subjects at high baseline risk for nursing home admission, there were no favourable intervention effects on $\mathrm{ADL}$ and an unfavourable increase in nursing home admissions. A Canadian study of Hébert et $\mathrm{al}^{20}$ revealed that preventive home visits by a nurse had no favourable effects on functional decline, functional autonomy, well-being, perceived social support and use of health care services among elderly people at risk for functional decline. Another Canadian study of Dalby et $\mathrm{al}^{21}$ among frail elderly people living in the community revealed that the home visits had no favourable effects on mortality, admissions to institutional care and the rate of health service utilisation after 14 months of follow-up. The results of these three recently published trials, which were also not included in the review of Elkan et al ${ }^{12}$ confirm our conclusion about the lack of convincing evidence in favour of the effectiveness of preventive home visits among elderly people.

\section{Lack of information on the intervention process}

One of the aims of our second systematic review was to give an indication of the magnitude of underreporting of information on the intervention process in randomised controlled trials. For pragmatic reasons we chose to review trials in the field of preventive home visits. Obviously this is only one of the many domains of study that could have been chosen for this purpose. Still we expect that the lack of information provided on the intervention process in preventive home visit trials is exemplary for a wide range of other field experiments. However, additional reviews for other study domains are needed to confirm this assumption.

\section{Conclusions and recommendations}

\section{Conclusions}

We have drawn the following conclusions with regard to the effectiveness and feasibility of our home visit programme and that of preventive home visit programmes in general.

- Our multifactorial home visit programme aimed at reducing falls and mobility impairments in elderly people at risk is not effective in the Dutch health care setting. This may probably also apply to comparable health care settings in other western European countries.

- The direct health care costs of the people receiving the home visit programme were lower than those for people receiving usual care. This difference was not statistically significant. It remains unclear whether this difference in costs may be attributed to the intervention programme or to chance, because of the low power of the cost-effectiveness analysis. Based on the absence of favourable effects of the home visit programme on falls 
and mobility, and based on the absence of clear favourable effects on costs, we conclude that our home visit programme is not cost-effective.

- Based on the results of the process evaluation, we conclude that the home visit programme was feasible for nurses and participants and that the visits were implemented according to protocol. Despite this we consider our one-year multifactorial home visit programme to be an unsuitable intervention technique to reduce falls and mobility impairments among elderly people at risk.

- Based on a systematic review of the results of 15 trials studying the effects of preventive home visits, combined with the results of 4 recent trials $\mathbf{s}^{4,20,21}$ not included in this review (including our own trial) it can be concluded that there is no clear evidence in favour of the effectiveness of preventive home visits on a variety of health outcomes among elderly people living in the community.

- There is a serious lack of information provided on the intervention process in home visiting trials. We consider it important that specific guidelines for describing the intervention process of randomised controlled trials are developed. Such guidelines should preferably be developed by an international consortium such as the CONSORT-group and could function as a supplement to or elaboration of the existing CONSORT-checklist for the report of randomised controlled trials.

\section{Recommendations for health care practice and further research}

\section{Preventive home visits to prevent falls and mobility impairments}

The results of our randomised controlled trial show that there are no convincing arguments in favour of adding our multifactorial home visit programme to regular health care. Alternative strategies to prevent falls and mobility impairments among elderly people living in the community should be developed and tested. In this regard the results of a recent trial of Close et $\mathrm{al}^{5}$ are promising. This trial shows that a detailed medical and occupational-therapy assessment with referral to relevant services was effective among a group of elderly people who attended the accident and emergency department of a hospital with a primary diagnosis of a fall. This intervention substantially reduced the number of (recurrent) falls and functional impairments. One of the factors which may explain the success of this programme is the fact that the target population of this intervention is likely to be motivated to take preventive measures, because they recently experienced the negative consequences of a fall.

In addition, the effects of some exercise programmes seem promising. In this regard we like to refer to a trial of Wolf et $\mathrm{a}^{22}$ in which the effects of a 15 week Tai Chi intervention was tested, and a trial of Robertson et al ${ }^{23}$ in which a nurse delivered home exercise programme was tested. Implementing and thoroughly evaluating these intervention programmes in other health care setting may be considered. 


\section{Preventive home visits in general}

Based on the conflicting results of 19 trials $1.24,9,13.21$ in the domain of preventive home visit programmes we conclude that there are no convincing arguments in favour of adding preventive home visit programmes to regular health care. For countries in which preventive home visits are already part of regular health care (United Kingdom and Denmark), it seems essential that the intervention process and effectiveness of these programmes are critically (re-)assessed.

Despite the lack of convincing effects of preventive home visit programmes in general, some individual home visit programmes have shown promising results, and most programmes seem to have some strong elements. Our process evaluation revealed that the following elements may positively influence the effectiveness of preventive home visit programmes: the nurse can provide emotional support to the participants (which seems to be a clear need of the participants); the nurse can function as an intermediary between participants and other professional caregivers; the nurse can detect previously untreated problems; and a trusting relationship between nurse and participant may improve compliance to recommendations. It seems important to explore the opportunities to optimally use the potentially favourable elements of preventive home visits and to diminish the influence of potentially hampering factors. In this regard it is in our opinion important that researchers and health professionals in the domain of preventive home visits exchange their knowledge and practical experiences. An international working group of researchers and health professional could facilitate this exchange. Such a working group should address a number of questions based on the existing lack of clarity in the domain of preventive home visits. The following topics may be relevant in this regard:

- The evidence with regard to the effectiveness of preventive home visits among specific risk groups is conflicting. There are both indications that home visit are more successful among elderly people at high risk, as among people at low risk for health problems or functional decline. More insight is needed into which target populations are most suitable for preventive home visits. Besides health related characteristics, in this regard also motivational aspects and factors related to compliance and self-efficacy of potential participants seem to be important.

- More insight is needed into the outcomes that may be improved by preventive home visits. Preventive home visits are often used to influence a variety of medical, functional, and psychosocial outcomes. Obviously, preventive home visits can not improve al these outcomes with the same level of success.

- A systematic qualitative inventory of practical experiences of health care professionals in different settings and countries with preventive home visits, may add to a better understanding of factors hampering and improving the effectiveness of home visit programmes. Such a qualitative review of intervention processes and protocols in different settings should provide more 
insight into the effective components of home visits. This inventory should also include the characteristics of the people who perform the visits.

- The factors that influence compliance to preventive interventions among elderly people living in the community should be thoroughly explored.

We recommend that researchers and health professionals in the domain of preventive home visits reach consensus about the (research) questions that need to be addressed in the future. This should result in a coherent research programme in which these questions are systematically tried to be answered. Trials in the field of preventive home visits should use uniform measurement instruments, and should include an economical evaluation and a detailed process evaluation. Topics that need special attention in the process evaluation are characteristics and intensity of the intervention programme as implemented, the presence and absence of protocol deviations, and compliance of the participants to the intervention. Guidelines for the process evaluation should be developed.

\section{References}

1. van Rossum E, Frederiks C.M.A., Philipsen H, Portengen K, Wiskerke J, Knipschild P. Effects of preventive home visits to elderly people. Br Med J 1993;307:27-32.

2. Tinetti ME, Baker DI, McAvay G, et al. A multifactorial intervention to reduce the risk of falling among elderly people living in the community. N Engl J Med 1994;331:821-827.

3. Büla CJ, Alessi CA, Aronow HU, Yuhas K, Gold M, Nisenbaum R, et al. Community physicians' cooperation with a program of in-home comprehensive geriatric assessment. J Am Geriatr Soc 1995;43:1016-20.

4. Stuck AE, Minder CE, Peter-Wüest I, Gillman G, Egli C, Kesselring A, et al. A randomised trial of in-home visits for disability prevention in community-dwelling older people at low and high risk for nursing home admission. Arch Intern Med 2000;160:977-86.

5. Close J, Ellis M, Hooper R, Glucksman E, Jackson S, Swift C. Prevention of falls in the elderly trial (PROFET): a randomised controlled trial. Lancet 1999;353:93-7.

6. de Bruin AF, Diederiks JPM, de Witte LP, Stevens JA, Philipsen H. The development of a short generic version of the Sickness Impact Profile. J Clin Epidemiol 1994;47:407-18.

7. de Bruin AF, Buys M, de Witte LP, Diederiks JPM. The Sickness Impact Profile:SIP68, a short generic version; First evaluation of the reliability and reproducibility. J Clin Epidemiol 1994; 47:863-871.

8. Rubenstein LZ, Josephson KR, Trueblood PR, Loy S, Harker JO, Pietruszka FM, et al. Effects of a group exercise program on strength, mobility, and falls among fall-prone elderly men. J Gerontol A Biol Sci Med Sci 2000;55:M317-21.

9. Stuck $A E$, Aronow $\mathrm{HU}$, Steiner $\mathrm{A}$, et al. A trial of annual in-home comprehensive geriatric assessments for elderly people living in the community. N Engl J Med 1995;333:1184-1189.

10. Alessi CA, Stuck AE, Aronow HU, Yuhas KE, Bula CJ, Madison R. The process of care in preventive in-home comprehensive geriatric assessment. J Am Geriatr Soc 1997;45:1044-50.

11. Braun BL. Knowledge and perception of fall-related risk factors and fall-reduction techniques among community-dwelling elderly individuals. Phys Ther 1998;78:1262-76.

12. Elkan R, Kendrick D, Dewey M, Hewitt M, Robinson J, Blair M, et al. Effectiveness of home based support for older people: systematic review and meta-analysis. Br Med J 2001;323:1-9.

13. Fabacher D, Josephson K, Pietruszka F, Linderborn K, Morley JE, Rubenstein LZ. An in-home preventive assessment program for independent older adults: a randomized controlled trial. J Am Geriatr Soc 1994;42:630-638.

14. Hall N, De Beck P, Johnson D, Mackinnon K, Gutman G, Glick N. Randomized trial of a health promotion program for frail elders. Can J Aging 1992;11:72-91.

15. Hendriksen C, Lund E, Stromgard E. Consequences of assessment and intervention among elderly people: a three year randomised controlled trial. Br Med J 1984;289:1522-1524. 
16. Luker KA. Health visiting and the elderly. Nursing Times 1981;77:137-140.

17. McEwan RT, Davison N, Forster DP, Pearson P, Stirling E. Screening elderly people in primary care: a randomized controlled trial. Br J Gen Pract 1990;40:94-97.

18. Pathy MSJ, Bayer A, Harding K, Dibble A. Randomised trial of case finding and surveillance of elderly people at home. Lancet 1992;340:890-893.

19. Vetter NJ, Jones DA, Victor CR. Effect of health visitors working with elderly patients in general practice: a randomised controlled trial. Br Med J 1984;288:369-372.

20. Hébert R, Robichaud L, Roy PM, Bravo G, Voyer L. Efficacy of a nurse-led multidimensional preventive programme for older people at risk of functional decline. A randomised controlled trial. Age Ageing 2001;30:147-53.

21. Dalby DM, Sellors JW, Fraser FD, Fraser FD, van Ineveld C, Howard M. Effect of preventive home visits by a nurse on the outcomes of frail elderly people in the community: a randomised controlled trial. CMAJ 2000;162:497-500.

22. Wolf SL, Barnhart HX, Kutner NG, McNeely E, Coogler $C, X_{U} T$. Reducing frailty and falls in older persons: an investigation of Tai Chi and computerized balance training. J Am Geriatr Soc 1993:41:329-32.

23. Robertson MC, Devlin N, Gardner MM, Campbell AJ. Effectiveness and economic evaluation of a nurse delivered home exercise programme to prevent falls. 1: Randomised controlled trial. Br Med J 2001;322:697-701. 

Summary 
Falls and mobility impairments are a major problem among elderly people. Approximately $30 \%$ of the people aged 65 years or over fall at least once a year, about $15 \%$ fall two or more times a year. A Dutch study among people aged 55 years or over revealed that $22 \%$ of community-living men and $36 \%$ of community-living women experienced mobility impairments such as problems with rising from a chair, getting in and out of bed, bending, getting in and out of a car, walking, and climbing stairs.

Mobility impairments and the consequences of falls can have a substantial impact on independent functioning of elderly people and can lead to increased costs of health care utilisation. There is a strong need for effective interventions aimed at the prevention of falls and mobility impairments. Therefore we have developed a multifactorial home visit programme aimed at the reduction of falls and mobility impairments among elderly people living in the community. This home visit programme consists of preventive home visits by a community nurse. The visits were aimed at people aged 70 years or over with moderate impairments in mobility or a history of recent falls.

This thesis reports the results of a randomised controlled trial in which we assessed the effects of this preventive home visit programme.

The main research questions are:

1. What are the effects of a multifactorial home visit programme on falls and mobility impairments among community-living elderly people at risk?

2. What are the effects of this programme on health care utilisation and associated costs?

3. To which extent is the programme feasible according to the persons performing and receiving the intervention?

In chapter 1 we describe the causes, incidence, prevalence and consequences of falls and mobility impairments among elderly people. In addition the research questions of the study are described.

Chapter 2 reports the results of a systematic review of randomised controlled trials assessing the effectiveness of preventive home visits to elderly people living in the community. The aim of this review is to assess whether there is convincing evidence in favour of the effectiveness of preventive home visit programmes. Fifteen trials were included in this review.

Favourable effects of the home visits were observed in 5 out of the 12 trials measuring physical functioning, in 1 out of 8 studies measuring psychosocial function, in 2 out of 6 studies measuring falls, in 2 out of the 7 studies measuring admissions to institutions, and in 3 of the 13 trials measuring mortality. None of the trials reported negative effects. We concluded that there is no clear evidence in favour of the effectiveness of preventive home visits aimed at the general population of elderly people living in the community. 
Chapter 3 describes the contents of our multifactorial home visit programme and the design of the evaluation study. The intervention consists of five preventive home visits performed by a community nurse during a period of approximately one year. During the home visits the participants were screened for medical, environmental and behavioural factors potentially influencing falls and mobility. The screening was followed by recommendations, referrals and other actions aimed at dealing with the hazards observed. The nurses followed a structured protocol for the home visits which focused on falls, mobility, fear of falling, physical health, medication, activities of daily living, social functioning, cognitive functioning and psychological functioning. The protocol also included a checklist for home safety.

The evaluation study accompanying the implementation of the intervention programme study was conducted from September 1997 to June 1999.

Participants were recruited from six general practices in Hoensbroek, the Netherlands, by means of a screening questionnaire. Participants had to be aged 70 years or over, be living in the community, and have reported two or more falls in the previous six months or have scored three or more on the mobility control scale of the short version of the Sickness Impact Profile. People who were bedridden, fully dependent on a wheelchair, terminally ill, on the waiting list for admission to a nursing home, or receiving home care from a community nurse on a regular basis, were excluded. Eligible patients were randomly allocated to either the home visit group $(n=159)$ or usual care group $(n=157)$.

The evaluation study consists of three components: effect evaluation (research question 1), economical evaluation (research question 2), and process evaluation (research question 3). Participants were assessed by means of selfadministered questionnaires before the start of the intervention programme and after 12 and 18 months of follow-up. Falls were recorded continuously by the participants by means of a weekly fall diary, during the 18 months of follow-up. In addition health care utilisation was registered during this period.

Chapter 4 describes the results of the effect evaluation. After 12 and 18 months of follow-up, data of $252(80 \%)$ and 235 persons $(74 \%)$ respectively were available for analysis. No differences were found in falls and mobility outcomes between the home visit and usual care group. In addition no significant effects were observed for the following secondary outcome measures: physical complaints, perceived health, perceived gait problems, mental health, social functioning and loneliness after 12 and 18 months of follow-up. People in the home visit group showed significantly less decline in daily activity and were less afraid to fall than people in the usual care group after 12 months of follow-up. These effects diminished after 18 months of follow-up.

We conclude that a multifactorial home visit programme aimed at reducing falls and mobility impairments in community-living elderly persons at risk, is not effective in the Dutch health care setting. 
In chapter 5 the results of the cost-effectiveness study of our trial are presented. Programme costs and direct health care costs were registered prospectively during 18 months of follow-up (December 1997 till June 1999). The following direct health care costs were considered in this study: costs of the home visit programme, hospitalisation, visits to medical specialists, general practitioners and physiotherapists, professional home care, medical aids and medication.

After 18 months of follow-up, mean total direct health care costs of persons in the usual care group exceeded those of the home visit group with 608 Euro. Costs of the home visit programme were on average 287 Euro per person per year. The differences in costs between the usual care and home visit group were not statistically significant. It remains unclear whether this difference in costs may be attributed to the intervention programme or to chance, owing to the low power of the cost-effectiveness study. Based on the absence of favourable effects of the home visits on falls and mobility impairment, and based on the absence of clear favourable effects on costs, we conclude that our home visit programme is not cost-effective.

In Chapter 6 the results of the process evaluation of our home visit programme are presented. The home visits were performed according to protocol. The majority of the participants had a favourable judgement about the home visits. With regard to the topics discussed during the visits, the nurses reported that health related risk factors, such as gait disorders and locomotor problems were important topics. In addition, the nurses reported that psychosocial problems attracted relatively much attention during the visits. On average the nurses made three recommendations to each participant regarding preventive actions. Overall, the participants complied to $46 \%$ of these recommendations. Strong and weak aspects of the home visits as reported by the nurses, are discussed.

Based on the results of the process evaluation, we conclude that the home visit programme was feasible for nurses and participants and that the visits were implemented according to protocol. Despite this we consider our one-year multifactorial home visit programme to be an unsuitable intervention technique to reduce falls and mobility impairments among elderly people at risk.

Chapter 7 addresses the results of a systematic review into the availability of information on the intervention process in trials examining the effects of preventive home visits. This review revealed that more than half of the 15 included trials did not describe the absence or presence of protocol deviations, the completion of the intervention programme, compliance to recommendations/interventions, and the opinion of the participants and home visitors about the programme. The information that was provided on other aspects of the intervention process was in most cases very general. We conclude that there is a serious lack of information provided on the intervention process of preven- 
tive home visit programmes. We consider it important that specific guidelines for describing the intervention process in randomised controlled trials, are developed.

In Chapter 8 the main results and conclusions of our randomised trial and systematic reviews are presented. In addition a number of methodological and theoretical considerations with regard to the study are discussed. The chapter is concluded with recommendations for health care practice and further research. The most important conclusion of the study presented in this thesis is that there is no convincing evidence in favour of the effectiveness of preventive home visits on falls and mobility impairments. Because falls and mobility impairments remain a serious problem among elderly people, alternative strategies to prevent falls and mobility impairments should be developed and evaluated in different health care settings. 

Samenvatting 
Valpartijen en mobiliteitsbeperkingen komen veel voor bij ouderen. Ongeveer $30 \%$ van de mensen van 65 jaar en ouder valt jaarlijks minstens eenmaal en $15 \%$ valt twee keer of vaker. Van de mensen van 55 jaar en ouder heeft $22 \%$ van de mannen en $36 \%$ van de vrouwen mobiliteitsbeperkingen, zoals moeite met lopen, traplopen, opstaan en bukken.

Mobiliteitsbeperkingen en de gevolgen van valpartijen kunnen een aanzienlijke negatieve invloed hebben op het functioneren van ouderen. Daarnaast kunnen ze het zorggebruik van ouderen doen toenemen. Gezien de omvang van de problemen en kosten die valpartijen en mobiliteitsbeperkingen met zich mee kunnen brengen, is het belangrijk om naar geschikte preventieve maatregelen te zoeken. Om deze reden hebben we een multifactorieel interventieprogramma ontwikkeld, dat specifiek gericht is op het voorkomen van valpartijen en het verminderen van mobiliteitsbeperkingen bij zelfstandig wonende ouderen. Dit interventieprogramma bestaat uit preventieve huisbezoeken uitgevoerd door een wijkverpleegkundige. De huisbezoeken zijn gericht op ouderen $(70+)$ met een verhoogd risico op valpartijen en/of matige mobiliteitsbeperkingen.

In dit proefschrift worden de resultaten gepresenteerd van een studie (randomised controlled trial) waarin de effecten van bovengenoemde interventie zijn onderzocht. De vraagstellingen die we willen beantwoorden zijn:

1) Wat zijn de effecten van preventieve huisbezoeken op valpartijen en mobiliteitsbeperkingen bij zelfstandig wonende ouderen met een verhoogd risico?

2) Wat zijn de effecten van de huisbezoeken op het zorggebruik en de bijbehorende kosten?

3) In hoeverre zijn de huisbezoeken uitvoerbaar voor de verpleegkundigen en acceptabel voor de ouderen?

In hoofdstuk 1 worden de oorzaken, incidentie, prevalentie en gevolgen van valpartijen en mobiliteitsbeperkingen bij ouderen beschreven. Daarnaast worden de belangrijkste vraagstellingen van de studie beschreven.

Hoofdstuk 2 rapporteert over een literatuurstudie (systematic review) naar de effecten van preventieve huisbezoeken op de gezondheid en het functioneren van zelfstandig wonende ouderen. Het doel van deze review is om na te gaan welke bewijzen er zijn voor de effectiviteit van preventieve huisbezoeken in het algemeen. In totaal werden er 15 studies (randomised controlled trials) in de review opgenomen. Positieve effecten van preventieve huisbezoeken werden gerapporteerd in 5 van de 12 studies waarin fysiek functioneren werd gemeten, in 1 van de 8 studies waarin psychosociaal functioneren werd gemeten, in 2 van 6 studies waarin het aantal valpartijen werd gemeten, in 2 van de 7 studies waarin opname in zorginstellingen werden gemeten, en in 3 van de 13 studies waarin het sterftecijfer werd gemeten. Geen van de studies rapporteerden negatieve effecten van de huisbezoeken. De conclusie van deze 
literatuurstudie luidt dat er geen overtuigend bewijs is, dat huisbezoeken, gericht op de algemene populatie zelfstandig wonende ouderen, positieve effecten hebben.

Hoofdstuk 3 beschrijft de inhoud van het door ons ontwikkelde huisbezoekprogramma en de opzet van de bijbehorende evaluatiestudie.

Het programma bestond uit vijf preventieve huisbezoeken uitgevoerd door een wijkverpleegkundige gedurende een periode van een jaar. Tijdens de huisbezoeken werden de deelnemers gescreend op risicofactoren voor valpartijen en mobiliteitsbeperkingen. Op basis van de screening werden preventieve maatregelen genomen en werd indien nodig doorverwezen naar andere zorgverleners. De verpleegkundigen volgden bij het uitvoeren van de huisbezoeken een gestructureerd protocol, dat zich richtte op de volgende factoren: valpartijen, mobiliteit, angst om te vallen, fysieke gezondheid, medicatie, activiteiten van het dagelijks leven, psychosociaal functioneren en cognitief functioneren. In het protocol was tevens een checklist voor veiligheid in de woning opgenomen.

De evaluatiestudie werd uitgevoerd van september 1997 tot juni 1999. Deelnemers aan het onderzoek werden geselecteerd door middel van een screeningsvragenlijst die werd toegestuurd aan in totaal 1310 ouderen verbonden aan een gezondheidscentrum in Hoensbroek. Deelnemers aan het onderzoek moesten minimaal 70 jaar oud zijn, zelfstandig wonen en twee keer gevallen zijn in de voorafgaande zes maanden en/of matig mobiliteitsbeperkt zijn ( $=$ een score van drie of hoger gescoord hebben op de Mobiliteitscontrole schaal van de korte versie van de "Sickness Impact Profile"). Mensen die bedlegerig waren, volledig rolstoelafhankelijk, terminaal, op de wachtlijst voor opname in een verpleeghuis, of die reeds regelmatig thuiszorg ontvingen, werden van deelname uitgesloten. De mensen die aan de insluitingcriteria voldeden werden door het lot toegewezen aan de huisbezoek groep $(n=159)$ of aan de controle groep ( $n=157)$.

De evaluatiestudie bestond uit drie onderdelen: een effectevaluatie (beantwoorden vraagstelling 1), een economische evaluatie (beantwoorden vraagstelling 2 ) en een procesevaluatie (beantwoorden vraagstelling 3 ).

$\mathrm{Er}$ vonden drie metingen plaats bij de deelnemende ouderen: een voormeting en een nameting na 12 en 18 maanden. Daarnaast hielden de deelnemers een valdagboek bij gedurende de totale onderzoeksperiode en werd het zorggebruik van de deelnemers geregistreerd.

In hoofdstuk 4 worden de resultaten gepresenteerd van de effectevaluatie. Bij de nameting na 12 en 18 maanden waren er respectievelijk van $252(80 \%)$ en 235 mensen $(74 \%)$ gegevens beschikbaar. Er bleken bij beide metingen geen significante verschillen te zijn in valpartijen en mobiliteitsbeperkingen tussen de huisbezoek en controlegroep. Tevens bleken er geen significante verschillen tussen de groepen te zijn op de volgende (secundaire) uitkomstmaten: het aantal fysieke klachten, de ervaren gezondheid, ervaren loopproblemen, 
mentale gezondheid, sociaal functioneren en eenzaamheid. Bij de nameting na 12 maanden waren de mensen die de huisbezoeken hadden ontvangen significant actiever en minder bang om te vallen dan de mensen in de controle groep. Na 18 maanden waren deze verschillen verdwenen.

De conclusie luidt dat ons multifactoriele huisbezoekprogramma niet effectief is ter preventie van valpartijen en mobiliteitsbeperkingen bij zelfstandig wonende ouderen met een verhoogd risico.

In hoofdstuk 5 worden de resultaten van de economische evaluatie beschreven. De kosten van het programma en de overige directe kosten van het zorggebruik werden gedurende 18 maanden geregistreerd (december 1997 tot juni 1999). De volgende kosten werden geregistreerd: kosten van het huisbezoekprogramma, ziekenhuisopnames, bezoeken aan medisch specialisten, huisartsen en fysiotherapeuten, professionele thuiszorg, medische hulpmiddelen en medicatie.

$\mathrm{Na} 18$ maanden waren de gemiddelde totale directe kosten van het zorggebruik 608 Euro lager in de huisbezoekgroep dan in de controlegroep. De kosten van het huisbezoekprogramma waren gemiddeld 287 Euro per persoon per jaar. Het verschil in kosten tussen huisbezoek en controlegroep was niet statistisch significant. Door de lage power (kleine aantallen patiënten) blijft het onduidelijk of het verschil toegeschreven kan worden aan de interventie of aan het toeval. Omdat ons huisbezoekprogramma geen positieve effecten had op valpartijen en mobiliteitsbeperkingen en ook geen significant positieve effecten liet zien op het zorggebruik en de bijbehorende kosten, wordt geconcludeerd dat het huisbezoekprogramma niet kosteneffectief is.

In hoofdstuk 6 worden de resultaten gepresenteerd van de procesevaluatie. De huisbezoeken bleken volgens protocol te zijn uitgevoerd. Het overgrote deel van de deelnemers had een positief oordeel over de huisbezoeken. Met betrekking tot de onderwerpen die aan bod kwamen tijdens de huisbezoeken, rapporteerden de verpleegkundigen dat gezondheidsgebonden risicofactoren zoals loopstoornissen en mobiliteitsproblemen belangrijke onderwerpen waren. Daarnaast gaven de verpleegkundigen aan dat psychosociale onderwerpen veel aandacht trokken tijdens de bezoeken.

Gemiddeld genomen gaven de verpleegkundigen drie concrete adviezen met betrekking tot preventieve maatregelen die de deelnemer zou kunnen ondernemen (bijvoorbeeld het aanbrengen van steunen in de badkamer, het doen van oefeningen en het gebruik van loophulpmiddelen). In totaal werd $46 \%$ van deze adviezen en aanbevelingen opgevolgd door de deelnemers. Het hoofdstuk wordt afgesloten met een beschrijving van de sterke en zwakke kanten van de huisbezoeken.

Gebaseerd op de resultaten van de procesevaluatie kan geconcludeerd worden dat het huisbezoekprogramma uitvoerbaar en acceptabel is volgens verpleegkundigen en deelnemers en dat de huisbezoeken volgens protocol zijn uitgevoerd. Ondanks dit blijkt uit de effectevaluatie dat ons éénjarig 
huisbezoekprogramma geen geschikte manier is om valincidenten en mobiliteitsbeperkingen bij zelfstandig wonende ouderen te verminderen.

Hoofdstuk 7 beschrijft de resultaten van een literatuurstudie (systematic review) naar de beschikbaarheid van informatie over het interventieproces in andere studies naar de effecten van preventieve huisbezoeken. Uit deze literatuurstudie komt naar voren dat in meer dan de helft van de 15 geïncludeerde studies (randomised controlled trials) de volgende zaken niet werden beschreven: a) of er wel of niet afgeweken is van het vooraf opgestelde protocol voor de huisbezoeken; b) in hoeverre de deelnemers het programma volledig hebben gevolgd; c) de mate waarin de deelnemers de adviezen van de huisbezoekers opgevolgd hebben; en d) de mening van de deelnemers en bezoekers over het huisbezoekprogramma. De informatie die beschikbaar was ten aanzien van andere aspecten van het interventieproces was in de meeste gevallen erg globaal. Geconcludeerd wordt dat er een ernstig tekort bestaat aan informatie over het interventieproces bij effectstudies op het gebied van preventieve huisbezoeken. Het is van belang dat specifieke richtlijnen worden ontwikkeld voor het beschrijven van het interventieproces binnen gerandomiseerde effectstudies.

In hoofdstuk 8 worden de belangrijkste resultaten van onze studies beschreven. Er worden een aantal methodologische en theoretische kanttekeningen bij de resultaten geplaatst. Het hoofdstuk wordt afgesloten met een aantal aanbevelingen voor de praktijk en toekomstig onderzoek.

De belangrijkste conclusie van het onderzoek is dat preventieve huisbezoeken geen positieve effecten hebben op valpartijen en mobiliteitsbeperkingen bij zelfstandig wonende ouderen met een verhoogd risico. Nieuwe manieren om valpartijen en mobiliteitsbeperkingen te verminderen moeten worden ontwikkeld en uitgetest in verschillende gezondheidszorgsettingen. 

Dankwoord 
Zo, dat was het. Het onderzoek is af. Het proefschrift is klaar. Nou ja, bijna klaar. Voordat ik echt de laatste punt achter dit proefschrift zet, wil ik graag nog een aantal mensen bedanken die ieder op hun eigen wijze een rol hebben gespeeld bij de totstandkoming ervan.

Allereerst wil ik de leden van het "promotie-team" bedanken: Harry Crebolder (promotor), Erik van Rossum (co-promotor), Jos Diederiks (co-promotor), Luc de Witte en Peter Voorhoeve. Een prima team, helder, "to the point" en ook nog gezellig. Harry, jij was de (pro)motor achter het proefschrift. Jij hebt gezorgd dat de vaart er goed in bleef en jouw enthousiaste en geïnteresseerde houding ten opzichte van alles wat met het onderzoek te maken heeft, heeft mij erg gestimuleerd. Erik, ik bewonder de manier waarop jij op een vriendelijke en rustige manier hele zinnige en bruikbare kritiek kan geven op stukken. Aan jouw kritische blik heb ik veel gehad. Jos, het regelmatig samen doorspreken van de stand van zaken van het onderzoek en de dingen die nog in de planning stonden, was heel nuttig en heeft ertoe bijgedragen dat het onderzoek prima volgens schema is verlopen. Luc, jouw heldere commentaar op stukken heb ik altijd erg gewaardeerd. Ik heb in de afgelopen jaren veel van je geleerd. Peter, jouw praktijkkennis en rol in het ondersteunen en adviseren van de wijkverpleegkundigen bij het uitvoeren van de huisbezoeken, zijn erg belangrijk geweest voor het project.

Vervolgens wil ik graag alle deelnemers aan het onderzoek bedanken. Zonder hun medewerking zou het onmogelijk zijn geweest om het onderzoek uit te voeren. Aan de bezoekjes bij een deel van hen heb ik waardevolle herinneringen overgehouden.

Graag wil ik de wijkverpleegkundigen bedanken die de huisbezoeken hebben uitgevoerd: Vera Hendrix, Claasje Rabou, Margot Rohof en Petra Wielders. Ik heb het heel prettig gevonden om met jullie samen te werken en heb veel van jullie geleerd. Jullie enthousiaste houding ten aanzien van het onderzoek heb ik als erg prettig ervaren. Een ding weet ik zeker: het feit dat de huisbezoeken niet het gewenste effect hebben gehad, heeft beslist niet aan jullie gelegen. Petra, bedankt voor je inzet bij het ontwikkelen van het protocol voor de huisbezoeken.

Wiel van 't Hoofd wil ik bedanken voor de vele "val-telefoontjes" die hij heeft gepleegd tijdens de periode van dataverzameling. Wiel, jouw manier van omgaan met de deelnemers aan het onderzoek en met je collega's heb ik altijd zeer gewaardeerd.

Directie, assistentes en overige medewerkers van het Gezondheidscentrum Hoensbroek Noord wil ik bedanken voor hun bereidwillige medewerking aan het onderzoek. Tevens wil ik de huisartsen Bruls, van Dijk, Helmers, van Nunen 
en Paas bedanken voor hun bijdrage aan de interventie en voor het verstrekken van gegevens omtrent het huisartsenbezoek van de deelnemers.

De Stichting Thuiszorg Oostelijk Zuid-Limburg wil ik bedanken voor hun medewerking aan het project. Hierbij wil ik speciaal Luus Huft noemen die op meerdere momenten tijdens het onderzoek een nuttige inbreng heeft gehad. Tevens dank ik de heer Helgers voor het verstrekken van gegevens omtrent de thuiszorg verleend aan deelnemers aan het onderzoek.

De CZ-groep en in het bijzonder Daniëlle Baenen, wil ik bedanken voor het beschikbaar stellen van gegevens over het zorggebruik van de deelnemers.

Andrew Davies dank ik voor het corrigeren van de Engelse teksten.

Mijn iRv-collega's wil ik bedanken voor de leuke tijd die ik op het iRv heb gehad. Van het verrassings afscheidsetentje heb ik erg genoten en door de 'oranje' screensaver met jullie foto's kan ik jullie onmogelijk vergeten.

Jeanine (reserve nimf), je was in de eerste jaren van het onderzoek mijn kamergenoot, wat erg gezellig was. Over ruim een jaar ben jij aan de beurt om op het "promotie-podium" te staan. Veel succes met de afronding van je proefschrift! Yvonne en Henk, hoewel ik aan jullie (bliep bliep) Primasys-data niet zulke goede herinneringen heb (bliep), heb ik dat zeker wel aan jullie. Bedankt voor jullie collegialiteit. Buurvrouw Caroline, bedankt dat je altijd een kopje thee voor me mee nam en voor je heldere kijk op soms ingewikkelde dingen. Roelof (de iRv "huisschilder"), bedankt voor het mooie schilderij van de mevrouw uit de doelgroep van het onderzoek. Ik zal je koffiepauzetjes missen.

Roland, bedankt voor je altijd snelle aflevering van spullen en je poging om mij een betere zithouding bij te brengen (waardoor de stoel minder slijt). Je missie is niet volledig geslaagd, maar ik blijf het proberen. Mijn stoel bij Medische Sociologie is nog heel.

Mijn nieuwe collega's van Medische Sociologie wil ik bedanken voor de prettige ontvangst en de aangename werksfeer. De vaste koffiepauzes bij het aanrecht vind ik een prima gewoonte.

En dan de nimfen. Cita, ik heb bij jouw promotie kunnen oefenen in het stilstaan, dus dat gedeelte moet me nu in ieder geval goed af gaan. Bedankt voor alle jaren (hechte) vriendschap. Je hebt altijd een luisterend oor en ik bewonder je goede inlevingsvermogen. Fijn dat je me geholpen hebt met het lay-outen van mijn proefschrift. Ik weet nu alles van kop- en voetteksten en begrijp al iets beter waarom ze altijd, als je net even niet kijkt, stiekem weer verspringen. 
Mariëlle, we hebben heel wat iRv lief en leed met elkaar gedeeld. Bedankt voor je tips omtrent het regelen van de promotie en bedankt voor de gezellige etentjes bij jou en Jeroen.

Tot slot wil ik mijn vrienden en familie bedanken, gewoon voor wie ze zijn en dat ze er zijn. Ingrid Nooyen, Tejoenke Koekkoek, Mirjam de Haart, de ex-Lage Barakkers, de "Rippers" (= mijn vriendinnen uit Rijpwetering en omstreken) en de anderen die belangrijk voor me zijn geweest en nog zijn. Bedankt voor jullie vriendschap.

Pap en mam, bedankt dat jullie mij altijd vrij hebben gelaten om de keuzes te maken die ik wilde maken en bedankt voor jullie onvoorwaardelijke steun. Corinne, bedankt voor het feit dat ik altijd bij je terecht kan als het nodig is. Jouw humor vind ik nog steeds de leukste!

Marise, ik had niets liever gewild dan dat je nog bij ons en bij de promotie had kunnen zijn, maar het mocht niet zo zijn. Bedankt voor alles wat je voor me hebt betekend. Je was een zus uit duizenden. Dit proefschrift is voor jou. Ik hoop dat je het goed hebt "ergens daarboven".

Ellis, bedankt voor je warmte, je grapjes, je zorgzaamheid, je aandacht en voor het feit dat je bent wie je bent: jij maakt het verschil!

En dan nu toch echt een punt achter het proefschrift. 


\section{About the author}

03-07-1967 Born in Leiden, the Netherlands.

1979-1985 Secondary school (NWO), Scholengemeenschap St. Agnes, Leiden, the Netherlands.

1985-1987 Cultural Anthropology, University of Amsterdam, Amsterdam, the Netherlands.

1987-1991 Health Sciences (specialisation in Health Education), Maastricht University, Maastricht, the Netherlands.

1991-1994 Research assistant at the Institute for Rehabilitation Research (iRv), Hoensbroek, the Netherlands.

1994-1997 Data-analyst at the iRv, Hoensbroek, the Netherlands

Research assistant at the Department of Nursing Sciences, Maastricht University, Maastricht, the Netherlands.

1997-2002 PhD student/researcher at the iRv, Hoensbroek the Netherlands.

2002- Postdoc researcher at the Department of Health Care Studies (section Medical Sociology), Maastricht University, Maastricht, the Netherlands. 

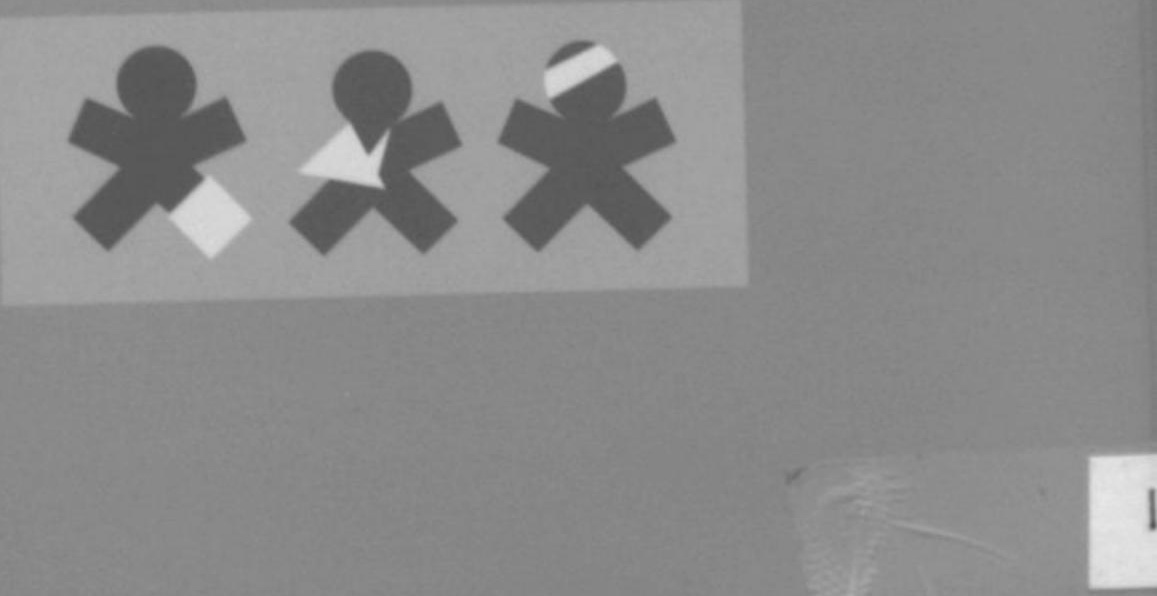